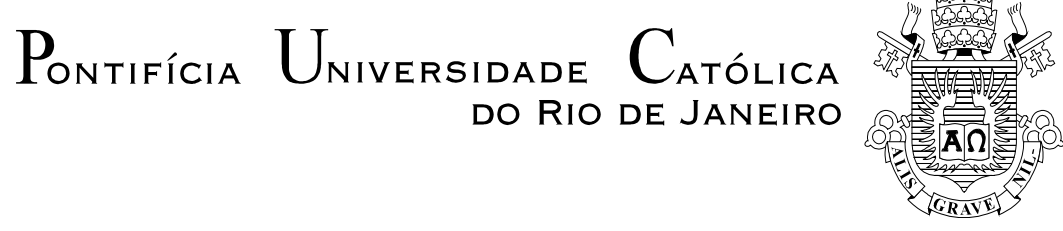

lakyra Borrakuens Couceiro

Sistema Interferométrico Primário para Medidas de Comprimento e Aplicações em Nanometrologia

\author{
Tese de Doutorado
}

Tese apresentada como requisito parcial para obtenção do grau de Doutor pelo Programa de Pós-graduação em Engenharia Elétrica do Departamento de Engenharia Elétrica da PUC-Rio. 


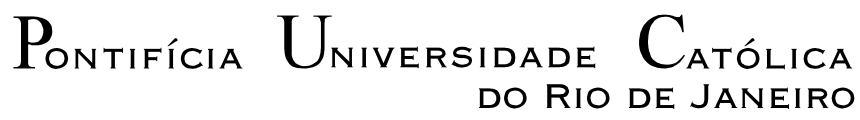

DO RIO DE JANEIRO

lakyra Borrakuens Couceiro

\section{Sistema Interferométrico Primário para Medidas de Comprimento e Aplicações em Nanometrologia}

Tese apresentada como requisito parcial para obtenção do grau de Doutor pelo Programa de Pós-Graduação em Engenharia Elétrica do Departamento de Engenharia Elétrica do Centro Técnico Científico da PUC-Rio. Aprovada pela Comissão Examinadora abaixo assinada.

Prof. Jean Pierre von der Weid Orientador Centro de Estudos de Telecomunicações - PUC-Rio

Prof. Anderson Stevens Leônidas Gomes UFPE

Prof. Hans Peter Henrik Grieneisen Inmetro

Prof. Djeisson Hoffmann Thomas Centro de Estudos de Telecomunicações - PUC-Rio

Prof. Rogerio Passy MLS Wireless

Prof. José Eugenio Leal Coordenador Setorial do Centro Técnico Científico - PUC-Rio

Rio de Janeiro, 28 de agosto de 2013 
Todos os direitos reservados. É proibida a reprodução total ou parcial do trabalho sem autorização da universidade, da autora e do orientador.

\section{lakyra Borrakuens Couceiro}

Graduou-se pela Universidade Federal Fluminense em 1990. Finalizou o mestrado em 1992. Fixou-se como pesquisador no Inmetro realizando atividades na área de radiometria e fotometria. Ingressou no doutorado, em 2008, no Departamento de Engenharia Elétrica da PUC-Rio.

Ficha Catalográfica

Couceiro, lakyra Borrakuens

Sistema interferométrico primário para medidas de comprimento e aplicações em nanometrologia / lakyra Borrakuens Couceiro; orientador: Jean Pierre Von der Weid. $-2013$.

108 f. : il. (color.) ; $30 \mathrm{~cm}$

Tese (doutorado) - Pontifícia Universidade Católica do Rio de Janeiro, Departamento de Engenharia Elétrica, 2013.

Inclui bibliografia

1. Engenharia elétrica - Teses. 2. Metrologia. 3. Interferometria. 4. Incerteza de medição. 5. Nanometrologia. I. Weid, Jean Pierre Von der. II. Pontifícia Universidade Católica do Rio de Janeiro. Departamento de Engenharia Elétrica. III. Título. 
"When you can measure what you are speaking about, and express it in numbers, you know something about it, when you cannot express it in numbers, your knowledge is of a meager and unsatisfactory kind; it may be the beginning of knowledge, but you have scarely, in your thoughts advanced to the stage of science.” William Thomson - Lorde Kelvin 
A minha família, a Renato, em especial a Nina. 


\section{Agradecimentos}

A minha pequena Nina, que me ajudou com sua alegria e amor a superar os obstáculos;

Ao Renato, pelo apoio, incentivo e, principalmente, pela paciência;

Aos meus avós e tios paternos que sempre me apoiaram e incentivaram a estudar.

Ao Prof. Jean Pierre von der Weid pela oportunidade que me deu, depois de tantos anos fora da área acadêmica, ao aceitar ser meu orientador e por acreditar que seria possível realizar o trabalho na área de metrologia. Também pelas discussões e orientações técnicas e científicas ao longo do trabalho.

Ao Prof. Anderson Zanardi de Freitas por ter cedido os softwares e explicado a forma de análise dos dados gerados pelo OCT;

Aos Profs. João Jornada e Humberto Brandi pelo apoio;

Ao Prof. Hans Peter Grieneisen pelo incentivo;

Ao meu amigo Maurício Simões pela ajuda nas medições, pelas discussões técnicas e pelo incentivo durante todo o trabalho;

Aos colegas do Inmetro, Igor Malinovski pelas discussões técnicas e ensinamentos na área de interferometria e nanometrologia dimensional e Thiago Ferreira pela ajuda nas medições e pela automação do sistema TD-OCT montado no Inmetro;

Ao colega Luiz Tarelho pela ajuda nas medições e discussões técnicas;

Aos meus amigos do Inmetro, Giovanna Borghi, Miguel Torres, Carla Thereza, Paulo Roberto, Angela Motta, Elsenir, Hakima e Maria Sylvana, que me incentivaram a finalizar este trabalho; 
Ao pessoal da Dimat/Inmetro, em especial a Clara, por ter viabilizado a realização das medições no AFM;

Ao pessoal do DCTA/IEAv, em especial ao Alvaro Damião, por ter viabilizado a realização das medições no Microscópio Confocal (CM).

Ao pessoal da secretaria da Diopt, em especial a Leidiane pela ajuda;

Ao pessoal do Laboratório de Optoeletrônica, em especial a Amália pela ajuda;

Ao pessoal da secretaria do DEE, em especial a Alcina pela ajuda. 


\section{Resumo}

Couceiro, Iakyra Borrakuens; von der Weid, Jean Pierre (Orientador). Sistema Interferométrico primário para medidas de comprimento e aplicações em nanometrologia. Rio de Janeiro, 2013. 108p. Tese de Doutorado - Departamento de Engenharia Elétrica, Pontifícia Universidade Católica do Rio de Janeiro.

Neste trabalho são apresentados os resultados referentes ao desenvolvimento de um sistema interferométrico primário, o interferômetro Linnik, para medidas de comprimento de amostras na escala micrométrica e nanométrica. O sistema experimental foi caracterizado e otimizado para prover rastreabilidade a degraus de altura, usados como referência na escala de comprimento. As principais fontes de incerteza foram avaliadas, sendo a planicidade do artefato o parâmetro com o maior valor de contribuição para a incerteza final. A estabilidade do sistema de referência pode ser mostrada através da alta reprodutibilidade apresentada ao longo de algumas semanas de medição. Este também serviu como base para prover a rastreabilidade no SI, para instrumentos ópticos tais como OCT, AFM e microscópios confocais, sendo os dois últimos usados na área de nanotecnologia. Estes instrumentos foram calibrados usando como padrão de transferência os degraus de altura, previamente avaliados no interferômetro Linnik. Com isto, foi estabelecida a rastreabilidade na escala de comprimento para alguns institutos no país.

\section{Palavras-chave}

Metrologia; interferometria; incerteza de medição; nanometrologia. 


\section{Abstract}

Couceiro, Iakyra Borrakuens; von der Weid, Jean Pierre (Advisor). Interferometric Primary System for Length Measurements and Applications in Nanometrology. Rio de Janeiro, 2013. 108p. D.Sc. Thesis - Departamento de Engenharia Elétrica, Pontifícia Universidade Católica do Rio de Janeiro.

In this work are presented the results related to the development of a primary interferometric system, the Linnik interferometer for length measurements of samples in the micrometer and nanometer scales. The experimental system has been characterized and optimized to provide traceability to step height, used as the reference standards in length scale. The main sources of uncertainty were evaluated, and the flatness of the artifact was the parameter with the highest contribution to the final uncertainty. The stability of the reference system can be demonstrated through the reproducibility that was evaluated over several weeks. This system also served as the basis to provide traceability to the SI for optical instruments such as OCT and confocal microscopes AFM, the latter two being used in the field of nanotechnology. These instruments were calibrated using step heights, as transfer standards, that were previously evaluated in Linnik interferometer. Therefore, it was established the traceability in length scale for some institutes in the country.

\section{Keywords}

Metrology; interferometry; uncertainty; nanometrology. 


\section{Sumário}

1. Introdução 16

1.1. Breve Histórico da Metrologia 16

1.2. Evolução da Grandeza Comprimento 18

1.3. Nanometrologia 21

2. Conceitos básicos de interferometria óptica 23

2.1. Interferência 23

2.2. Coerência das fontes de luz 26

2.3. Interferômetros 32

2.3.1. Interferômetro de Michelson 33

2.3.2. Interferômetro de Mach Zender $\quad 34$

2.3.3. Interferômetro de Twyman Green 35

2.3.4. Interferômetro Linnik 36

3. Princípios Básicos de Tomografia de Coerência Óptica (OCT) 39

3.1. Princípios Básicos do OCT 41

3.2. Resoluções Axial e Transversal no OCT 42

3.3. Geração de Imagem no OCT 45

3.4. OCT comerciais no domínio do espectro 46

4. Princípios Básicos de Microscopia Confocal (CM) 51

5. Princípios básicos de Microscopia de Força Atômica (AFM) 54

6. Conceitos básicos de Incerteza de Medição 57

6.1. Avaliação de incerteza padrão 58

6.1.1. Incerteza padrão tipo A $\quad 59$

6.1.2. Incerteza padrão tipo B 60

6.1.3. Incerteza padrão combinada $\quad 61$

6.1.4. Incerteza padrão expandida $\quad 62$

7. Resultados Experimentais e Discussão 66

7.1. Interferômetro Linnik 67

7.2. Tomógrafos de Coerência Óptica (TD-OCT, SD-OCT, SS-OCT) 80

7.3. Microscópio Confocal 92

7.4. Microscópio de Força Atômica 94

7.5. Rastreabilidade 96

$\begin{array}{ll}\text { 8. Conclusão e perspectivas futuras } & 101\end{array}$

9. Referências bibliográficas 103 


\section{Lista de figuras}

Figura 1 - Cadeia de rastreabilidade metrológica na área de comprimento do Instituto Nacional de Metrologia, Inovação e Tecnologia - Inmetro

Figura 2 - Intensidade de luz na saída do interferômetro de Michelson para uma fonte coerente monocromática

Figura 3 - Intensidade de luz na saída de um interferômetro de Michelson para uma fonte de baixa coerência

Figura 4 - Esquema básico do interferômetro de Michelson

Figura 5 - Esquema básico do interferômetro de Mach Zender

Figura 6 - Esquema básico do interferômetro de Twyman Green

Figura 7 - Esquema básico do interferômetro Linnik

Figura 8 - Resolução e profundidade de técnicas de diagnóstico por imagem

Figura 9 - Montagem básica do TD-OCT

Figura 10 - Limites de foco de abertura grande e pequena

Figura 11 - Princípio de geração de imagens em OCT

Figura 12 - Esquema básico do sistema SR-OCT

Figura 13 - Esquema com componentes do SR-OCT

Figura 14 - Esquema básico do sistema SS-OCT

Figura 15 - Esquema experimental detalhado do SS-OCT, onde MZI é o interferômetro de Mach Zehnder

Figura 16 - Esquema básico do microscópio confocal

Figura 17 - Esquema simplificado do sistema de varredura a laser sobre a amostra no LSCM

Figura 18 - Esquema básico do AFM

Figura 19 - Força resultante em função da distância cantilever superfície da amostra, potencial de Lennar Jones

Figura 20 - (a) Diagrama esquemático e (b) foto do sistema experimental do interferômetro Linnik 
Figura 21 - Comparação de medição de bloco degrau triplo de altura

(step height) no interferômetro Linnik e outros interferômetros

Figura 22 - Amostra de altura de $2 \mu \mathrm{m}$ e $10 \mu \mathrm{m}$, fabricante Mitutoyo

Figura 23 - Degrau de altura de $100 \mathrm{~nm}$ produzido no Inmetro pela Divisão de Materiais (Dimat)

Figura 24 - Qualidade da franja (linha sólida) e ajuste (linha tracejada)

Figura 25 - Vista do software para a medida dos degraus de altura de (a)

$2 \mu \mathrm{m}$ e (b) $10 \mu \mathrm{m}$

Figura 26 - Padrão de franja do degrau de altura de $10 \mu \mathrm{m}$ no interferômetro Linnik

Figura 27 - Padrão de franjas observado nas medidas usando a amostra degrau de altura de $100 \mathrm{~nm}$

Figura 28 - Reprodutibilidade das medidas obtidas usando o degrau de altura de $100 \mathrm{~nm}$

Figura 29 - Esquema do TD-OCT montado no Inmetro

Figura 30 - Espectro óptico do diodo superluminescente (SLD)

Figura 31 - Medição do degrau de altura de $2 \mu \mathrm{m}$ e de $10 \mu \mathrm{m}$ do fabricante Mitutoyo

Figura 32 - Interferograma gerado nas medidas com o TD-OCT a partir de uma varredura axial completa

Figura 33 - Imagem gerada no TD-OCT nas medições com o degrau de altura de $10 \mu \mathrm{m}$

Figura 34 - Perfil obtido nas medidas com o TD-OCT para o padrão de profundidade

Figura 35 - Sistema de amostra dos OCT comerciais do fabricante Thorlabs, (a) SR-OCT e (b) SS-OCT

Figura 36 - Imagem gerada pelo SS-OCT para o degrau de altura de $10 \mu \mathrm{m}$

Figura 37 - Imagens geradas no Origin na análise das medidas realizadas com o SR-OCT (a) $10 \mu \mathrm{m}$ e (b) $2 \mu \mathrm{m}$ e SS-OCT (c) $10 \mu \mathrm{m}$

Figura 38 - Imagem das medições com o microscópio confocal para o degrau de altura de $2 \mu \mathrm{m}$ 
Figura 39 - Imagem das medições no AFM com o degrau de altura de $100 \mathrm{~nm}$, (a) 2D, (b) 3D e (c) perfil da amostra

Figura 40 - Comparação das medições no sistema Linnik, microscópio confocal (CM), Microscópio de força atômica (AFM) e sistemas OCT para os degraus de altura de (a) $100 \mathrm{~nm}$, (b) $2 \mu \mathrm{m}$ e (c) $10 \mu \mathrm{m}$

Figura 41 - Ajuste CM com os degraus de 100 nm, $2 \mu \mathrm{m}$ e $10 \mu \mathrm{m}$ 


\section{Lista de tabelas}

Tabela 1 - Valor do fator de abrangência $k_{p}$ para uma distribuição normal 64

Tabela 2 - Desvio do valor nominal e incerteza, degraus de $2 \mu \mathrm{m}$ e $10 \mu \mathrm{m} \quad 72$

Tabela 3 - Desvio do valor nominal e incerteza do sistema Linnik 74

Tabela 4 - Planilha de incerteza do sistema Linnik 79

Tabela 5 - Incerteza dos instrumentos ópticos $\quad 80$

Tabela 6 - Planilha de incerteza do TD-OCT 84

Tabela 7 - Medida dos degraus de altura de $2 \mu \mathrm{m}$ e $10 \mu \mathrm{m}$ e incertezas associadas ao TD-OCT e Linnik 85

Tabela 8 - Medida do padrão de profundidade no TD-OCT comparado com o $\begin{array}{ll}\text { certificado PTB para um perfilômetro } & 86\end{array}$

Tabela 9 - Planilha de incerteza dos sistemas OCT comerciais 91

Tabela 10 - Medida do degrau de altura no sistema interferométrico Linnik e nos OCT comerciais, SS-OCT e SR-OCT 92

Tabela 11 - Planilha de incerteza do microscópio confocal 94

Tabela 12 - Planilha de incerteza do microscópio de força atômica 96

Tabela 13 - Medida dos degraus de altura no Linnik e nos instrumentos

ópticos para (a) $100 \mathrm{~nm}$, (b) $2 \mu \mathrm{m}$ e (c) $10 \mu \mathrm{m} \quad 97$ 


\section{Lista de abreviaturas e siglas}

BIPM - Bureau International des Poids et Mesures - Bureau Internacional de Pesos e Medidas;

CGPM - Conferência Geral de Pesos e Medidas;

CIPM - Comitê Internacional de Pesos e Medidas;

SI - Sistema Internacional de Unidades;

NMI - National Institute of Metrology - Instituto Nacional de Metrologia;

CCTF - Comitê Consultivo de Tempo e Frequência;

CIPM - Comitê Internacional de Pesos e Medida;

MEV - Microscópio Eletrônico de Varredura;MET - Microscópio Eletrônico de Transmissão;

AFM - Atomic Force Microscope- Microscópio de Força Atômica;

OCT - Optical Coherence Tomography- Tomografia de Coerência Óptica;

CM - Confocal Microscope-Microscópio Confocal;

TD-OCT - Time Domain Optical Coherence Tomography - Tomografia de

Coerência Óptica no Domínio do Tempo;

SS-OCT - Swept Source Optical Coherence Tomography - Tomografia de

Coerência Óptica de Fonte Varrida;

SR-OCT - Spectral Radar Optical Coherence Tomography-Tomografia de

Coerência Óptica com Sonda Espectral;

MOCVD - Metal Organic Chemical Vapor Deposition-Deposição de Vapor

Químico Orgânico em Metal;

CCD - Charge Coupled Device-Dispositivo de Carga Acoplada;

PMMA - Polimetilmetacrilato;

DAC - Digital-to-Analog Converter- Conversor Analógico Digital;

PTB - Physikalisch Technische Bundeanstalt

SLD - Superluminescent Diodes- Diodo Supderluminescente

PZT - Lead Zirconate Titanate - Titanato Zirconato de Chumbo; 


\section{1}

\section{Introdução}

\section{1}

\section{Breve Histórico da Metrologia}

A metrologia é definida como sendo a ciência que abrange todos os aspectos teóricos e práticos relativos às medições, qualquer que seja a incerteza de medição e campo de aplicação [1, 2]. A palavra metrologia tem origem grega, onde metron significa medida e logos ciência. A necessidade de medir é muito antiga, entretanto cada país tinha seu sistema de medição, o que prejudicava o comércio entre eles. Para resolver este problema, em 1789 o governo francês solicitou a academia de ciências da França que criasse um sistema de medidas baseado em uma constante natural. Assim, foi criado o sistema métrico decimal, constituído de duas unidades básicas, o metro e o quilograma.

Em 1875, com a convenção do metro [3], o "Bureau Internacional de Pesos e Medidas” (BIPM), teve como responsabilidade o estabelecimento de um sistema de medição que tivesse abrangência mundial. Pelos termos dessa convenção, protótipos internacionais do metro e do quilograma foram fabricados e formalmente adotados pela primeira Conferência Geral de Pesos e Medidas (CGPM), em 1889. Em 1960, a $11^{\text {a }}$ CGPM decidiu que este sistema deveria ser chamado Sistema Internacional de Unidades, SI [4, 5].

Atualmente, são sete as unidades de base do SI, definidas a seguir:

Comprimento/metro (m): "O metro é o comprimento do trajeto percorrido pela luz, no vácuo, durante um intervalo de tempo de 1/299 792458 de segundo”.

Massa/quilograma (kg): “O quilograma é a unidade de massa (e não de peso, nem força); ele é igual à massa do protótipo internacional do quilograma”. 
Tempo/segundo (s): “O segundo é a duração de 9192631770 períodos da radiação correspondente à transição entre os dois níveis hiperfinos do estado fundamental do átomo de césio 133”.

Corrente elétrica/ampère (A): $O$ ampère é a intensidade de uma corrente elétrica constante que, mantida em dois condutores paralelos, retilíneos, de comprimento infinito, de seção circular desprezível, e situado à distância de 1 metro entre si, no vácuo, produz entre estes condutores uma força igual a $2 \times 10^{-7}$ newton por metro de comprimento”.

Temperatura termodinâmica/kelvin (K): “O kelvin, unidade de temperatura termodinâmica, é a fração 1/273,16 da temperatura termodinâmica do ponto tríplice da água.”

Quantidade de substância/mol (mol): $1^{\circ}$ ) “O mol é a quantidade de matéria de um sistema contendo tantas entidades elementares quantos átomos existem em 0,012 kilograma de carbono 12”; $2^{\circ}$ ) “Quando se utiliza o mol, as entidades elementares devem ser especificadas, podendo ser átomos, moléculas, íons, elétrons, assim como outras partículas, ou agrupamentos especificados de tais partículas”.

Intensidade luminosa/candela (cd): “A candela é a intensidade luminosa, numa dada direção de uma fonte que emite uma radiação monocromática de frequência $540 \times 10^{12}$ hertz e cuja intensidade energética nessa direção é 1/683 watt por esterradiano".

Neste trabalho, nos concentraremos na grandeza comprimento, que será o elo para alcançar o objetivo desta tese. Para entender melhor esta grandeza é importante o conhecimento da sua evolução ao longo do tempo. 


\section{2}

\section{Evolução da Grandeza Comprimento}

A metrologia, nas várias grandezas, tem demonstrado eficácia na ligação do conhecimento científico aos interesses da cadeia produtiva de um país, sendo de fundamental importância para uma sociedade desenvolvida tecnologicamente e focada nas trocas comerciais.

Uma das grandezas que foi se desenvolvendo ao longo do tempo e passou por várias mudanças tanto na definição quanto em relação aos padrões e é foco desta tese é a grandeza comprimento [6, 7], que teve como padrões desde o uso de pés e protótipos materializados até definições relacionando comprimento e velocidade da luz.

O primeiro experimento que contribuiu de forma significativa para a área foi feito, no final do século XIX, por Michelson. Neste experimento, mediu-se o comprimento de onda (vermelho) do cádmio em termos do protótipo internacional de comprimento. Isto foi à base para estabelecer técnicas interferométricas para medidas de comprimento de um protótipo em termos de comprimentos de onda conhecidos.

Em 1960, o trabalho de Michelson foi uma base para a adoção da definição do metro em função do comprimento de onda. Assim, a primeira definição do metro, baseado no protótipo internacional de platina-irídio, foi modificada pela $11^{\text {a }}$ CGPM, usando uma definição baseada no comprimento de onda de vácuo da radiação correspondente à transição entre níveis de energia específicos do átomo de $\mathrm{Kr}^{86}$, para melhorar a exatidão com a qual a definição do metro era realizada [8]. Neste caso, a realização tinha como base a utilização de um interferômetro de Michelson, para medir as diferenças de passo óptico das franjas geradas.

Em 1983, na $17^{\mathrm{a}}$ CGPM, a definição do metro foi modificada incluindo cinco radiações lasers recomendadas como também aquelas de lâmpadas espectrais. Para verificar a exatidão das medições realizadas nos países, nas diversas grandezas, são realizadas comparações internacionais.

Na área de comprimento, essas comparações são feitas entre frequência de lasers estabilizados pela técnica de batimento de frequência. 
Em 1992, o Comitê Internacional de Pesos e Medidas (CIPM) decidiu, com base no trabalho de vários Institutos Nacionais de Metrologia (NMI), aumentar para oito radiações lasers recomendadas e, em 1997, para doze radiações.

Em 1999, o BIPM publicou uma lista, no trabalho intitulado "Realização prática da definição do metro”, com 14 radiações recomendadas, incluindo aquelas radiações de outros padrões de frequência óptica [9]. Uma das radiações recomendadas é a do laser de Nd: YAG estabilizado à transição do iodo $\left(\mathrm{I}_{2}\right)$ em $532 \mathrm{~nm}$.

Em 2003, com a publicação da nova lista de radiações recomendadas, observou-se uma modificação na nomenclatura da implementação prática de radiações recomendadas para a realização da definição do metro e outros padrões de frequência óptica, demonstrando uma sutil modificação na lista de radiações que definem o metro, como também de outros padrões de frequência [10, 11, 12].

Ainda em 2003, houve uma forte recomendação do BIPM para que os NMI desenvolvessem a técnica do pente de frequência [13, 14] ao nível mais elevado de exatidão, tanto que em 2007 foi aprovada pelo Comitê Consultivo de Tempo e Frequência (CCTF) do BIPM uma mudança para o nome da lista de radiações recomendadas para Valores recomendados de padrões de frequência para aplicações, incluindo a realização prática do metro e representações secundárias do segundo. Essas mudanças refletem a importância que as frequências ópticas vêm assumindo na representação da grandeza de tempo, o segundo (s).

No Brasil, o Inmetro possuía lasers estabilizados de He-Ne para a realização do metro. No entanto, a realização prática da definição do metro somente foi iniciada em 2005 com a implantação de outra radiação recomendada no comprimento de onda de $532 \mathrm{~nm}$, materializada no laser de Nd: YAG [15, 16].

Em 2011, atendendo às novas recomendações do BIPM, o Inmetro adquiriu um pente de frequências que será usado conjuntamente com os lasers estabilizados na definição do metro o que poderá melhorar a exatidão das medidas realizadas na área.

A cadeia de rastreabilidade na área de comprimento, mostrada na figura 1, foi elaborada levando em consideração os padrões e instrumentos do Instituto Nacional de Metrologia, Inovação e Tecnologia (Inmetro). 
Os desdobramentos da grandeza comprimento abrangem desde o uso de blocos padrão para serem usados como referência nas indústrias metal mecânica, aeronáutica, etc, até o uso de padrões de altura para aplicações em áreas cuja cadeia de rastreabilidade ainda está sendo criada, como em nanometrologia, abordada de forma resumida na próxima seção.

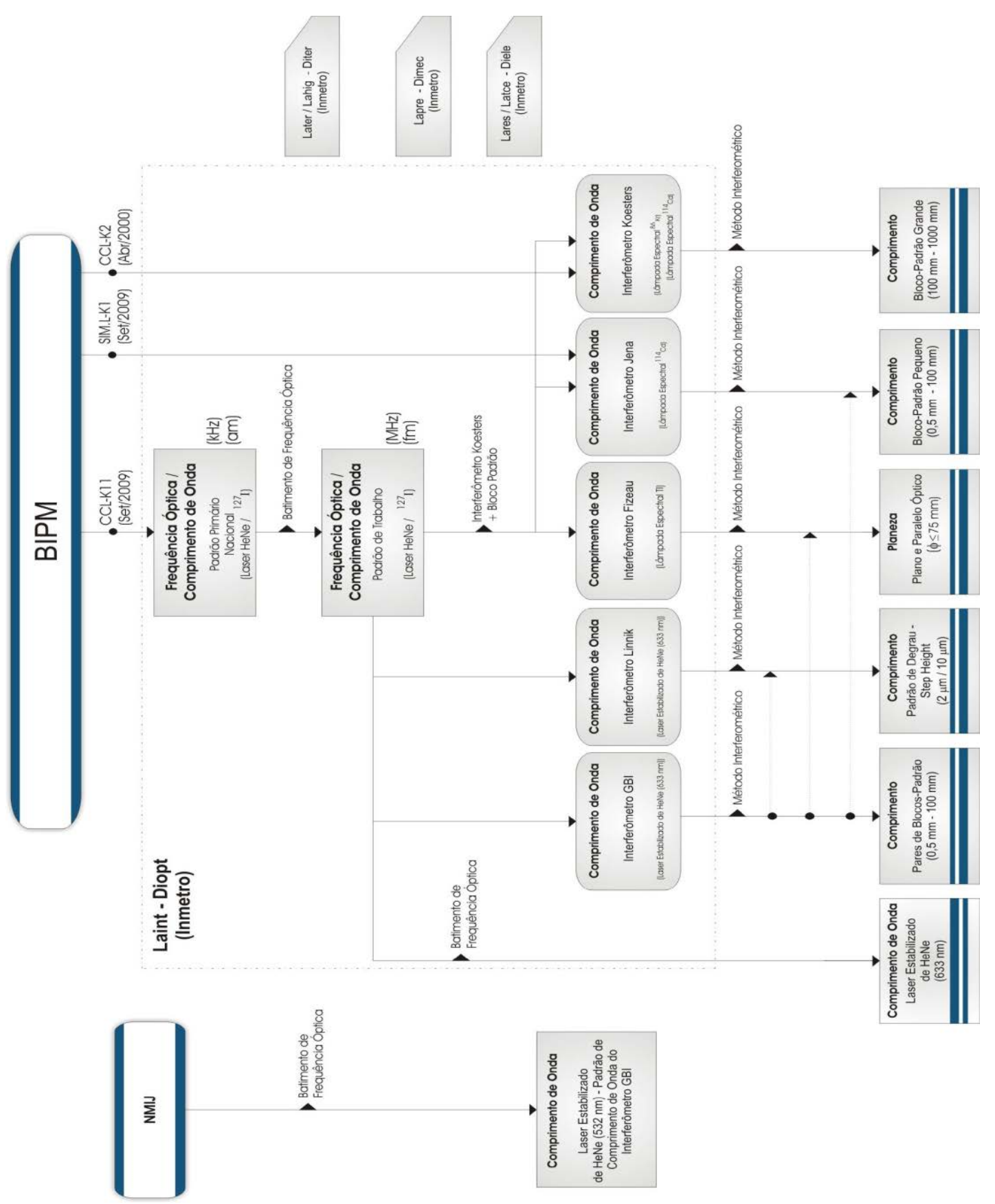

Figura 1 - Cadeia de rastreabilidade metrológica na área de comprimento do Instituto nacional de Metrologia, Inovação e Tecnologia - Inmetro. 


\section{3}

\section{Nanometrologia}

Nanotecnologia é definida como sendo a ciência e tecnologia de estruturas e materiais com dimensões iguais ou menores que $100 \mathrm{~nm}[17,18,19]$. Atualmente, este campo tem recebido grandes investimentos e se desenvolveu rapidamente em todo o mundo e com isto começou a requerer a utilização de novas técnicas de medição confiáveis na escala nanométrica, rastreadas ao Sistema Internacional de Unidades (SI). Esta ciência de medidas na nanoescala é chamada de nanometrologia, que tem papel crucial na produção de nanomateriais com alto grau de exatidão e confiabilidade. A nanometrologia [20] está focada diretamente em procedimentos de calibração em escala nanométrica de medições de várias grandezas em nível macro e microscópico ou a medidas relacionadas a padrões primários e, consequentemente, em prover a rastreabilidade de microscópios eletrônicos de varredura ou transmissão (MEV, MET) ou microscópios de força atômica (MFA) ou qualquer outro tipo de equipamento de microscopia. Em resumo, a nanometrologia é a medição de uma grandeza específica com rastreabilidade na nano-escala [21]. Em geral, isto tem sido o papel de estudo de vários Institutos Nacionais de Metrologia (NMI) no desenvolvimento de métodos e instrumentação rastreáveis e na elaboração de normas e regulamentos.

A realização de medidas confiáveis em nanometrologia, por exemplo, na área de comprimento, pode ser realizada através do desenvolvimento de um sistema interferométrico para realizar medições de comprimento na escala nanométrica. Todo um novo conceito, neste caso, foi incorporado, pois propriedades e características que poderiam ser desprezíveis nas dimensões usuais das medições macroscópicas se tornam importantes nesse contexto.

No Brasil, esse sistema interferométrico foi desenvolvido no Inmetro e tem demonstrado ser um instrumento capaz de realizar medições rastreáveis aos submúltiplos do metro, o que significa prover confiabilidade a instrumentos e padrões usados na área. Nesta tese foi feita a construção e caracterização de um sistema interferométrico de referência, interferômetro Linnik, com estudo dos erros sistemáticos e avaliação das componentes de incerteza do sistema experimental. Usando padrões rastreados ao Linnik, pôde-se prover a 
rastreabilidade na escala de comprimento de vários instrumentos ópticos, como a Tomografia de Coerência Óptica (OCT), o Microscópio de Força Atômica (AFM), o Microscópio Confocal (CM), etc.

Como as teorias relacionadas às técnicas de AFM e CM são bastante conhecidas na literatura, serão abordados apenas aspectos básicos no escopo da tese. O OCT, no entanto, será abordado com um pouco mais de detalhes pelas novas perspectivas de aplicação dessa técnica no campo tecnológico e de diagnóstico não invasivo.

No capítulo 2 são apresentados os conceitos básicos de interferometria óptica e a apresentação de alguns tipos de interferômetros usados na área de comprimento.

No capítulo 3 são apresentados os princípios de tomografia de coerência óptica, com ênfase em sua resolução espacial (axial e transversal), geração de imagens e descrição dos Tomógrafos de Coerência Óptica (OCT) comerciais usados. Os OCT foram rastreados a partir de degraus de altura, tendo como referência o sistema interferométrico Linnik, desenvolvido na tese.

Nos capítulos 4 e 5 são apresentados os aspectos básicos da microscopia confocal e da microscopia de força atômica, respectivamente, já que os instrumentos ligados a essas técnicas (Microscópios de força atômica e confocal) também foram comparados às medições realizadas no interferômetro Linnik.

O capítulo 6 tem como foco a avaliação da incerteza associada a uma medição, com os tipos e incerteza e a forma de avaliação de cada uma delas.

O capítulo 7 descreve os procedimentos e a metodologia de medição usada no desenvolvimento do sistema de referência (interferômetro Linnik) e nas medições com os instrumentos ópticos usados na tese.

Finalmente, no capítulo 8 apresentam-se as conclusões da tese e as perspectivas futuras. 


\section{Conceitos básicos de interferometria óptica.}

A interferometria pode ser definida como uma técnica onde se combinam duas ou mais ondas de luz que interferem entre sí e é muito usada em metrologia onde é importante detectar ou medir parâmetros com alta exatidão. Na metrologia de comprimento são usados interferômetros como instrumento de referência para prover a rastreabilidade dessa grandeza para os chamados blocos padrão de comprimento que por sua vez são usados como padrão secundário nos sistemas industriais. Nas seções seguintes serão descritos aspectos básicos de interferência e medidas de comprimento a partir de técnicas interferométricas. Aspectos mais profundos sobre os temas não serão abordados aqui, já que estão em bibliografias disponíveis na área [22, 23, 24, 25].

\section{1}

\section{Interferência}

Interferência é um fenômeno que está relacionado à superposição de feixes de luz, resultando em um padrão de intensidade que varia entre máximos e mínimos, dependendo dos feixes estarem em fase ou fora de fase. As variações de intensidade são chamadas de franjas de interferência.

Se considerarmos dois feixes monocromáticos coerentes, a irradiância da luz (média temporal da quantidade de energia que atravessa por unidade de tempo a unidade de superfície perpendicular à direção do fluxo de energia no mesmo estado de polarização) é dada por:

$$
I=\varepsilon_{0} c<E . E>=\varepsilon_{0} c<E^{2}>
$$

Onde $\varepsilon_{0}$ é a permissividade elétrica do vácuo, E é o campo elétrico e c a velocidade da luz. 
A irradiância será representada por $\left\langle E^{2}\right\rangle$ já que comparamos as irradiâncias no mesmo meio. Os campos elétricos individuais podem ser descritos por:

$$
\begin{aligned}
& E_{1}=A \exp i\left(w t-k_{1} x\right) \\
& E_{2}=B \exp i\left(w t-k_{2} x\right)
\end{aligned}
$$

Sendo 2.2 e 2.3, quantidades reais. As duas ondas se superpõem em um ponto P, onde o campo elétrico total é:

$$
\mathrm{E}=\mathrm{E}_{1}+\mathrm{E}_{2}
$$

Assim, a irradiância é definida por:

$$
\begin{gathered}
I=<E_{1}^{2}>+<E_{2}^{2}>+<E_{1} E_{2}^{*}>+<E_{1}^{*} E_{2}> \\
I=A^{2}+B^{2}+2 A B \cos \delta
\end{gathered}
$$

Os dois primeiros termos da equação (2.6) são as irradiâncias das duas ondas e o último termo ( $2 \mathrm{AB} \cos \boldsymbol{\delta})$ descreve a interferência. Assim, podemos escrever:

$$
I=I_{1}+I_{2}+2 \sqrt{I_{2} I_{1}} \cos \delta
$$

Os máximos de irradiância ocorrerão quando:

$$
|\delta|=0,2 \pi, 4 \pi, \ldots
$$

E os mínimos de irradiância quando:

$$
|\delta|=\pi, 3 \pi, \ldots
$$

No caso especial de irradiâncias iguais $I_{1}=I_{2}$, a expressão reduz-se a: 


$$
I=4 I_{1} \cos ^{2} \frac{\delta}{2}
$$

Cuja variação fica entre os valores máximos de $4 \mathrm{I}_{1}$ e mínimos que são zero.

Os máximos e mínimos de irradiância observados no padrão de interferência são chamados franjas de interferência.

O fenômeno da interferência torna-se mais complexo devido a não monocromaticidade, às dimensões das fontes e pela existência de diferentes estados de polarização da luz. No entanto, a análise mais simplificada, considerando ondas monocromáticas coerentes e no mesmo estado de polarização, é suficiente para o entendimento desse fenômeno e pode ser usada para estudo de situações mais complexas.

Para entender como a teoria de interferência está relacionada à medida de comprimento, é levado em consideração um princípio básico de medidas de comprimento usando técnicas interferométricas, demonstrado por Michelson em 1892. Ele mediu o comprimento de onda vermelho do cádmio em relação ao protótipo internacional do metro. O princípio da medição de comprimento por interferometria é feito através da comparação de um comprimento mecânico, ou uma distância no espaço, contra um comprimento de onda conhecido. Isto pode ser expresso pela equação (2.11):

$$
L=(N+f) \lambda
$$

Onde L é o comprimento a ser medido, $\lambda$ é o comprimento de onda, $\mathrm{N}$ é um número inteiro e f é a fração de franja $(0<\mathrm{f}<1)$.

Normalmente, a óptica no interferômetro é disposta de modo que o feixe de luz meça exatamente o dobro do comprimento desejado (sistema de dupla passagem), assim, a equação (2.11) é expressa como:

$$
\mathrm{L}=(\mathrm{N}+\mathrm{f}) \frac{\lambda}{2}
$$


Uma franja de interferência corresponde à distância ou ao comprimento igual a $\lambda / 2$. Usando uma fonte de luz na qual o comprimento de onda é conhecido, as medidas de $\mathrm{N}$ e de $\mathrm{f}$ conduz diretamente a um valor para $\mathrm{L}$.

\section{2}

\section{Coerência das fontes de luz}

As fontes luminosas podem ser caracterizadas como coerentes, não coerentes ou parcialmente coerentes. As fontes são coerentes se a relação entre as suas fases é constante no tempo. São incoerentes se relação entre as fases não é constante no tempo e parcialmente coerentes se a relação entre as fases ela se apresenta coerente, durante um tempo de observação. Uma luz estritamente monocromática proveniente de uma fonte pontual é descrita por uma função senoidal infinita no espaço e no tempo. Quaisquer perturbações deste tipo, que se encontrem num ponto $P$, são coerentes, uma vez que a sua relação de fase é bem definida. No entanto, luz proveniente de uma fonte real nunca é estritamente monocromática e, além disso, a fonte real nunca é pontual.

A coerência pode ser classificada como temporal ou espacial, estando diretamente relacionada à largura de banda finita da fonte de luz ou à sua finita extensão no espaço, respectivamente. É um parâmetro que quantifica a qualidade da interferência através do chamado grau de coerência, cuja medida define o quão perfeitamente as ondas podem cancelar-se devido à interferência destrutiva. A coerência de duas ondas é uma medida da correlação entre elas, quantificada pela função de auto correlação, que nos permite saber o valor de uma segunda onda, tendo conhecimento da primeira onda. Nesta tese iremos focar na coerência temporal que mede a interferência de uma mesma fonte de luz com ela mesma em tempos diferentes. A diferença de tempo máximo onde ainda é possível observar a interferência entre as ondas é chamada de tempo de coerência e a distância que a onda viaja durante o tempo de coerência é chamado de comprimento de coerência. Existe uma relação entre a largura de banda espectral de uma fonte de luz e a sua coerência temporal, que diminui gradativamente com o aumento da largura de banda. Para uma fonte óptica coerente, usada, por exemplo, em um arranjo experimental de um interferômetro de Michelson, que será discutido na próxima seção, as franjas de interferência provenientes da modificação do comprimento do 
braço de referência alteram o valor da autocorrelação dos campos elétricos, ou seja, são observados máximos e mínimos resultantes das interferências construtiva e destrutiva na saída onde o sinal é medido. Na figura 2 pode ser observado o padrão de franjas de interferência para uma fonte monocromática e coerente.

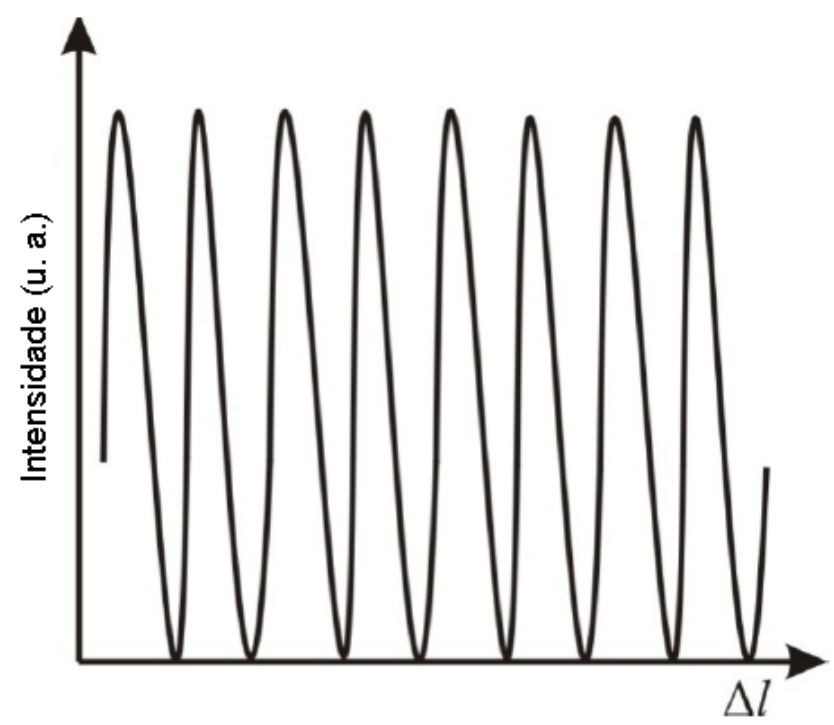

Figura 2 - Intensidade de luz na saída de um interferômetro de Michelson para uma fonte coerente monocromática.

Onde $\Delta \mathrm{l}$ é a diferença de caminho óptico entre os braços de um interferômetro de Michelson.

Na prática, não existe uma fonte perfeitamente coerente e monocromática, o que significa uma oscilação na intensidade das franjas, ou seja, uma diminuição gradual da amplitude de oscilação das franjas, conforme pode ser observado na figura 3. O intervalo que separa os pontos da envoltória onde a intensidade tem a metade do valor do máximo é chamado de comprimento de coerência.

Uma formulação mais simplificada das teorias relacionadas à interferência e propagação de ondas será usada aqui para introduzir a teoria de baixa coerência. Neste caso, a corrente média resultante no detector é expressa como:

$$
I=\frac{\eta e}{h v} \frac{\left|\left(E_{R}+E_{S}\right)^{2}\right|}{2 \eta_{0}}
$$


Onde $\eta$ é a eficiência quântica do detector, e é a carga do elétron, hv é a energia do fóton e $\eta_{0}$ é a impedância intrínsica do espaço livre (vácuo).

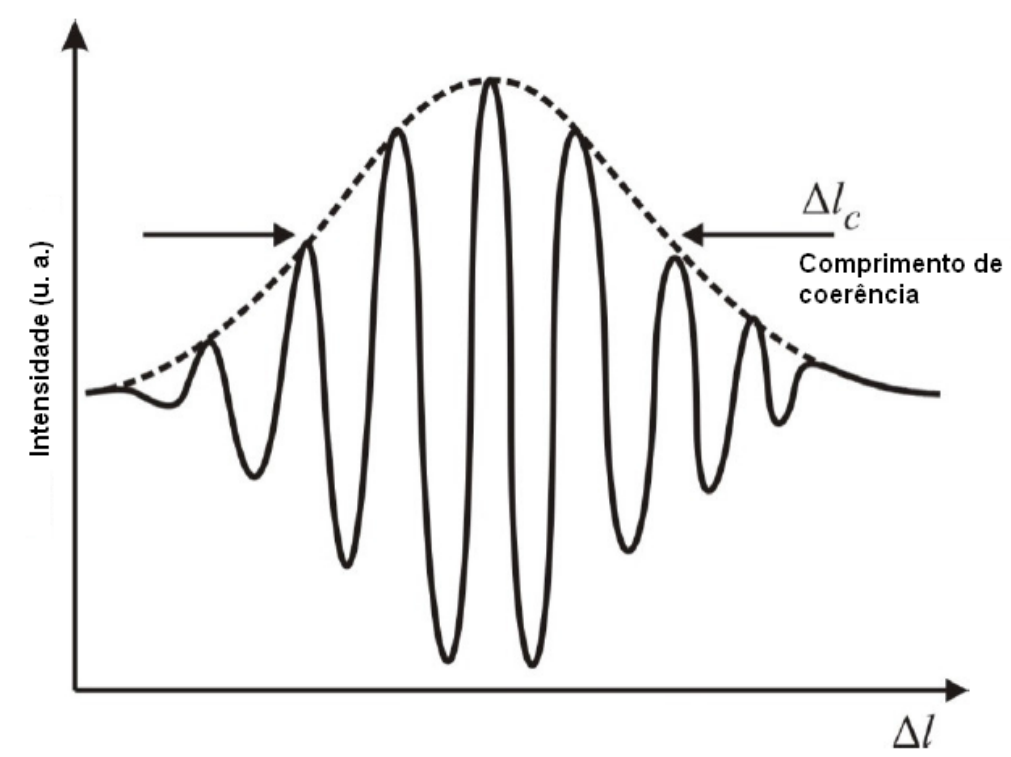

Figura 3 - Intensidade de luz na saída de um interferômetro de Michelson para uma fonte de baixa coerência.

Considerando o caso de uma onda monocromática, o campo elétrico é representado por:

$$
E_{i}=A_{i} e^{i \omega t-\beta z}
$$

Onde A é a amplitude, $\omega$ é a frequência óptica e $\beta$ é a constante de propagação. Substituindo a expressão de $E_{\mathrm{i}}$ na corrente média resultante no detector (I), teremos:

$$
I=\frac{\eta e}{h v \eta_{0}}\left(\frac{\left|A_{R}\right|^{2}}{2}+\frac{\left|A_{S}\right|^{2}}{2}+\operatorname{Re}\left\{E_{R} E_{S}{ }^{*}\right\}\right)
$$

Onde o termo Re $\left\{E_{R} E_{S}{ }^{*}\right\}=A_{R} A_{S} \cos 2\left(\beta_{R} L_{R}-\beta_{S} L_{S}\right)$ está relacionado à parte real do termo de interferência e representa a variação da corrente em função da distância dos espelhos dos braços de referência e de amostra, para uma fonte de luz de alta coerência. $\mathrm{O}$ fator 2 é devido a luz percorrer duas vezes a distância L. 
No vácuo as constantes são iguais para os caminhos da referência e da amostra, assim, podemos escrever $\beta_{R}=\beta_{S}=2 \pi / \lambda$. Dessa forma, o termo $\operatorname{Re}\left\{E_{R} E_{S}^{\prime *}\right\}$ pode ser escrito como:

$$
\operatorname{Re}\left\{E_{R} E_{S}^{\prime *}\right\}=A_{R} A_{S} \cos \left(2 \pi \frac{\Delta L}{\lambda / 2}\right)
$$

Onde $\Delta \mathrm{L}=\mathrm{L}_{\mathrm{R}}-\mathrm{L}_{\mathrm{S}}$ e é a diferença de caminho óptico dos feixes de referência e da amostra.

A equação (2.16) mostra que existe um termo oscilante (senoidal) em relação à diferença de caminho óptico que representa a interferência entre os campos do braço de referência e de amostra. Essa interferência tem um período de $\lambda / 2$ relativo à diferença de caminho óptico percorrido pela luz.

Quando a fonte de luz é de baixa coerência, os campos são dados por:

$$
\begin{aligned}
& E_{R}=A_{R}(\omega) e^{-i\left[2 \beta_{R}(\omega) L_{R}-\omega t\right]} \\
& E_{S}^{\prime *}=A_{S}(\omega) e^{-i\left[2 \beta_{S}(\omega) L_{S}-\omega t\right]}
\end{aligned}
$$

Onde $A_{R}(\omega)$ e $A_{S}(\omega)$ são as amplitudes dependentes da frequência da luz e estão relacionadas à distribuição espectral da fonte nos braços de referência e amostra, respectivamente, $\beta_{\mathrm{i}}(\omega)$ é a constante de propagação da fonte de luz.

A corrente no fotodetector é dada por:

$$
I=\frac{\eta e}{h v \eta_{0}} \operatorname{Re}\left\{\int_{-\infty}^{+\infty}\left(\frac{\left|A_{R}\right|^{2}}{2}+\frac{\left|A_{S}\right|^{2}}{2}+S(\omega) e^{-i \Delta \phi(\omega)}\right) \frac{d \omega}{2 \pi}\right\}
$$

Onde os dois primeiros termos quadráticos da equação são constantes (termos DC) e o terceiro termo é oscilante (termo AC) são definidos por:

$$
\begin{gathered}
S(\omega)=A_{R}(\omega) A_{S}(\omega)^{*} \\
\Delta \phi(\omega)=2\left[\beta_{S}(\omega) L_{S}-\beta_{R}(\omega) L_{R}\right]
\end{gathered}
$$


Os termos da equação (2.18) foram integrados para que todas as contribuições de frequência da fonte de baixa coerência fossem levadas em consideração.

O $1^{0}$ termo (componentes $A_{R}$ e $A_{S}$ ) da equação (2.18) é uma componente DC e é constante, já o $2^{\circ}$ termo $(\mathrm{S}(\omega))$ depende da diferença de caminho óptico das distâncias percorridas pelo sinal óptico entre os braços de referência e daquele que contêm a amostra e representa a amplitude das franjas geradas contendo as informações da estrutura interna da amostra.

Quando os campos da amostra e da referência tem a mesma componente espectral, $S(\omega)$ é equivalente ao espectro de potência de luz e $\Delta \phi(\omega)$ corresponde ao descasamento de fase, de cada frequência, no detector.

Considerando que os caminhos de referência e da amostra sejam meios uniformes, lineares e não dispersivos e que a distribuição de potência espectral da fonte de luz seja dada por $S\left(\omega-\omega_{0}\right)$, sendo que a largura de banda é limitada e centrada na frequência $\omega_{0}$ e a constante de propagação, $\beta_{\mathrm{i}}$, igual nas duas portas do interferômetro, ou seja, a amostra se comportando como um espelho, podemos escrever $\beta_{\mathrm{i}}(\omega)$ em primeira ordem de expansão de Taylor em torno da frequência central $\omega_{0}$ :

$$
\beta_{R}(\omega)=\beta_{S}(\omega)=\beta\left(\omega_{0}\right)+\beta^{\prime}\left(\omega_{0}\right)\left(\omega-\omega_{0}\right)
$$

Assim, o descasamento de fase, $\Delta \phi(\omega)$, será determinado somente pela diferença de caminho óptico entre os braços de referência e da amostra, $\Delta \mathrm{L}=\mathrm{L}_{\mathrm{R}}-\mathrm{L}_{\mathrm{S}}$ e será dado por:

$$
\Delta \phi(\omega)=\beta\left(\omega_{0}\right) 2 \Delta L+\beta^{\prime}\left(\omega_{0}\right)\left(\omega-\omega_{0}\right) 2 \Delta L
$$

Desta forma, integrando a equação gaussiana, temos:

$$
I \propto R e\left\{e^{-i \omega_{0} \Delta \tau_{p}} \int_{-\infty}^{+\infty} S\left(\omega-\omega_{0}\right) e^{-i\left(\omega-\omega_{0}\right) \Delta \tau_{g}} \frac{d\left(\omega-\omega_{0}\right)}{2 \pi}\right\}
$$

Onde $\Delta \tau_{\mathrm{p}}$ é o atraso do descasamento de fase e $\Delta \tau_{\mathrm{g}}$ é o atraso do descasamento de grupo, definidos por: 


$$
\begin{aligned}
& \Delta \tau_{p}=\frac{\beta\left(\omega_{0}\right)}{\omega_{0}} 2 \Delta l=\frac{2 \Delta l}{v_{p}} \\
& \Delta \tau_{g}=\beta^{\prime}\left(\omega_{0}\right) 2 \Delta l=\frac{2 \Delta l}{v_{g}}
\end{aligned}
$$

Onde $v_{p}=\frac{\omega_{0}}{\beta\left(\omega_{0}\right)}$ é a velocidade de fase da frequência central do espectro de potência e $v_{g}=\frac{1}{\beta^{\prime}\left(\omega_{0}\right)}$ é a velocidade de grupo.

A equação (2.23) pode ser interpretada usando o fato de que a função de auto-correlação é a transformada de Fourier inversa da densidade de potência espectral. O termo de transporte dessa equação oscila com a mudança na diferença de caminho óptico, $2 \Delta L$, na frequência $\beta\left(\omega_{0}\right)$. O envelope, que determina a função de propagação pontual (point spread function) do interferômetro é essencialmente a transformada de Fourier inversa do espectro de potências da fonte $S\left(\omega-\omega_{0}\right)$. Considerando que a fonte de luz tem uma densidade de potência espectral Gaussiana definida por:

$$
S\left(\omega-\omega_{0}\right)=\sqrt{\frac{2 \pi}{\sigma_{\omega}^{2}}} e^{-\left(\omega-\omega_{0}\right)^{2} /} \sigma_{\omega}^{2}
$$

Onde $\omega_{0}$ é a frequência central e $2 \sigma$ é o desvio padrão da largura de banda espectral.

A equação normalizada para a unidade é $\int_{-\infty}^{\infty} S(\omega) \frac{d \omega}{2 \pi}=1$

Usando a equação (2.26) na expressão para a fotocorrente (2.23), teremos:

$$
I \propto R e\left\{e^{-\frac{\Delta \tau_{g}}{\sigma_{\tau}^{2}}} e^{-i \omega_{0} \Delta \tau_{p}}\right\}
$$

A fotocorrente contém um envelope de onda Gaussiano com um desvio padrão $2 \sigma_{\tau}$, que é inversamente proporcional à largura de banda do espectro de potência $2 \sigma_{\tau}=2 / \sigma_{\omega}$. O envelope tende rapidamente a zero com o aumento da diferença de caminho óptico $\Delta \mathrm{l}$ e é modulado pelas franjas de interferência 
geradas. O detector somente enxerga as franjas de interferência quando a diferença de percurso óptico estiver dentro do comprimento de coerência da fonte. O desvio padrão da resolução axial, ou seja, a largura da função de propagação pontual (a largura $\sigma_{\tau}$, do envelope Gaussiano) é dada por $\Delta \sigma=\frac{v_{g}}{\sigma_{\omega}}$.

Para medidas de largura de banda e resolução, é mais conveniente o uso da largura total à meia altura (FWHM) comparado ao uso do desvio padrão. Para um pulso de perfil Gaussiano com desvio padrão $\sigma$, a largura total à meia altura é dada por: $2 \sigma \sqrt{2 \ln 2}$, sendo a resolução do sistema expressa como:

$$
\Delta L_{F W H M}=\frac{2 \ln 2}{\pi} \frac{\lambda_{0}^{2}}{\Delta \lambda}
$$

Onde $\lambda_{0}$ é o comprimento de onda central e $\Delta \lambda$ é a largura total à meia altura do espectro de potência.

A equação (2.29) define a resolução axial nos sistemas de baixa coerência, como no sistema de OCT.

Na próxima seção será mostrado o funcionamento de alguns interferômetros, com prioridade para aqueles com aplicações em metrologia de comprimento, que é o foco da tese.

\section{3}

\section{Interferômetros}

Interferômetros são instrumentos e/ou configurações que usam o fenômeno da interferência para determinação de algumas grandezas físicas [26, 27, 28, 29, 30]. Existem dois tipos de interferômetros, aqueles em que o feixe é dividido após passar por diferentes aberturas colocadas lado a lado e aqueles em que o feixe é dividido ao passar por uma superfície parcialmente refletora. Nesta tese nos basearemos no segundo tipo que também é chamado de interferômetro de divisão de amplitude, como por exemplo, o interferômetro de Michelson. 


\subsection{1}

\section{Interferômetro de Michelson}

O interferômetro de Michelson foi desenvolvido em 1881 e foi usado no experimento de Michelson-Morley, que teve como resultado a primeira evidência da não existência do éter, o que foi demonstrado posteriormente por Einstein em seu trabalho sobre relatividade especial. O esquema básico do interferômetro de Michelson pode ser observado na figura 4.

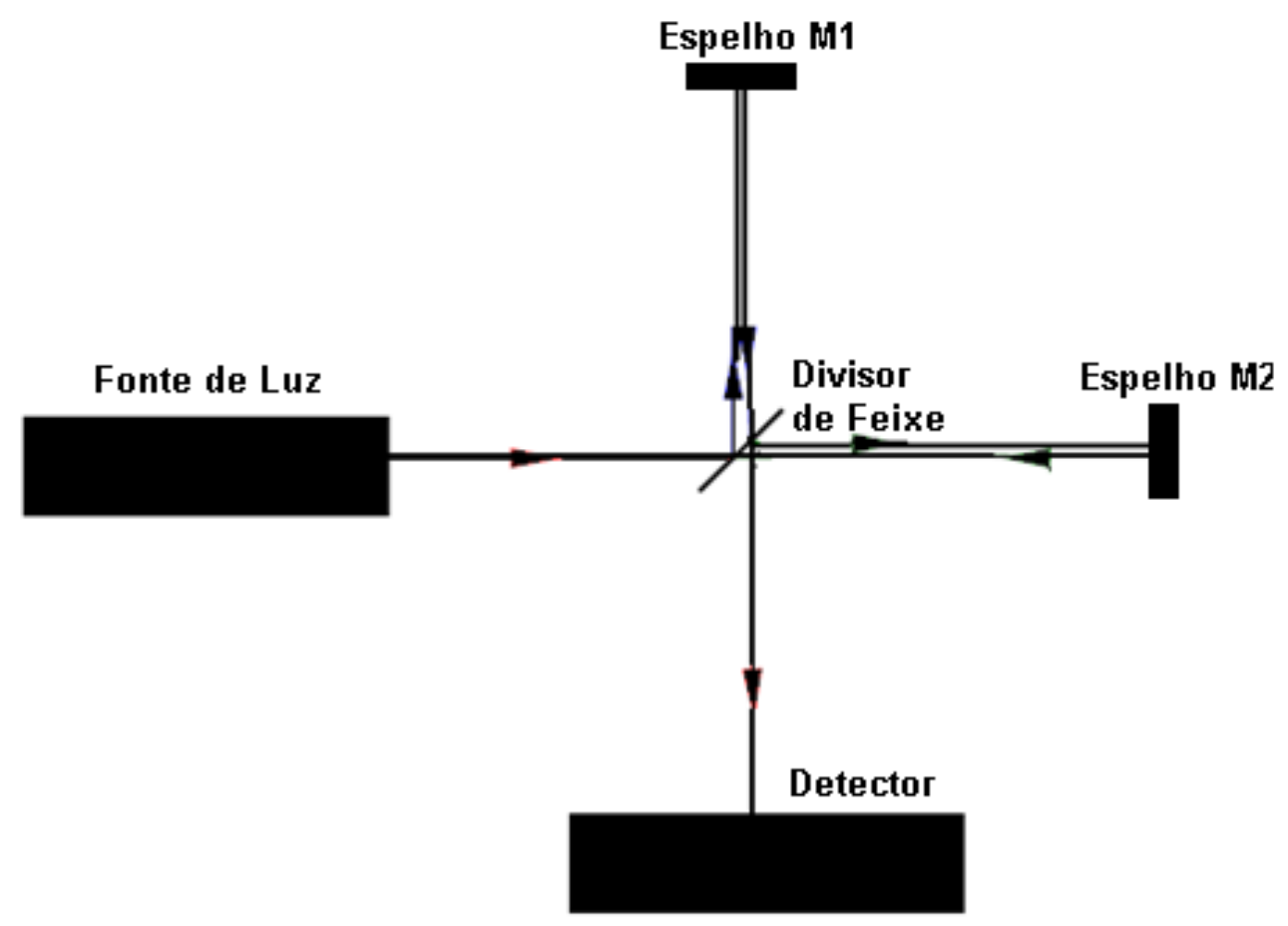

Figura 4 - Esquema básico do Interferômetro de Michelson.

Neste caso, a radiação emitida por uma fonte de luz é dividida em duas partes, sendo o primeiro feixe refletido no divisor de feixe e dirigindo-se até o espelho $\mathrm{M}_{1}$, onde é refletido, retornando ao divisor de feixe e ao detector. $\mathrm{O}$ segundo feixe atravessa o divisor de feixe e refletido no espelho $\mathrm{M}_{2}$, retorna ao divisor de feixe, onde é refletido e também chega ao detector. Ambos os feixes refletidos se recombinam no divisor de feixe e são direcionados para o detector. Dependendo da diferença de fase dos dois feixes que varia em função dos caminhos percorridos por eles, a intensidade do padrão de franjas no plano do detector pode ser modificada variando a posição dos espelhos nos braços do interferômetro. Caso os caminhos ópticos percorridos pelos dois feixes forem exatamente iguais, haverá interferência construtiva com intensidade máxima no 
feixe de interferência. À medida que a diferença de caminho óptico entre os feixes se aproxima do comprimento de coerência da luz, a intensidade das franjas diminuirá até não serem mais visíveis. O padrão de franjas de interferência é observado no detector, ao se variar a posição de um dos espelhos.

\subsection{2}

\section{Interferômetro de Mach Zender}

O interferômetro de Mach-Zehnder (MZI) é um tipo particular de um interferômetro de dois feixes, similar ao interferômetro de Michelson. Seu arranjo experimental é relativamente simples e consiste de espelhos e semi-espelhos que demonstram o fenômeno da interferência da luz pela divisão de um feixe luminoso. Sua configuração, mostrada na figura 5, consiste de dois divisores de feixe, dois espelhos reflexivos e, usualmente, dois detectores de radiação.

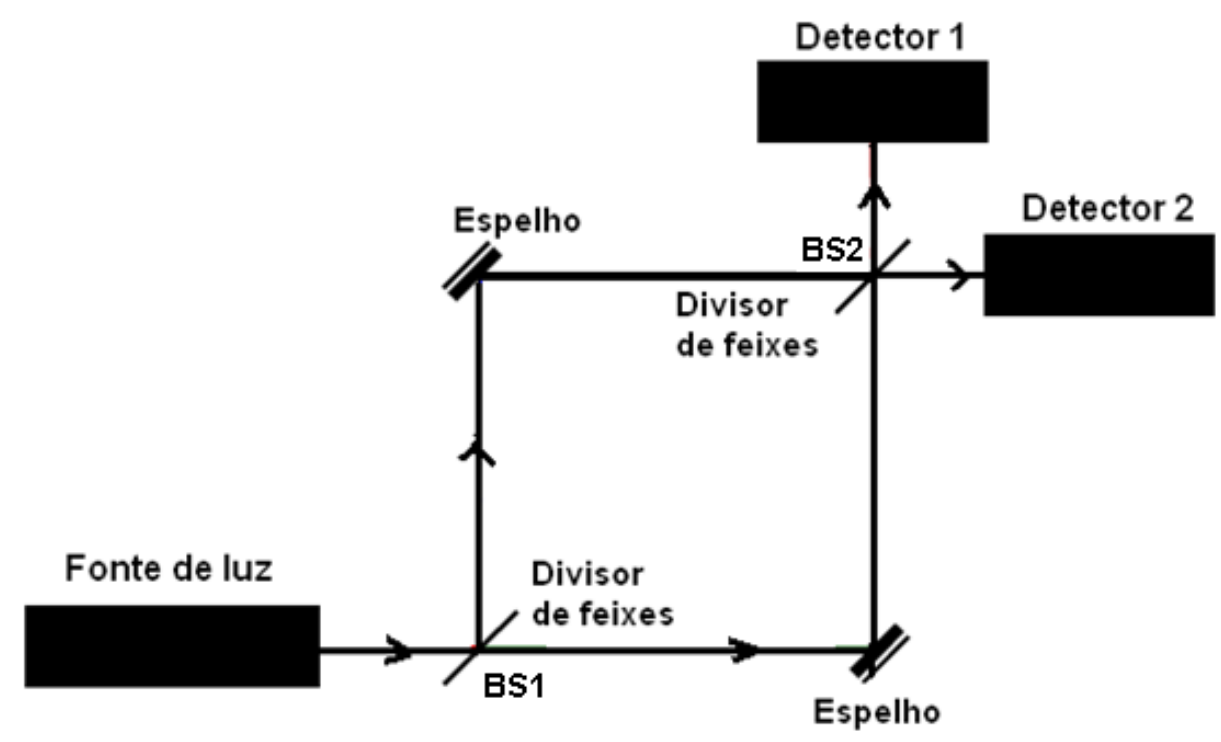

Figura 5 - Esquema básico do Interferômetro de Mach Zehnder.

A radiação proveniente de uma fonte é colimada e dividida por um divisor de feixe (BS1). Os feixes que foram divididos percorrem caminhos diferentes e depois são refletidos pelos espelhos se recombinado em outro divisor de feixes (BS2). O padrão de interferência pode ser observado tanto na saída do detector 1 quanto na saída do detector 2, ao ser variada a diferença de caminho óptico. A dificuldade no alinhamento do interferômetro é compensada pela sua alta 
sensibilidade que proporciona seu uso em várias aplicações tecnológicas e de pesquisa, que vai interferometria básica até o processamento em óptica quântica e biofísica.

\subsection{3}

\section{Interferômetro de Twyman Green}

O interferômetro de Twyman Green é um instrumento simples e muito usado para medir defeitos em componentes ópticos tais como lentes, prismas, etc, assim como para medir blocos padrão pequenos (<100 mm). O divisor de feixes e o arranjo dos espelhos assemelham-se ao do interferômetro de Michelson. A diferença está na maneira como são iluminados, já que no interferômetro de Michelson é usada uma fonte de luz extensa e no Twyman Green é usada uma fonte pontual monocromática que é localizada no foco principal de uma lente. A luz de uma fonte monocromática pontual, localizada no foco principal de uma lente convergente $\mathrm{L}_{1}$ é colimada e dividida em dois feixes de igual intensidade por um divisor de feixe $\mathrm{P}_{1}$, sendo direcionadas e refletidas no plano dos espelhos $\mathrm{M}_{1} \mathrm{e}$ $M_{2}$. Os feixes são recombinados em P1 e ao passar pela lente $L_{2}$ são levados ao foco em S. Para alinhar adequadamente o interferômetro ambos os espelhos são ajustados com parafusos micrométricos até que as duas imagens de $\mathrm{S}$ dos espelhos $\mathrm{M}_{1}$ e $\mathrm{M}_{2}$ coincidam com a fonte de luz em $\mathrm{S}$, o qual é usualmente uma abertura muito pequena. Ao mesmo tempo as duas imagens no plano contendo a imagem $\mathrm{S}$ também será coincidente. Com os espelhos ajustados dessa maneira às ondas planas sobrepostas em cada espelho são exatamente paralelas. Além disso, a diferença de fase constante entre os feixes recombinados existe em todo o campo de visão. A intensidade de iluminação depende da diferença de passo, sendo: $\mathrm{P}_{1} \mathrm{M}_{1} \mathrm{P}_{1}-\mathrm{P}_{1} \mathrm{M}_{2} \mathrm{P}_{1}=\Delta \mathrm{m} \lambda_{0}$, onde $\lambda_{0}$ é o comprimento de onda da fonte em $\mathrm{S}$. A intensidade é máxima quando a diferença de passo é zero ou difere de um número inteiro de comprimento de onda quando $\Delta \mathrm{m}=1,2,3$, etc, por outro lado, quando $\Delta \mathrm{m}=1 / 2,3 / 2,5 / 2$, etc, o campo de visão como observado em $\mathrm{S}$ é escuro.

Um esquema básico do interferômetro de Twyman Green pode ser observado na figura 6 . 


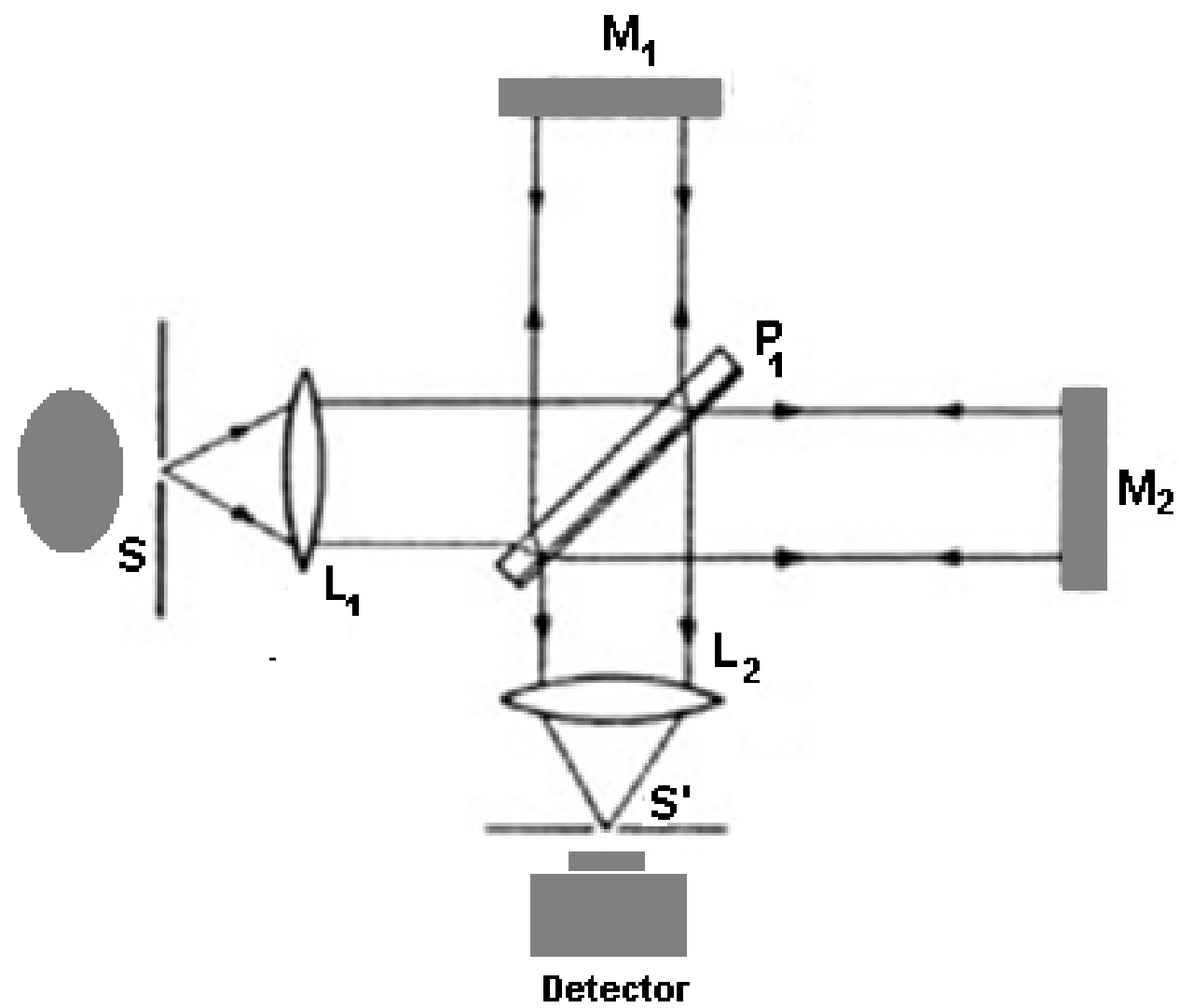

Figura 6 - Esquema básico do interferômetro de Twyman Green.

Se ambos os espelhos $\mathrm{M}_{1}$ e $\mathrm{M}_{2}$ são perfeitamente planos e são alinhados apropriadamente, as ondas recombinadas, são paralelas. Neste caso, o campo de visão é uniformemente iluminado e nenhuma franja é observada. Entretanto, se existe uma pequena irregularidade na superfície, tal como um pequeno vale ou aresta em um dos espelhos, como no $\mathrm{M}_{2}$, a irregularidade levará a um padrão de franja localizado, parecido com um mapa de contorno.

\subsection{4}

\section{Interferômetro Linnik}

O Linnik [31, 32, 33, 34, 35] é um interferômetro de dois feixes usado principalmente em microscopia e medidas de contorno de superfície. A configuração básica é idêntica ao interferômetro de Michelson. Na figura 7 é mostrado o esquema do interferômetro Linnik, que compreende uma fonte de luz $\mathrm{L}$, um colimador $\mathrm{C}$, uma ocular (eyepiece) E, lentes objetivas $\mathrm{O}$ e $\mathrm{O}$ ’ com 
distâncias ópticas idênticas, o braço de amostra $S$, dando uma imagem $F$, um espelho de referência M cuja imagem refletora é M’ e um detector D.

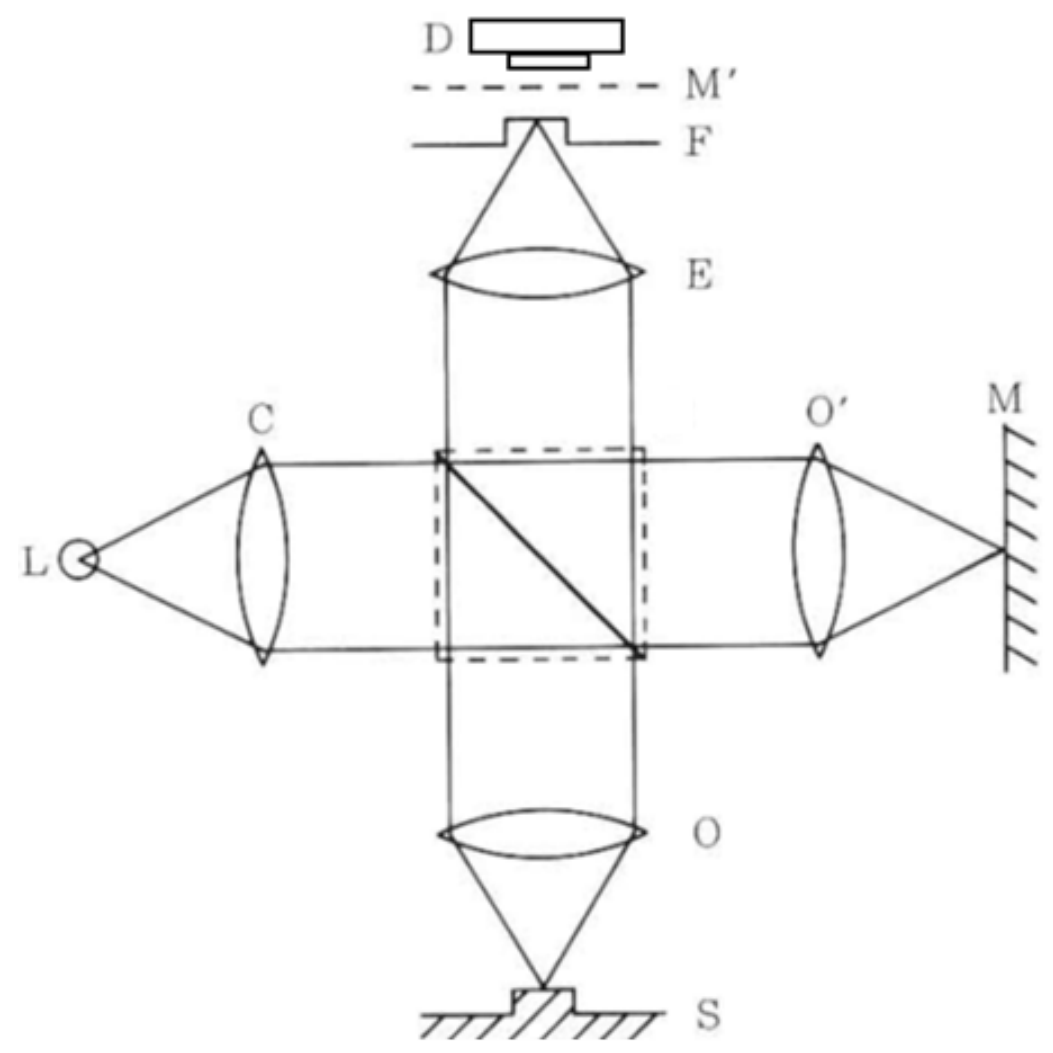

Figura 7 - Esquema básico do Interferômetro Linnik.

No interferômetro, a fonte de luz é dividida por um divisor de feixes e enviada ao longo de dois caminhos. Em ambos os caminhos, os feixes é refletido nos braços de referência e de amostra, se recombinam no divisor de feixe e é enviado ao detector. No detector, se os dois caminhos estão combinados dentro do comprimento de coerência da fonte, a luz dos dois caminhos combinam interferometricamente. Se os comprimentos dos caminhos diferem de um múltiplo inteiro de comprimento de onda, ou seja, se recombinam em fase é criado um padrão de franja de interferência. Se os comprimentos dos caminhos diferem de $1 / 2$ comprimento de onda desta condição, a luz proveniente dos dois caminhos irão combinar fora de fase, não gerando franja de interferência.

O que distingue a configuração Linnik é o uso de lentes objetivas de alta ampliação para que a técnica de interferência seja aplicada para observar de forma detalhada o objeto a ser medido. 
Na próxima seção são mostrados os aspectos básicos da tomografia de corência óptica (OCT), uma técnica de imagem usada para diagnóstico não invasivo, que foi rastreado na escala de comprimento, a partir do interferômetro primário desenvolvido nesta tese. 


\section{3}

\section{Princípios Básicos de Tomografia de Coerência Óptica (OCT)}

Em 1991, Huang e colaboradores [36, 37] iniciaram experimentos baseados no interferômetro de baixa coerência que foi denominado de Tomografia de Coerência Óptica (OCT). Esta técnica não invasiva e em tempo real tem sido fundamental em aplicações em diversas áreas, já que é possível fazer imagens de alta resolução da microestrutura de vários tipos de materiais, como por exemplo, de tecidos humanos.

Tomografia de coerência óptica (OCT) [38, 39, 40, 41] é uma tecnologia de imagens e diagnósticos relativamente nova que tem um importante impacto nas pesquisas na área de biologia e medicina, sendo análogo ao ultrassom [42], exceto pelo uso da luz em vez do som. Com OCT pode-se gerar imagens de alta resolução (1 - $15 \mu \mathrm{m})$, imagens da seção transversal e tridimensional da microestrutura interna em materiais e sistemas biológicos. A técnica oferece a vantagem de mostrar a imagem em tempo real, permitindo visualizar a área afetada (patologia) diretamente in situ em vez de fazer, por exemplo, uma biopsia convencional. Uma comparação entre as técnicas de ultrassom, microscopia e OCT é mostrada na figura 8.

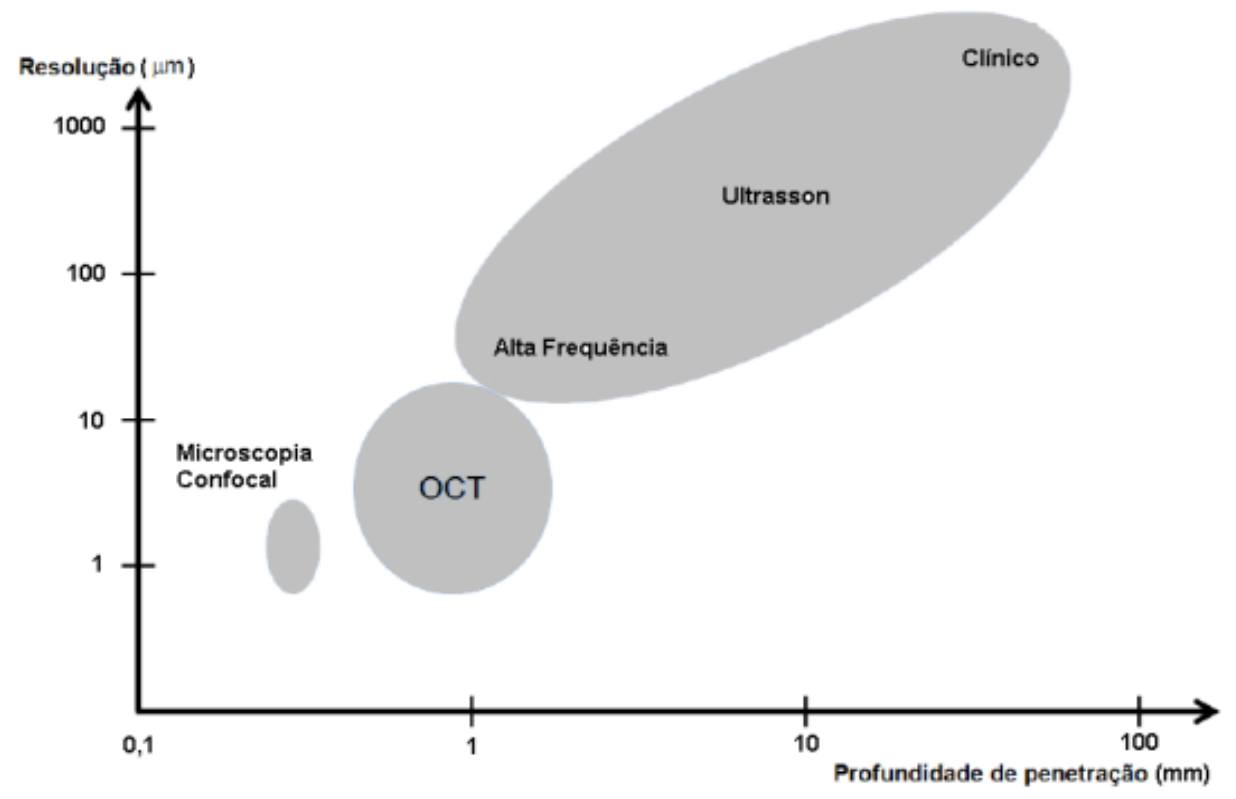

Figura 8 - Resolução e profundidade de técnicas de diagnóstico por imagem [45]. 
Podemos observar na figura 8 que o OCT pode ser usado na região em que as outras técnicas não podem atuar. No caso do ultrassom, tanto a penetração (profundidade da imagem) como a resolução são determinadas pela frequência ou pelo comprimento de onda. Tipicamente, em sistemas clínicos, a frequência da onda de som é da ordem de $10 \mathrm{MHz}$, podendo atingir resolução da ordem de $150 \mu \mathrm{m}$. A técnica de ultrassom tem a vantagem que as ondas sonoras nessa frequência são facilmente transmitidas nos tecidos biológicos, dessa forma é possível obter imagens com algumas dezenas de centímetros de profundidade. Para frequências maiores, pode-se obter resolução de algumas dezenas de micrômetros, mas a penetração nesses casos é reduzida a alguns milímetros.

A tecnologia atual em OCT permite atingir valores de resolução entre

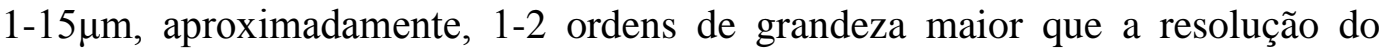
ultrassom e diferentemente desse pode adquirir imagens sem que seja necessário o contato com a amostra. A técnica do OCT pode também ser usada em pesquisas sobre câncer, engenharia de tecido e também na avaliação de materiais, principalmente, em estudos de matrizes poliméricas e de compósitos (PMC) que são usados na construção de pontes, armamentos militares, equipamentos esportivos, etc. Como esses materiais são caros de se produzir e existe a necessidade de se verificar a qualidade do produto, o ideal é que sejam realizados ensaios não destrutivos, mas para isto essas medições têm de ter rastreabilidade a um padrão confiável, que é uma aplicação proposta nesta tese.

No caso da microscopia confocal, a resolução está diretamente ligada aos componentes ópticos utilizados, onde é possível obter alta resolução, mas com baixa penetração, enquanto a técnica de ultrassom tem baixa resolução e alta penetração. Em sistemas de microscopia convencionais é possível obter resolução transversal da ordem de sub-micrômetro. No entanto, quando a resolução transversal é muito pequena, a resolução axial é prejudicada. Em microscopia confocal tradicional, a penetração não ultrapassa algumas centenas de micrometros em tecidos biológicos, por esse motivo sua maior aplicação está na geração de imagem de amostras in vitro.

Todas essas técnicas de geração de imagem são complementares, cada uma atuando melhor em uma região específica. Uma técnica não substitui a outra, cada qual tem uma aplicação diferente, sendo o ponto mais importante à 
possibilidade do uso conjunto dessas técnicas para melhorar o diagnóstico de várias doenças.

Na próxima seção serão abordados apenas aspectos principais de funcionamento do sistema OCT, já que o assunto está disponível em teses e artigos [43, 44, 45, 46, 47] na área.

\section{1}

\section{Princípios Básicos do OCT}

A tomografia por coerência óptica [48, 49, 50,51] é uma técnica baseada na detecção e análise do sinal de interferência produzido entre uma reflexão de referência e o sinal refletido ou o sinal retroespalhado, vindo de vários pontos da amostra que está sendo avaliada. O princípio de operação do OCT é a interferometria de baixa coerência. Uma montagem típica para esse sistema é a do OCT no domínio do tempo (TD-OCT) que pode ser observado na figura 9, que consiste de interferômetro de Michelson com uma fonte de luz de baixa coerência e grande largura espectral.

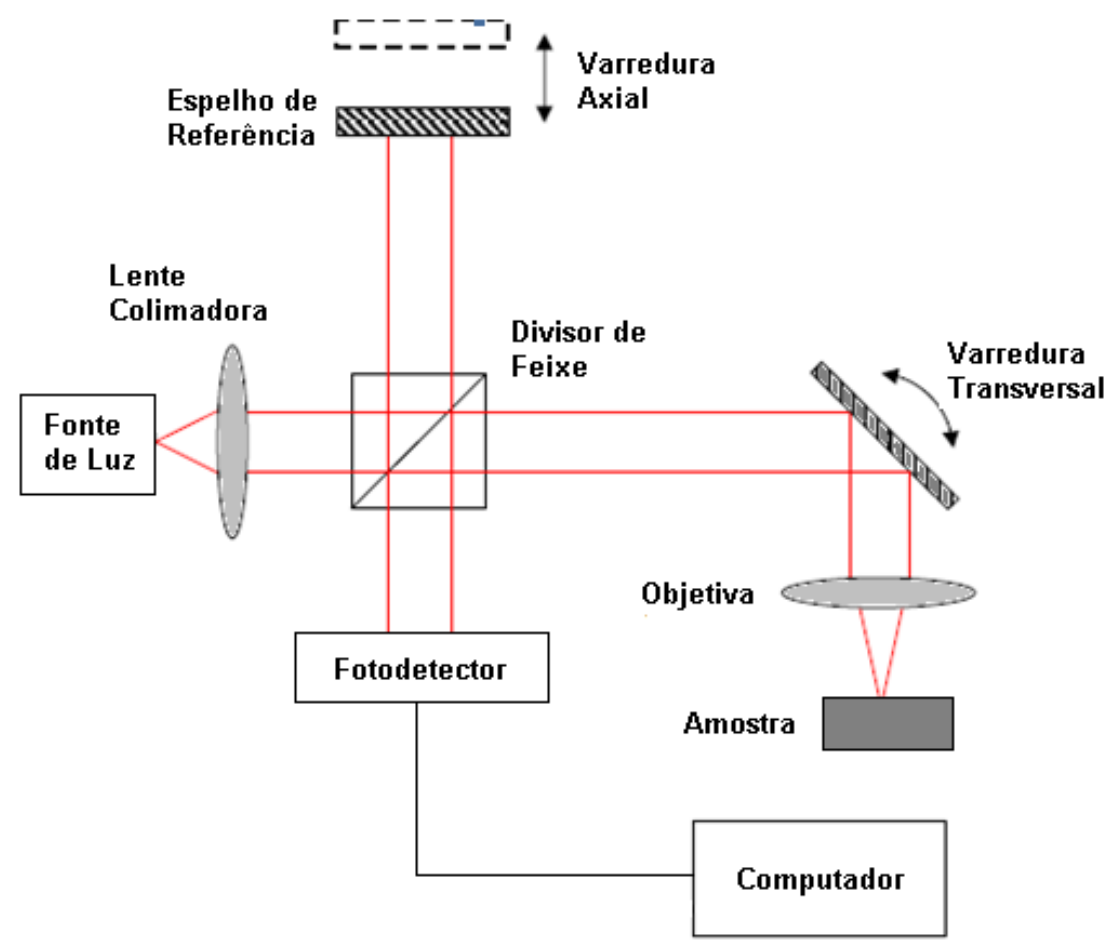

Figura 9 - Montagem básica do TD-OCT. 
O feixe, após passar pelo divisor de feixe, se divide nos braços de referência e amostra e percorrem caminhos distintos. A interferência ocorre no detector, pela soma dos campos elétricos refletidos nos sistemas de amostra e referência, onde neste último é usado um espelho móvel. Nesta configuração, o espelho do braço de referência é montado sobre um braço de translação, para ter uma linha de atraso óptico. A geração de imagens é realizada a partir da diferença de caminho ótico gerada entre os dois braços do interferômetro. O perfil de refletividade, chamado A-scan, é obtido fazendo uma varredura do espelho de referência e contém informação sobre a dimensão e posição axial das estruturas dentro da amostra. Para obter o B-scan, que é uma imagem tomográfica de seção transversal, é realizada uma série de varreduras axiais (A-scan). A geração de imagem en face (C-scan) em uma profundidade específica é possível variando-se a posição da amostra com relação ao feixe de prova. Existem várias maneiras de se construir uma imagem no OCT, uma delas seria a formação de imagens através da medida do atraso do eixo temporal e da intensidade da luz de retorno, refletida ou espalhada, sendo esta imagem obtida através da diferença na medição de um conjunto de dados bidimensionais ou tridimensionais.

\section{2}

\section{Resoluções Axial e Transversal no OCT}

Os mecanismos que governam a resolução das imagens axial e transversal são independentes na tecnologia de OCT que utiliza técnicas interferométricas para obter elevada resolução espacial.

A resolução axial do sistema depende do comprimento de coerência da fonte luminosa. O comprimento de coerência é a largura da autocorrelação de campo produzida pelo interferômetro. O envelope da autocorrelação do campo é equivalente à transformada de Fourier do espectro de potência. A resolução axial é inversamente proporcional à largura do espectro de potência. Para uma fonte com distribuição Gaussiana, a resolução axial é dada pela equação (3.1):

$$
\Delta_{Z}=2 \ln 2 \frac{\lambda^{2}}{\pi \Delta \lambda}
$$


Onde $\lambda=$ comprimento de onda central da fonte de luz, $\Delta \lambda=$ largura a meia altura do espectro de potência da fonte de luz.

A resolução axial é inversamente proporcional à largura de banda da fonte de luz o que implica que para ter alta resolução axial é importante usar fontes com maiores larguras de banda. Uma formulação simplificada da teoria relacionada à expressão (3.1) é discutida no capítulo 2, na seção 2.2.

A resolução transversal funciona do mesmo modo que em microscopia óptica convencional, ou seja, em função de quanto é possível focalizar o feixe. Assim, a resolução transversal é inversamente proporcional à abertura numérica do sistema óptico (lente objetiva) que focaliza o feixe, assim:

$$
\Delta_{\mathrm{x}}=2 \mathrm{w}_{0}=4 \lambda \mathrm{f} / \pi \mathrm{d}
$$

Onde d é duas vezes a cintura do feixe nas lentes objetivas, $\lambda$ é o comprimento de onda central da fonte de luz e f é a distância focal da lente objetiva.

A resolução transversal também está relacionada ao comprimento do foco ou ao parâmetro confocal $b=2 Z_{R}$, sendo $b=\pi \Delta x^{2} / 2 \lambda$, onde, $\lambda$ é o comprimento de onda central da fonte de luz, $\Delta x$ é a resolução transversal e $Z_{R}$ é o comprimento de Rayleigh. Alta resolução transversal pode ser obtida usando-se uma objetiva com abertura numérica grande e focalizando o feixe para o menor diâmetro possível. No entanto, aumentar a resolução transversal implica em diminuir a profundidade de foco, como representado na figura 10. Portanto, há um compromisso entre a resolução transversal desejada e a profundidade de foco possível, por exemplo, pelo uso de um sistema dinâmico de foco. 

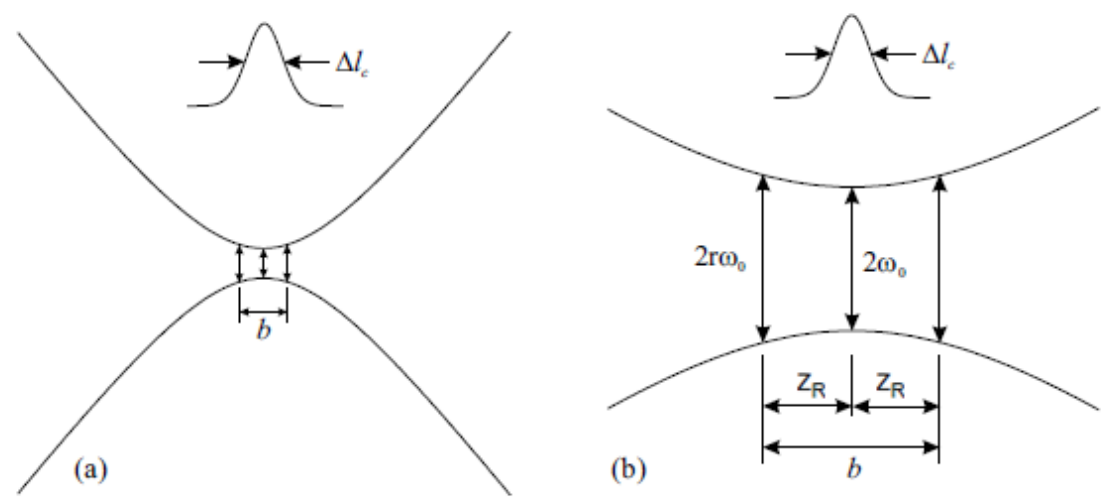

Figura 10 - Limites de foco de abertura numérica grande e pequena [48].

Podemos operar o OCT em sistemas de alta e baixa resolução transversal. A maior parte dos sistemas OCT usa lente com abertura numérica pequena, otimizada para que o comprimento do foco seja igual ao comprimento de varredura do braço de referência e permitindo a possibilidade de se desenvolverem braços de varredura de alta velocidade.

Sistemas de alta resolução transversal são interessantes quando se quer usar o modo de varredura en face, modalidade em que a amostra é varrida em profundidade constante. Pode-se usar alta resolução para sistemas de varredura com profundidade em prioridade ou transversal em prioridade. Mas nesses casos, precisa-se varrer axialmente a profundidade do foco, o que resulta em sistema cuja implementação experimental é complexa. Para modalidades de OCT no domínio de Fourier, focalização usando lentes com altas aberturas numéricas não são interessantes, pois essas modalidades, por princípio, operam em protocolo com profundidade em prioridade. Na varredura com prioridade em profundidade, as aquisições são realizadas em posições transversais sucessivas, em que cada varredura contém informações em profundidade em um ponto da amostra. $\mathrm{Na}$ prioridade transversal, o feixe varre rapidamente a direção transversal e o sinal obtido contém informação à profundidade constante. Neste caso, as varreduras vizinhas contêm informações em profundidades diferentes. O protocolo en face prioriza imagens superficiais da amostra, útil, por exemplo, em análises de rugosidade ou acabamento de superfície. A escolha mais adequada à aplicação pode diminuir o tempo de aquisição dos dados. 
A aquisição dos interferogramas nas direções $\mathrm{x}$, $\mathrm{y}$ e axial fornece as informações necessárias para a construção da imagem tomográfica, assunto discutido nas próximas seções.

\section{3}

\section{Geração de imagem no OCT}

Em geral, o processo de aquisição do sinal converte as flutuações de amplitude do sinal óptico no detector em uma sequência de dados que contém informação sobre as reflexões na amostra e localização longitudinal. O detector converte o sinal óptico em corrente elétrica. Esse sinal é filtrado, com filtro passa banda, para remover as frequências fora da região do sinal amplificado, demodulado e armazenado.

As imagens de seção transversal são obtidas fazendo-se sucessivas medidas em profundidade (varredura axial) e medindo-se a luz retroespalhada ou refletida em várias posições. As imagens bidimensionais são adquiridas, fazendose sucessivas medidas do sinal refletido em varreduras axiais e variando a posição do feixe na amostra. No final, será obtido um conjunto de dados, formando um mapa bidimensional, que corresponde à intensidade no detector em função da posição na amostra. Cada linha representa uma varredura axial e cada coluna corresponde a uma posição transversal diferente. A figura 11 mostra como uma imagem de tomografia por coerência óptica é gerada, sendo (a) imagem 1D, (b) imagem 2D e (c) imagem 3D.

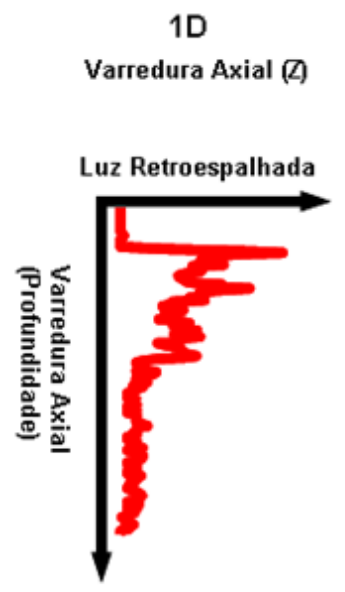

(a)

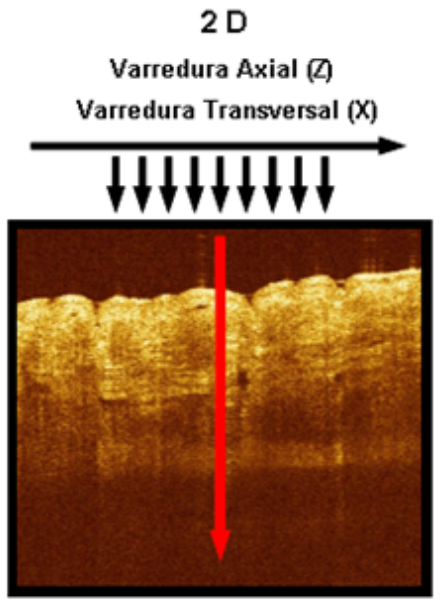

(b)

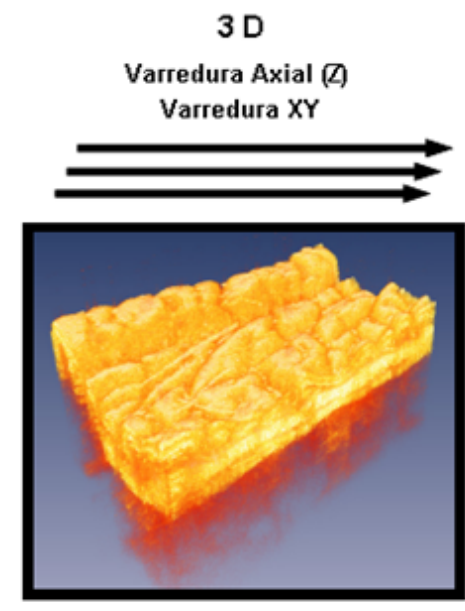

(c)

Figura 11 - Princípios de geração de imagens em OCT [45]. 
O OCT gera seções transversais e imagens tridimensionais da microestrutura do tecido e a arquitetura morfológica in vivo e em tempo real. O método mais comum na geração de imagens em OCT é aquele em que se mede o A-scan, ou seja, a medida de profundidade na amostra. Pode-se também fazer medidas de $B$-scan priorizando a direção transversal, o que significa fazer várias sequências de varreduras da posição do feixe na amostra, na direção $\mathrm{x}$, em diversas profundidades, ajustando as posições do espelho de referência. A visualização de dados é feita em um computador, onde é apresentada uma imagem bidimensional em escala de cinza. Caso também sejam realizadas varreduras da posição do feixe na direção y, o resultado é um mapa 3D da estrutura da amostra, como mostra a figura 11 (c).

\section{4}

\section{OCT comerciais no domínio do espectro}

Foram avaliados nesta tese, além de um OCT no domínio do tempo (TDOCT), montado no Inmetro, 02 (dois) OCT comerciais do fabricante Thorlabs no domínio do espectro [52, 53], um Spectral Radar OCT (SR-OCT), e um Swept Source OCT (SS-OCT). O sistema SR-OCT consiste basicamente de uma fonte de banda larga iluminando um interferômetro de Michelson. O espectro de interferência gerado pela luz refletida nos braços de referência e amostra é registrado pelo espectrômetro. A intensidade e o atraso temporal da luz refletida são determinados e medidos através do espectro de interferência da transformada de Fourier. O esquema do sistema SR-OCT é mostrado na figura 12. 


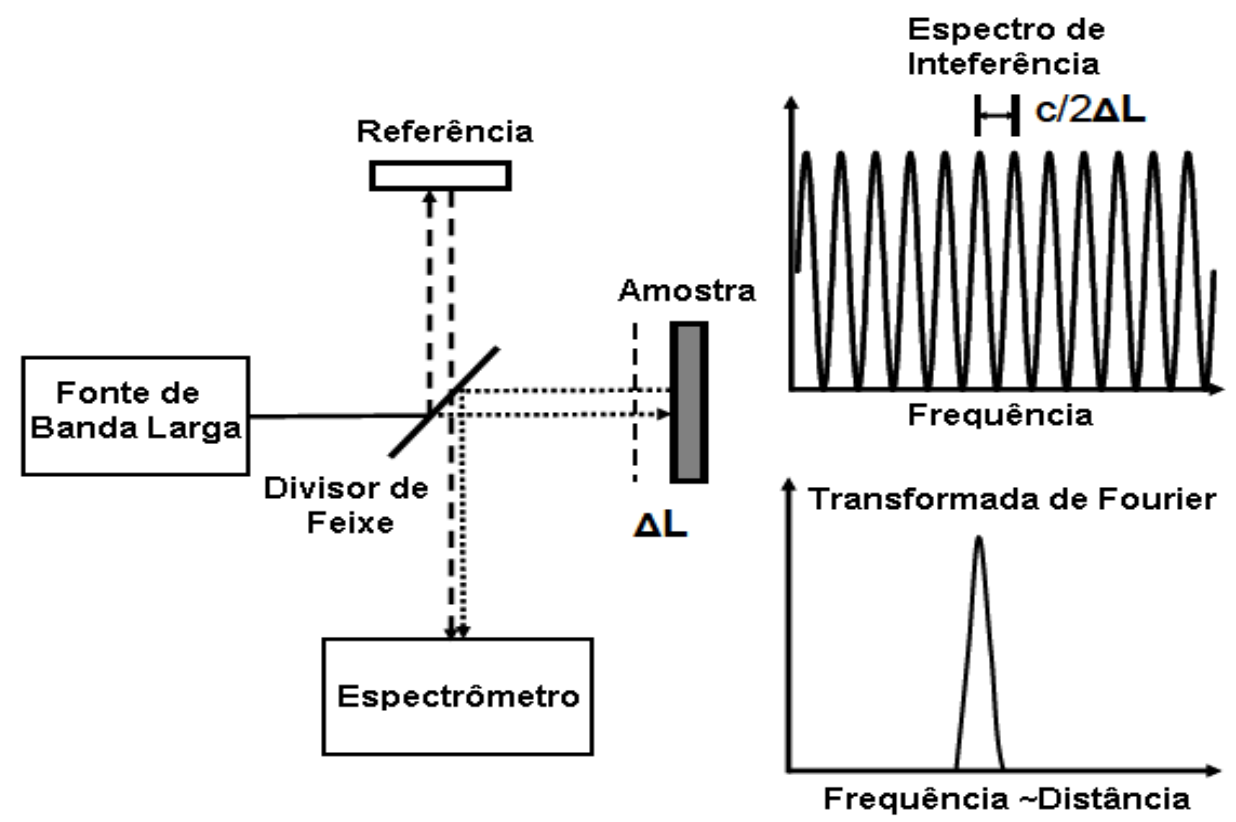

Figura 12 - Esquema básico do sistema SR-OCT.

O diagrama do sistema SR-OCT da empresa Thorlabs é mostrado na figura 13. O sistema é constituído de uma sonda portátil que pode ser acoplada a um microscópio, uma unidade de base inclui um diodo superluminescente de banda larga (SLD) como fonte de luz, um espectrômetro com circuito analógico e digital e uma unidade eletrônica para o galvanômetro, dentro da sonda portátil. 


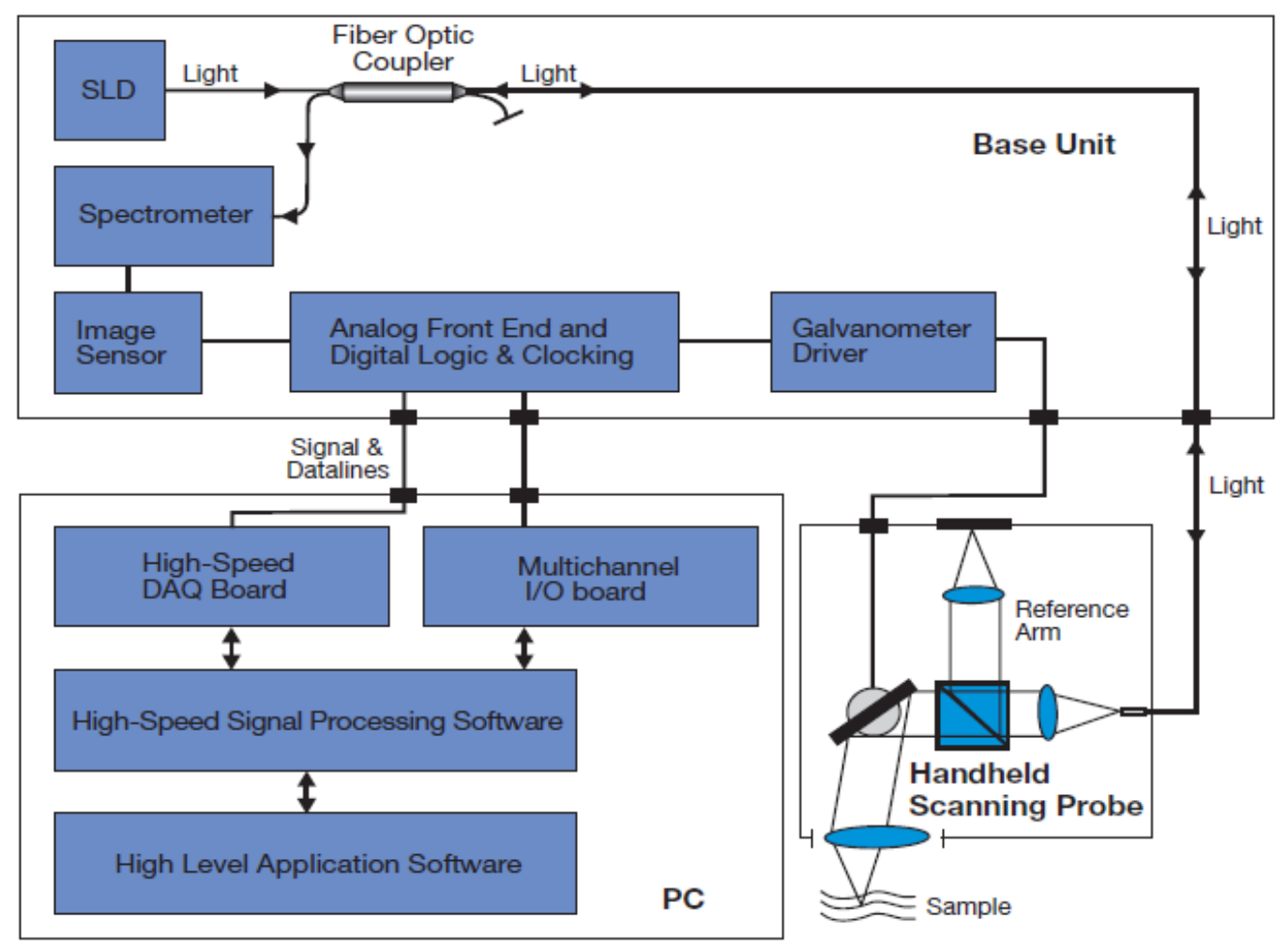

Figura 13 - Esquema com componentes do SR-OCT.

Um acoplador de fibra óptica é usado para direcionar a luz da fonte SLD para o espectrômetro e para o sensor de imagem, localizados na unidade de base. A resolução axial é 6,2 $\mu \mathrm{m}$. A unidade de base é conectada ao computador que é equipado com cartões de aquisição de dados de alto desempenho. Toda aquisição e processamento de dados são feitas via pacote de software, que contêm um conjunto completo de funções para medida, coleta, processamento e controle de dados, bem como para mostrar e gerenciar arquivos de imagens do OCT. As imagens 2D ou 3D podem ser mostradas no computador a taxas de até oito quadros por segundo.

O esquema básico do SS-OCT pode ser observado na figura 14. Os sinais de luz refletida ou espalhada de retorno são medidos usando-se um interferômetro com uma fonte de luz varrida (swept source). A fonte de frequência de luz varrida é direcionada aos braços de referência e amostra de um interferômetro de Michelson. A luz atrasada temporalmente forma o padrão de interferência com o feixe de referência e produz um sinal de batimento que é medido por um detector de alta velocidade. A intensidade e atraso temporal da luz podem ser medidos pela transformada de Fourier do sinal de batimento. 


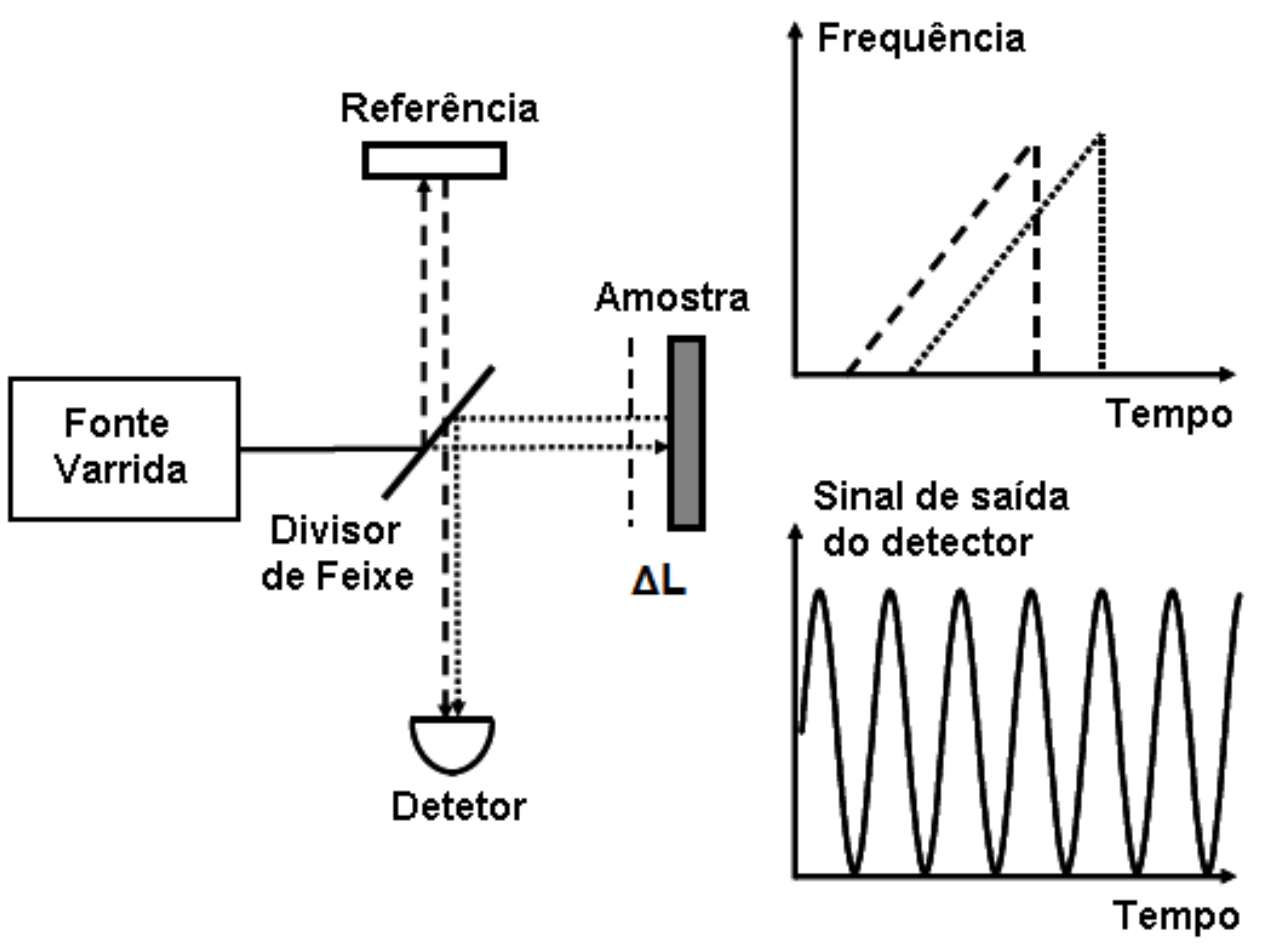

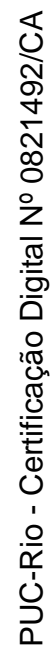

Figura 14 - Esquema básico do sistema SS-OCT.

O esquema experimental de um SS-OCT comercial da empresa Thorlabs é mostrado nas figuras 15.

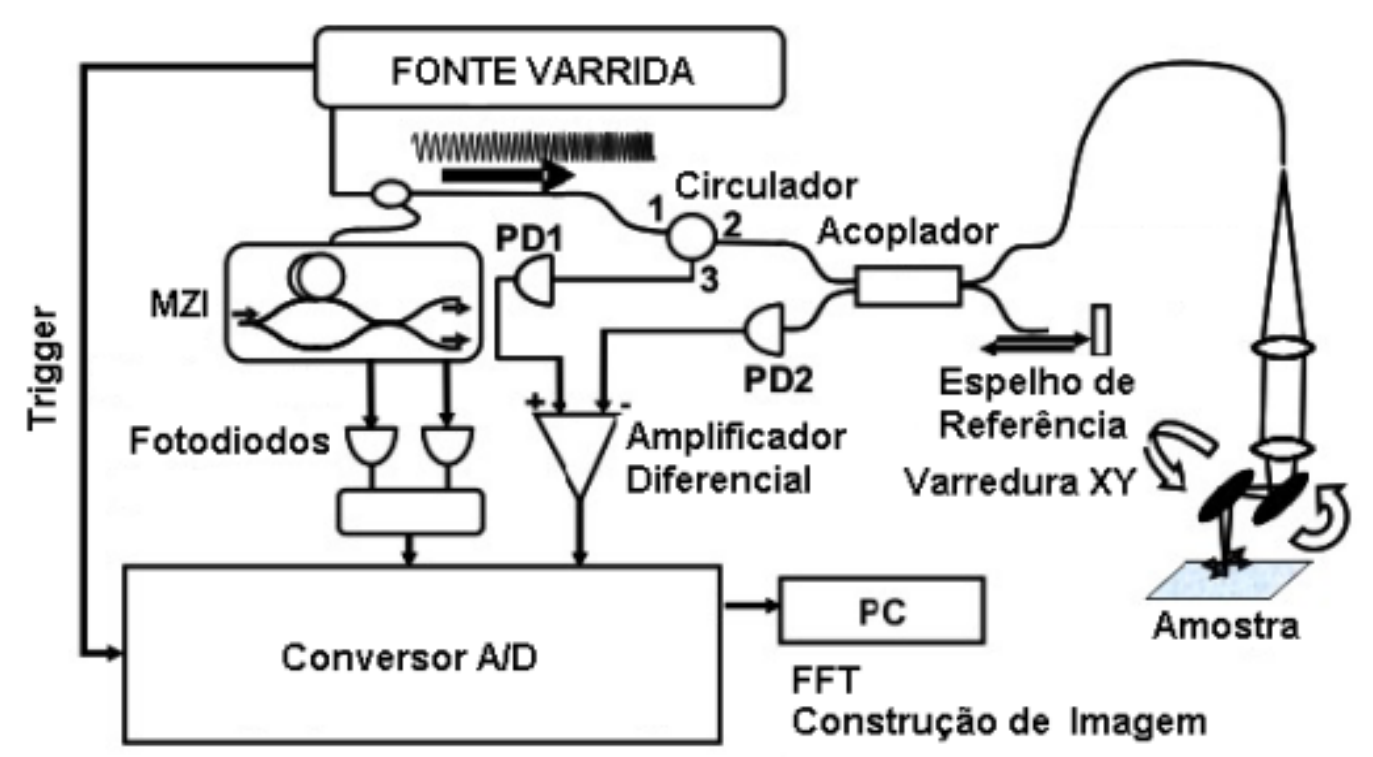

Figura 15 - Esquema experimental detalhado do SS-OCT, onde MZI é o interferômetro de Mach-Zehnder. 
O sistema é constituído de uma cavidade laser externa de frequência varrida (swept source) de alta velocidade, com uma largura de banda espectral maior que $100 \mathrm{~nm}$. A fonte varrida é constituída de um interferômetro de MachZehnder que contém acopladores e amplificadores de transimpedância de alta velocidade que fornece um sinal de potência assim como um sinal de frequência para monitorar a potência de saída e o comprimento de onda da fonte laser varrida. A saída do laser é acoplada a um interferômetro de Michelson e é direcionada para os braços de referência e da amostra, através de um acoplador 50/50. No braço de referência do interferômetro, a luz é refletida de volta para a fibra por um espelho estacionário (fixo) e a refletividade é controlada por um atenuador óptico variável. No braço da amostra, a luz é acoplada na sonda de imagem (imaging probe) e focada na superfície da amostra através de um braço que tem uma objetiva de longa distância. A amostra é colocada sobre uma base deslocadora, fornecendo uma variação micrométrica em XY e uma translação rotacional. Uma câmera CCD na sonda fornece uma visão microscópica da amostra que auxilia o alinhamento da amostra. Um par de espelhos varre o feixe através da superfície da amostra, criando imagens 1D, 2D ou 3D. No sistema, o sinal de interferência é detectado usando um fotodetector. Um digitalizador de alta velocidade (14 bits) é usado para os sinais de interferência da amostra do OCT, que são primeiramente convertidos de tempo para o espaço da frequência usando uma transformada de Fourier rápida (FFT). A FFT do sinal de interferência produz o perfil de refletividade dependente da profundidade para a imagem de OCT.

Na próxima seção são mostrados aspectos básicos de um microscópio confocal. Esse instrumento foi rastreado usando os degraus de altura calibrados no sistema interferométrico de referência, o interferômetro Linnik. 


\section{4}

\section{Princípios Básicos de Microscopia Confocal (CM)}

O microscópio confocal [54, 55, 56, 57, 58, 59, 60, 61] foi desenvolvido e patenteado por Marvin Minsky em 1955 e 1957, respectivamente. Um esquema simplificado desse tipo de microscópio pode ser observado na figura 16.

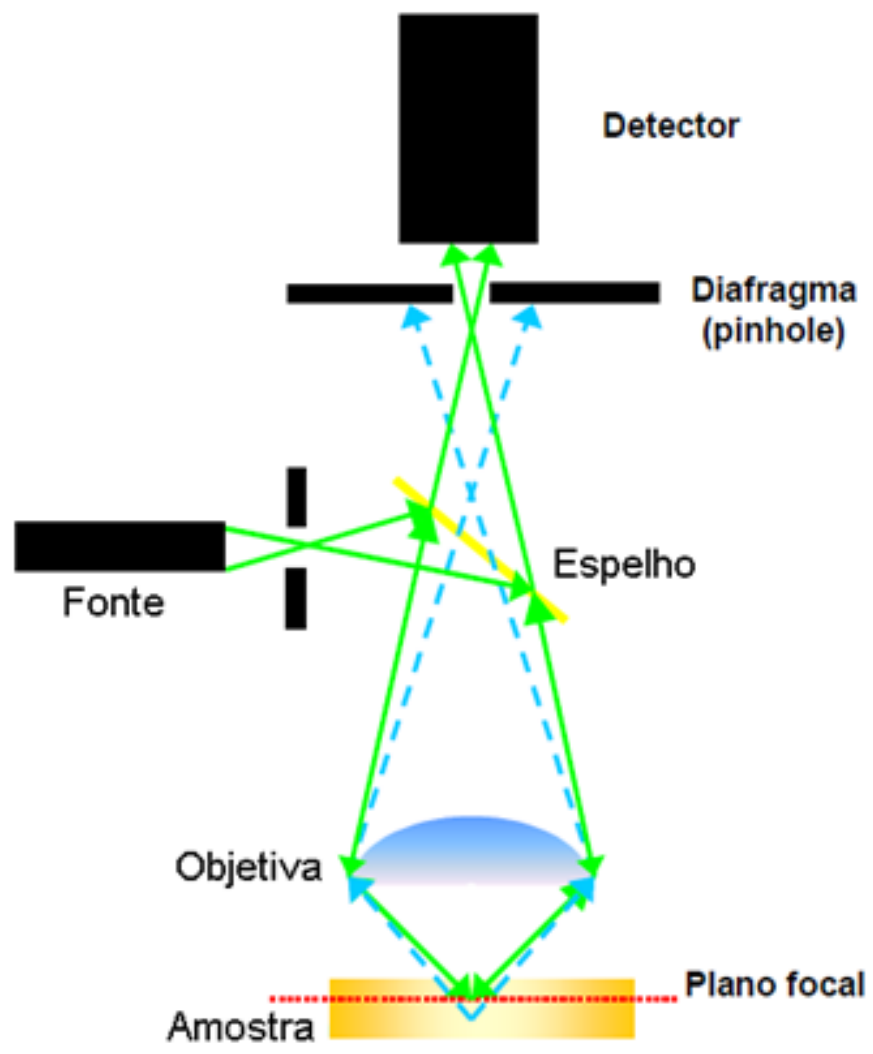

Figura 16 - Esquema básico do microscópio confocal [61].

A luz proveniente da fonte atravessa um primeiro pinhole, é refletida pelo espelho dicroico e foca no ponto da amostra através da objetiva. O sinal refletido volta pelo mesmo caminho óptico passa através do espelho e é focado em um detector. Um segundo pinhole é colocado antes do detector para eliminar os sinais vindos da área fora do foco.

A resolução do microscópio confocal é caracterizada por uma elevada abertura numérica, NA, do sistema óptico, sendo $N A=n \sin \alpha$, onde $\alpha$ corresponde ao ângulo máximo de coleta de luz pela objetiva e n é o índice de 
refração do meio de propagação da luz. A teoria da difração determina que a profundidade de foco, nestas condições, seja inversamente proporcional ao quadrado da abertura numérica, sendo, $\delta \mathrm{z}_{\text {confocal }} \sim \lambda \mathrm{n} / \mathrm{NA}^{2}$. A resolução do microscópio confocal, ou seja, a capacidade de distinguir dois pontos ou partes de um objeto é dado pelo limite de resolução, que é definido por $\mathrm{LR}=0,67 \lambda / \mathrm{NA}$, onde $\lambda$ é o comprimento de onda da fonte de radiação e NA a abertura numérica da lente objetiva usada. A resolução da imagem melhora quanto menor for à profundidade de foco pelo que se justifica a utilização de objetivas de elevada abertura numérica. Na configuração confocal as resoluções transversal e longitudinal chegam a dimensões subcelulares, de 200-500 nm.

A microscopia confocal exige distâncias de trabalho muito curtas, requerendo frequentemente contato com a amostra em estudo, o que nem sempre é satisfatório para aplicações de diagnóstico e imagem in vivo. Por isso o uso da tomografia de coerência óptica, que é uma técnica não invasiva e sem contato, que utiliza técnicas interferométricas para obter elevada resolução espacial (resolução transversal definida pelo limite de difração do sistema coletor na cabeça sensora e a resolução axial, em profundidade, fixada pelo uso da interferometria de baixa coerência), conforme visto na seção 4 .

Atualmente, o microscópio confocal de varredura a laser (LSCM) é o tipo de confocal mais usado, devido à elevada qualidade da imagem o que permite a obtenção de imagens de alta resolução através de cortes ópticos. Esses cortes ópticos são posteriormente agrupados para fazer a reconstrução tridimensional da topografia da amostra. O LSCM utiliza um feixe laser para varrer a amostra. É possível iluminar toda a superfície em estudo, ponto a ponto, mantendo a profundidade de foco e transladando o foco, através da objetiva. A luz refletida na amostra retorna pelo mesmo caminho óptico até passar pela abertura circular. A luz proveniente do plano focal da imagem é detectada e os sinais gerados são processados para que seja construída uma imagem virtual da luz varrida pelo laser.

Na construção virtual da imagem da amostra, em microscopia confocal, o resultado depende das combinações de máximos e mínimos de amplitude e é realizada pelo deslocamento do feixe laser sobre a amostra e pelo sincronismo de captura do sinal de reflexão sobre a mesma. Para isto, é necessário que o feixe 
laser translade sobre a amostra de forma precisa. Isto pode ser observado na figura 18.

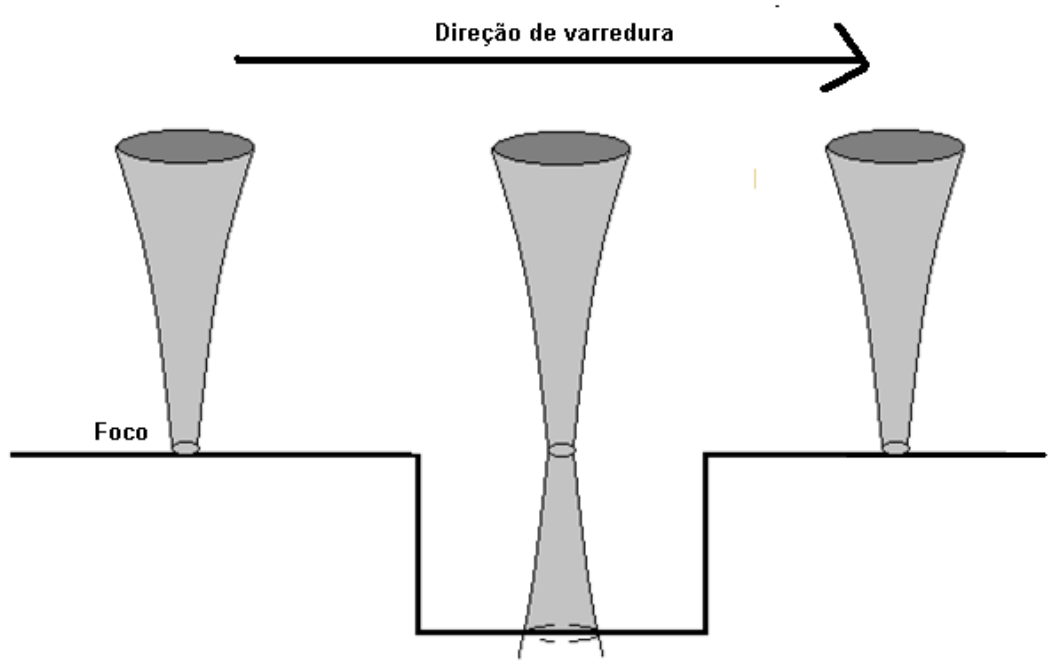

Figura 17 - Esquema simplificado do sistema de varredura laser sobre a amostra no LSCM [59].

Em pontos mais próximos do foco, a intensidade do sinal é mais concentrada o que resulta em uma reflexão mais intensa. O espectrômetro detecta o sinal luminoso da reflexão da amostra e converte em sinal digital. O registro é convertido em uma matriz XY com valores da intensidade da luz refletida. Através dessa matriz se obtêm a imagem da superfície da amostra. A matriz XY contém em cada célula o valor da intensidade da reflexão detectada.

Na próxima seção são mostrados aspectos básicos de microscopia de força atômica, cujo instrumento teve a sua rastreabilidade na escala de comprimento realizada a partir da comparação com o sistema interferométrico de referência, desenvolvido nesta tese. 


\section{5}

\section{Princípios Básicos de Microscopia de Força Atômica (AFM)}

A microscopia de força atômica [62, 63, 64, 65] consiste em analisar a superfície de uma amostra com uma ponta de prova, que é montada sobre uma alavanca com constante de mola conhecida. Esta ponta utiliza uma haste, denominada alavanca (cantilever). Quando a alavanca está próxima da superfície da amostra, ela deflete devido às forças de interação. Essa força de interação pode ser dada pela lei de Hooke, $\mathrm{F}=\mathrm{k} . \Delta \mathrm{z}$, onde $\mathrm{k}$ é a constante da mola, $\mathrm{F}$ é à força de interação entre ponta e superfície na direção normal e $\Delta z$ é a deflexão vertical da alavanca. A amostra fica presa a uma cerâmica piezoelétrica com um sistema de controle que se movimenta de acordo com a deflexão da alavanca devido a mudanças na topografia da superfície da amostra. Na figura 18 pode-se observar o esquema básico do AFM.

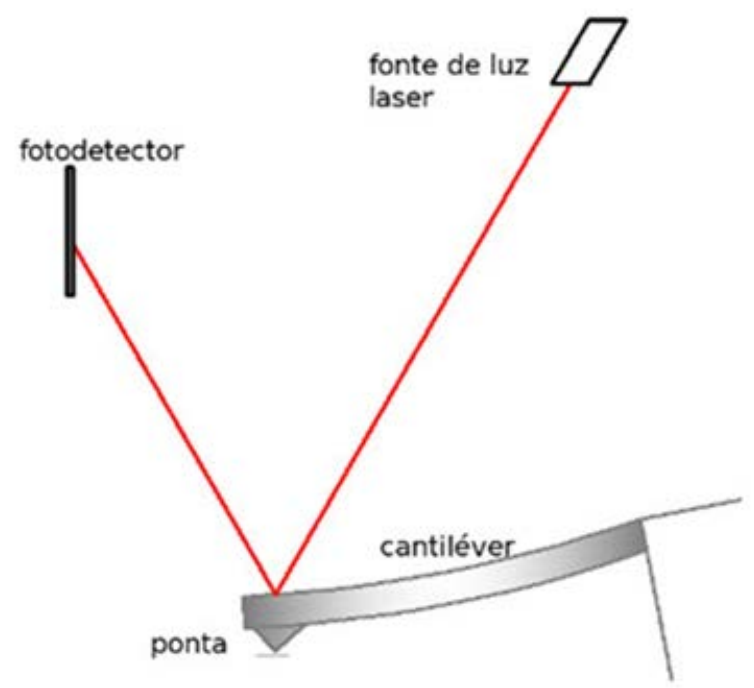

Figura 18 - Esquema básico do AFM.

A detecção da deflexão é feita com o auxílio de um feixe laser que é refletido na superfície superior da alavanca, depois refletido novamente em um espelho e direcionado para o fotodetector. O sinal é corrigido pelo sistema de controle do microscópio que atua como um sistema de correção da posição em z da ponta sobre a superfície, mantendo constante a força normal de interação 
durante o processo de varredura da amostra. As variações na posição da amostra fornecem as imagens da topografia da superfície.

$\mathrm{Na}$ figura 19 pode ser observado o comportamento qualitativo da dependência da força interatômica com a distância entre a ponta de prova e a superfície da amostra. Em grandes distâncias, a interação entre a alavanca e a superfície da amostra é predominantemente atrativa, tipo Van der Walls. Quando a ponta se aproxima da superfície da amostra predomina a região de contato, onde o regime é de força repulsiva e a alavanca sofre uma deflexão vertical para cima. No modo de contato intermitente ocorre uma inversão no tempo entre forças repulsivas e atrativas onde a alavanca tem uma vibração em uma frequência definida.

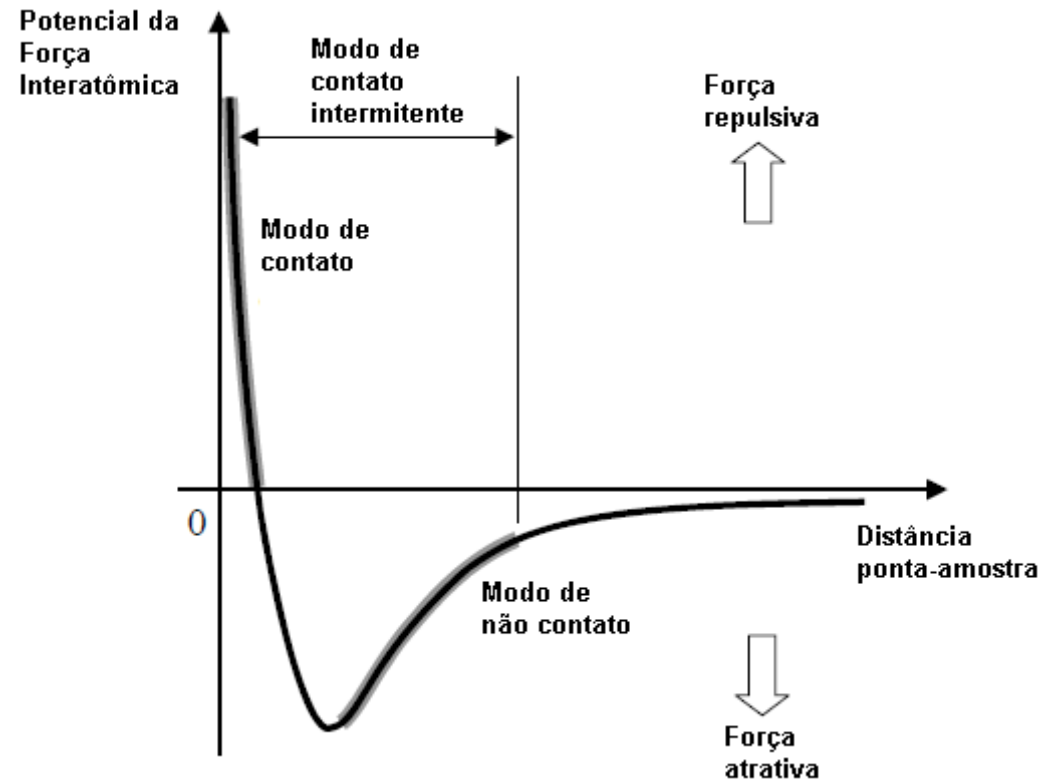

Figura 19 - Força resultante em função da distância alavanca-superfície da amostra, potencial de Lennar-Jones.

No modo de contato, no qual foram realizadas as medidas no AFM usado na tese, onde existe contato físico entre a alavanca e amostra, a intensidade da força é suficientemente baixa para que não ocorram deformações permanentes na amostra ou na alavanca, o que prejudica a qualidade dos resultados. O método usando o sistema de detecção óptica é o mais usado para detectar a deflexão. Neste caso, um feixe laser incide sobre a alavanca e atinge o fotodetector sensível a posição. Quando a alavanca sofre uma deflexão ocorre à mudança de posição do 
feixe laser, refletido pela alavanca no fotodetector. Neste modo podem ser obtidas variações menores que $1 \AA$, dependendo do fator de amplificação do sistema óptico que é proporcional à razão do caminho óptico entre a alavanca, o detector e o comprimento da alavanca. O sistema de translação XYZ permite que a amostra realize varreduras nas direções $\mathrm{XY}$ e durante essas varreduras a topografia da amostra é conseguida através da medida das variações na direção vertical, $z$, produzidas pelo sistema de realimentação para manter a força constante. As imagens topográficas de alta resolução podem ser adquiridas mantendo fixa a posição vertical, modo de altura constante, e medindo somente as deflexões da alavanca para o caso de superfícies planas.

No modo de não contato, as forças são de aproximadamente $0,01 \mathrm{nN}$. Neste caso, um oscilador, que pode ser um piezoelétrico colado em uma superfície metálica faz o cantilever vibrar em uma frequência um pouco maior que a frequência de ressonância do equipamento. A amplitude do sinal que é medido no fotodetector é enviada ao sistema de realimentação do AFM. Na região próxima a superfície da amostra, na presença do gradiente de força, a nova frequência de ressonância monitorada pelo oscilador é menor que a frequência de ressonância do equipamento, ocorrendo uma diminuição na amplitude de vibração da alavanca. O sistema de alimentação, neste caso, trabalha mantendo fixa uma diminuição nessa amplitude, mantendo constante a distância alavanca-amostra.

Na próxima seção serão discutidos os conceitos básicos para avaliar a dispersão dos valores atribuídos a um mensurando, a chamada incerteza de medição. 
Conceitos básicos de incerteza de medição

Em metrologia, quando o resultado da medição de uma grandeza física é relatado é importante demonstrar quantitativamente a confiabilidade dessa medição. Isto é necessário para que possa ser feito a comparação desses resultados com valores conhecidos de referência para que seja possível expressar e avaliar corretamente a incerteza de medição. Segundo o Vocabulário Internacional de Termos Fundamentais e Gerais de Metrologia (VIM) [66, 67] a incerteza [68] é definida como um parâmetro não negativo que caracteriza a dispersão dos valores atribuídos a um mensurando, com base nas informações utilizadas. O método ideal para avaliar a incerteza deve ser aplicável a todas as espécies de medição e a todos os tipos de dados de entrada. Em várias aplicações, como por exemplo, nas áreas de segurança e saúde, torna-se necessário fornecer um intervalo em torno do resultado da medição que espera abranger uma grande fração de valores, que poderiam ser atribuídos à grandeza que se está medindo. Assim, um método para a avaliação da incerteza deve ser capaz de fornecer tal intervalo, com uma probabilidade de abrangência, ou nível de confiança ao nível requerido. Em geral, a incerteza é o resultado de uma medição expressa como um desvio-padrão. A incerteza tipo A pode ser avaliada através da análise estatística dos valores medidos em uma série de observações, como por exemplo, a condição de repetitividade e a condição de reprodutibilidade. Já a incerteza tipo B é baseada em outros métodos de avaliação por meios que não a análise estatística de série de observações, como por exemplo, certificados de calibração, manuais de equipamentos, etc. Além dessas avaliações de incerteza, existe a incerteza-padrão combinada que é o resultado de uma medição, quando este resultado é obtido por meio dos valores de várias outras grandezas, sendo igual à raiz quadrada positiva de uma soma de termos, que constituem as variâncias ou covariâncias destas outras grandezas, e a incerteza expandida que é a quantidade que define um intervalo em torno do resultado de uma medição com o qual se espera abranger uma grande fração da distribuição dos valores que podem ser razoavelmente atribuídos ao mensurando. Essa fração pode ser vista como a probabilidade de 
abrangência ou nível da confiança do intervalo. O fator numérico usado como multiplicador da incerteza-padrão combinada de modo a obter uma incerteza expandida é chamado de fator de abrangência e é tipicamente 2.

O objetivo de uma medição é determinar o valor de uma grandeza específica e o resultado de uma medição é somente uma aproximação ou estimativa do valor do mensurando e somente está completo se for acompanhado da incerteza dessa estimativa. Em geral, uma medição tem imperfeições que dão origem a um erro no resultado da medição, que pode ser aleatório, originando de variações temporais ou espaciais sendo a causa de variações em observações repetidas do mensurando que pode ser reduzido aumentando-se o número de observações, e o erro sistemático que, assim como o aleatório não pode ser eliminado, porém pode ser reduzido. Se o erro sistemático se origina de um efeito reconhecido de uma grandeza de influência em um resultado de uma medição, chamado de efeito sistemático, ele pode ser quantificado. Se for significativo com relação à exatidão, que é o grau de concordância entre um valor medido e um valor verdadeiro de um mensurando, pode ser aplicada uma correção ou fator de correção para compensar o efeito. Supõe-se que após esta correção o valor esperado do erro provocado por um efeito sistemático seja zero.

Os termos incerteza e erro devem ser usados apropriadamente, sendo a incerteza avaliada após o resultado de uma medição ter sido corrigido para todos os efeitos aleatórios e sistemáticos reconhecidos como significativos e que todo o esforço tenha sido feito para identificar tais efeitos.

\section{1}

\section{Avaliação da incerteza padrão}

Para avaliar a incerteza padrão vamos supor a medição de um determinado mensurando $\mathrm{Y}$ que somente pode ser determinado a partir de $\mathrm{N}$ outras grandezas, $\mathrm{X}_{1}, \mathrm{X}_{2}, \ldots, \mathrm{X}_{\mathrm{N}}$, a partir da relação:

$$
Y=f\left(X_{1}, X_{2}, \ldots, X_{N}\right)
$$

Para uma série de observações podemos dizer que o k-ésimo valor observado $\mathrm{X}_{\mathrm{i}}$ é designado como $\mathrm{X}_{\mathrm{i}, \mathrm{k}}$. A estimativa de Xi (estritamente falando, de 
sua esperança) é designada por $\mathrm{x}_{\mathrm{i}}$. Assim, uma estimativa do mensurando Y para uma série de observações, designado y, é obtida da equação 6.1 usando estimativas de entrada $\mathrm{X}_{1}, \mathrm{X}_{2}, \ldots, \mathrm{X}_{\mathrm{N}}$ para os valores das $\mathrm{N}$ grandezas $\mathrm{X}_{1}, \mathrm{X}_{2}, \ldots, \mathrm{X}_{\mathrm{N}}$. Assim, a estimativa de saída y que é o resultado da medição é dada pela equação:

$$
y=f\left(x_{1}, x_{2}, \ldots, x_{N}\right)
$$

Em alguns casos a estimativa pode ser expressa como:

$$
y=\bar{Y}=\frac{1}{n} \sum_{k=1}^{n} Y_{k}=\frac{1}{n} \sum_{k=1}^{n} f\left(x_{1 . k}, \ldots, x_{N . k}\right)
$$

Neste caso, y é a média aritmética ou média de $\mathrm{n}$ determinações independentes $\mathrm{Y}_{\mathrm{k}}$ de $\mathrm{Y}$. Cada determinação tem a mesma incerteza e cada uma delas é baseada em um conjunto completo de valores observados das $\mathrm{N}$ grandezas de entrada $\mathrm{X}_{\mathrm{i}}$. Assim:

$$
\bar{X}_{i}=\frac{1}{n} \sum_{k=1}^{n} X_{i, k}
$$

Onde, $\bar{X}_{i}$ é a média aritmética das observações individuais $X_{i, k}$.

O desvio-padrão estimado associado com a estimativa de saída ou resultado de medição y chamada incerteza-padrão combinada e designado por $\mathrm{u}_{\mathrm{c}}(\mathrm{y})$, é determinado pelo desvio-padrão estimado associado com cada estimativa de entrada $\mathrm{x}_{\mathrm{i}}$, denominado incerteza-padrão e designado por $\mathrm{u}\left(\mathrm{x}_{\mathrm{i}}\right)$. Cada estimativa de entrada $x_{i}$ e sua incerteza-padrão associada $\mathrm{u}\left(\mathrm{x}_{\mathrm{i}}\right)$ são obtidas de uma distribuição de valores possíveis da grandeza de entrada $X_{i}$. Essa distribuição de probabilidade pode ser baseada em uma série de observações $X_{i, k}$ de $X_{i}$.

\subsection{1}

\section{Incerteza padrão tipo A}

A melhor estimativa disponível ou valor esperado de uma grandeza que varia aleatoriamente e para a qual $n$ obervações independentes foram obtidas, sob as mesmas condições de medição, é a média aritmética das n observações: 


$$
q=\frac{1}{n} \sum_{k=1}^{n} q_{k}
$$

Onde, $\mathrm{q}_{\mathrm{k}}$ são as $\mathrm{n}$ observações individuais.

Se as observações individuais $q_{k}$ diferem em valor por causa das variações aleatórias nas grandezas de influência ou dos efeitos aleatórios, a variância experimental das observações, que estima a variância da distribuição de probabilidade de q, é dada por:

$$
S^{2}\left(q_{k}\right)=\frac{1}{n-1} \sum_{j=1}^{n}\left(q_{j}-\bar{q}\right)^{2}
$$

A estimativa de variância e sua raiz quadrada positiva $s\left(\mathrm{q}_{\mathrm{k}}\right)$, chamada de desvio padrão experimental, caracteriza a dispersão em torno da média. Para uma melhor estimativa, a variância da média é dada por:

$$
S^{2}(\bar{q})=\frac{1}{n} S^{2}\left(q_{k}\right)
$$

Onde $S^{2}(\bar{q})$ é a variância experimental da média e $S(\bar{q})$ é o desvio experimental da média.

Para uma grandeza de entrada $\mathrm{X}_{\mathrm{i}}$, determinada por $\mathrm{n}$ observações repetidas e independentes $\mathrm{X}_{\mathrm{i}, \mathrm{k}}$, a incerteza padrão $\mathrm{u}\left(\mathrm{x}_{\mathrm{i}}\right)$ de sua estimativa $x_{i}=\bar{x}_{i}$ é $u\left(x_{i}\right)=$ $s\left(\bar{X}_{i}\right), \operatorname{com~s}^{2}\left(\bar{X}_{i}\right)$ calculada de acordo com (6.7).

Por conveniência, $\mathrm{u}^{2}\left(\mathrm{x}_{\mathrm{i}}\right)=\mathrm{s}^{2}\left(\bar{X}_{i}\right)$ e o desvio padrão médio $\mathrm{u}\left(\mathrm{x}_{\mathrm{i}}\right)=\mathrm{s}\left(\bar{X}_{i}\right)$ são denominados variância do tipo A e incerteza padrão do tipo A, respectivamente.

\section{1 .2}

\section{Incerteza padrão tipo B}

A incerteza padrão tipo B pode ser avaliada para uma estimativa $\mathrm{x}_{\mathrm{i}}$ de uma grandeza de entrada que não tenha sido obtida através de observações repetidas. Neste caso, a variância estimada associada, $\mathrm{u}^{2}\left(\mathrm{x}_{\mathrm{i}}\right)$, ou a incerteza padrão $\mathrm{u}\left(\mathrm{x}_{\mathrm{i}}\right)$ é 
avaliada por julgamento científico, baseando-se em todas as informações disponíveis sobre a possível variabilidade de $\mathrm{X}_{\mathrm{i}}$. Neste caso, podemos extrair dados de várias fontes, como por exemplo, certificados de calibração, manuais de instrumentos, dados de medições prévias, especificações do fabricante, como por exemplo, a incerteza relacionada a resolução do equipamento, etc.

\section{1 .3}

\section{Incerteza padrão combinada}

A incerteza padrão combinada, quando as grandezas de entrada são independentes e não correlacionadas, é representada por $\mathrm{u}_{\mathrm{c}}(\mathrm{y})$ e é a raiz quadrada positiva da variância $\mathrm{u}_{\mathrm{c}}{ }^{2}(\mathrm{y})$. Se a incerteza padrão de $\mathrm{y}$, onde y é a incerteza do mensurando Y, tem como resultado de medição uma combinação apropriada de incertezas padrão das estimativas de entrada $\mathrm{x}_{1}, \mathrm{x}_{2}, \ldots ., \mathrm{x}_{\mathrm{n}}$, então a incerteza padrão combinada pode ser definida como:

$$
u_{c}^{2}(y)=\sum_{i=1}^{N}\left[\frac{\partial f}{x_{i}}\right]^{2} u^{2}\left(x_{i}\right)
$$

Onde f é função de várias grandezas, sendo $\mathrm{Y}=\mathrm{f}\left(\mathrm{X}_{1}, \ldots . ., \mathrm{X}_{\mathrm{N}}\right)$, $\mathrm{Y}$ é o mensurando e $\mathrm{u}\left(\mathrm{x}_{\mathrm{i}}\right)$ é a incerteza padrão tipo A ou tipo B.

A incerteza padrão combinada $\mathrm{u}_{\mathrm{c}}{ }^{2}(\mathrm{y})$ é um desvio padrão estimado e caracteriza a dispersão dos valores que poderiam ser atribuídos ao mensurando Y.

A derivada parcial $\left(\frac{\partial f}{\partial x_{i}}\right)$ é frequentemente denominada coeficiente de sensibilidade e descreve como a estimativa de saída y varia com alterações nos valores de entrada $x_{1}, x_{2}, x_{3}, \ldots, x_{n}$. A alteração em y produzida por uma pequena variação $\Delta \mathrm{x}_{\mathrm{i}}$ na estimativa de entrada $\mathrm{x}_{\mathrm{i}}$ é dada por $\Delta y_{i}=\left(\frac{\partial f}{\partial x_{i}}\right) \Delta x_{i}$. Se esta alteração é gerada pela incerteza padrão da estimativa $x_{i}$, a variação correspondente em y é $\left(\frac{\partial f}{\partial x_{i}}\right) u\left(x_{i}\right)$. A variância combinada $\mathrm{u}_{\mathrm{c}}^{2}(\mathrm{y})$ pode ser obtida como a soma dos termos de variância estimada associada com a estimativa de saída y, gerada pela variância estimada, associada com cada estimativa de entrada $\mathrm{X}_{\mathrm{i}}$. Assim, a equação (6.8) fica: 


$$
u_{c}^{2}(y)=\sum_{i=1}^{N}\left[c_{i} u\left(x_{i}\right)\right]^{2} \equiv \sum_{i=1}^{N} u_{i}^{2}(y)
$$

Onde $c_{i}=\left(\frac{\partial f}{\partial x_{i}}\right)$ e $u_{i}(y) \equiv\left|c_{i}\right| u\left(x_{i}\right)$

A incerteza padrão combinada trata-se do desvio padrão, caracterizando a dispersão dos valores que podem ser atribuídos ao mensurando Y.

Quando as grandezas de entrada são correlacionadas à expressão apropriada para a variância combinada, $\mathrm{u}_{\mathrm{c}}^{2}(\mathrm{y})$, associada com o resultado de uma medição é:

$$
\begin{array}{r}
u_{c}^{2}(y)=\sum_{i=1}^{N} \quad \sum_{j=1}^{N} \frac{\partial f}{\partial x_{i}} \frac{\partial f}{\partial x_{j}} u\left(x_{i}, x_{j}\right)= \\
\sum_{i=1}^{N}\left[\frac{\partial f}{\partial x_{i}}\right]^{2} u^{2}\left(x_{i}\right)+2 \sum_{i=1}^{N-1} \quad \sum_{j=i+1}^{N} \frac{\partial f}{\partial x_{i}} \frac{\partial f}{\partial x_{j}} u\left(x_{i}, x_{j}\right)
\end{array}
$$

O grau e correlação entre $X_{i}$ e $X_{j}$ e $u\left(x_{i}, x_{j}\right)=u\left(x_{j}, x_{i}\right)$ é a covariância estimada, associada com xi e $x_{j}$. O grau de correlação entre $x_{j}$ e $x_{i}$ é caracterizado pelo coeficiente de correlaçao:

$$
r\left(x_{i} x_{j}\right)=\frac{u\left(x_{i}, x_{j}\right)}{u\left(x_{i}\right) u\left(x_{j}\right)}
$$

Ambas as avaliações, para grandezas de entrada correlacionadas e não correlacionadas, respectivamente, estão baseadas numa aproximação de $1^{\text {a }}$ ordem da série de Taylor de $Y=f\left(X_{1}, \ldots . X_{N}\right)$ que expressam o que é denominado no Guia para expressão da incerteza de medição como a lei de propagação da incerteza.

\section{1 .4}

\section{Incerteza padrão expandida}

A incerteza padrão combinada $\mathrm{u}_{\mathrm{c}}(\mathrm{y})$ é universalmente usada para expressar a incerteza de um resultado de medição. No entanto, em muitos casos, principalmente em saúde e segurança, é necessário ter uma medida de incerteza que defina um intervalo em torno do resultado da medição com o qual se espera abranger uma extensa fração da distribuição de valores que poderiam ser razoavelmente atribuídos ao mensurando. A medida adicional de incerteza que satisfaz o requisito de fornecer um intervalo é denominada incerteza expandida e é 
representada por $U$, sendo obtida multiplicando-se a incerteza padrão combinada, $\mathrm{u}_{\mathrm{c}}(\mathrm{y})$, por um fator de abrangência k, assim:

$$
U=k u_{c}(y)
$$

Onde, k é o fator para um nível de confiança (para uma distribuição normal, k=2 corresponde a 95,45 \% de confiança).

Com isto, o resultado de uma medição é convenientemente expresso da seguinte forma:

$$
Y=y \pm U
$$

Isto significa que a melhor estimativa do valor atribuído ao mensurando $\mathrm{Y}$ é y, e que o intervalo que se espera abranger uma extensa fração da distribuição de valores que podem ser atribuídos a $\mathrm{Y}$ é expresso como $y-U \leq Y \leq y+U$. Neste caso, U é interpretado como definindo um intervalo em torno do resultado de medição que abrange uma extensa fração p da distribuição de probabilidade, caracterizada por aquele resultado e sua incerteza padronizada combinada, e p é a probabilidade de abrangência ou nível da confiança do intervalo.

Sempre que praticável, o nível da confiança p, associado ao intervalo definido por $U$ deve ser estimado e declarado. Deve ser entendido que na maioria dos casos, o nível da confiança p (especialmente para valores de p próximos de 1) é um tanto incerto, não somente por causa do conhecimento limitado da distribuição de probabilidade caracterizada, por y e $\mathrm{u}_{\mathrm{c}}(\mathrm{y})$, especialmente nas extremidades, mas também por causa da incerteza da própria $\mathrm{u}_{\mathrm{c}}(\mathrm{y})$. Por exemplo, um intervalo dentro de um nível de confiança de 95 \% significa ter uma chance em vinte que o valor do mensurando $\mathrm{Y}$ esteja fora do intervalo.

Para obter o valor do fator de abrangência $k_{p}$ que produz um intervalo correspondente a um nível específico de confiança p, é necessário o conhecimento da distribuição de probabilidade caracterizada pelo resultado da medição e sua incerteza padrão combinada. Além disso, deve levar em conta o número de graus de liberdade efetivos associados para o intervalo $\mathrm{y}-\mathrm{U}$ a $\mathrm{y}+\mathrm{U}$. O valor de $\mathrm{k}$ geralmente está entre 2 e 3, mas podem assumir diversos outros valores. É comum 
calcular o número de graus de liberdade efetivos $\left(v_{\mathrm{ef}}\right)$ através da equação de Welch-Satterthwaite:

$$
v_{e f}=\frac{u_{c}^{4}}{\sum_{i=1}^{N} \frac{u_{i}^{4}}{v_{i}}}
$$

Onde $\mathrm{u}_{\mathrm{c}}$ é a incerteza combinada, $\mathrm{u}_{\mathrm{i}}$ é a incerteza padronizada associada a i-ésima fonte de incerteza, $v_{\mathrm{i}}$ é o número de graus de liberdade associado a i-ésima fonte de incerteza e N é o número total de fontes de incertezas analisadas.

Aplicando a equação 6.14 podemos calcular o número de graus de liberdade efetivo. Na tabela 1 pode ser observado o valor de $k_{p}$ para uma distribuição normal.

Tabela 1 - Valor do fator de abrangência $k_{p}$ para uma distribuição normal.

\begin{tabular}{|c|c|}
\hline $\begin{array}{c}\text { Nível de confiança } \mathbf{p} \\
(\mathbf{\%})\end{array}$ & $\begin{array}{c}\text { Fator de abrangência } \\
\mathbf{k}_{\mathbf{p}}\end{array}$ \\
\hline 68,27 & 1 \\
\hline 90 & 1,645 \\
\hline 95 & 1,960 \\
\hline 95,45 & 2 \\
\hline 99 & 2,576 \\
\hline 99,73 & 3 \\
\hline
\end{tabular}

Para descrever a incerteza de um sistema, devem ser coletadas informações que permitam estimar a incerteza associada a cada fonte de erro. Recomenda-se apresentar o valor associado aos limites de variação da fonte de incertezas em sua unidade natural e identificar o tipo de distribuição de probabilidade envolvida (normal, retangular, triangular ou outra). Em função do tipo de distribuição será definido o divisor utilizado para converter o valor conhecido na incerteza padronizada. Para distribuições normais este valor geralmente é unitário no caso da avaliação de incerteza tipo A, ou coincide com o fator de abrangência utilizado na fonte de informação quando a avaliação tipo B é considerada. 
Na próxima seção são mostrados os resultados experimentais obtidos na tese com o desenvolvimento do sistema interferométrico de referência e as aplicações desse sistema para prover rastreabilidade a instrumentos ópticos, na escala de comprimento. 


\section{Resultados Experimentais e Discussão}

O grande desafio da nanometrologia é prover a base metrológica (instrumentação, métodos, padrões e materiais de referência) para a análise das propriedades de materiais nano estruturados auxiliando no aproveitamento das características avançadas desses materiais em práticas industriais e, por outro lado, impedindo a transformação do aspecto metrológico da nanotecnologia em uma barreira técnica para o setor.

O principal desafio neste trabalho foi construir um interferômetro metrologicamente confiável que pudesse realizar medições sub-micrométricas rastreáveis à definição do metro e ser empregado para dar confiabilidade à medição na escala de comprimento de instrumentos ópticos usados na área de nanotecnologia, garantindo o desenvolvimento de materiais de referência, procedimentos e métodos para análise e caracterização físico-química de nanomateriais com a qualidade assegurada. Com isto é possível estabelecer metodologias de medição visando à avaliação de parâmetros de controle e contribuindo para a pesquisa e desenvolvimento de produtos nanotecnológicos seguros e eficazes.

O interferômetro Linnik desenvolvido no Inmetro [69, 70, 71, 72] garante a rastreabilidade metrológica a vários instrumentos ópticos, por exemplo, os microscópios de força atômica (AFM) que, por sua vez, se encarregariam de fazer a medição de tamanho de uma partícula, assim como os tomógrafos de coerência óptica (OCT) e microscópios confocais usados em aplicações específicas nas áreas de biologia e medicina. A cadeia de rastreabilidade construída a partir desse interferômetro é a sequência de padrões e calibrações utilizada para relacionar um resultado de medição a uma referência. Isto é a base para mostrar a confiabilidade de uma medição realizada em metrologia.

Os resultados experimentais obtidos na tese são descritos nas próximas seções. 


\section{1}

\section{Interferômetro Linnik}

O interferômetro Linnik desenvolvido no Inmetro pode ser observado na figura 20 .

(a)

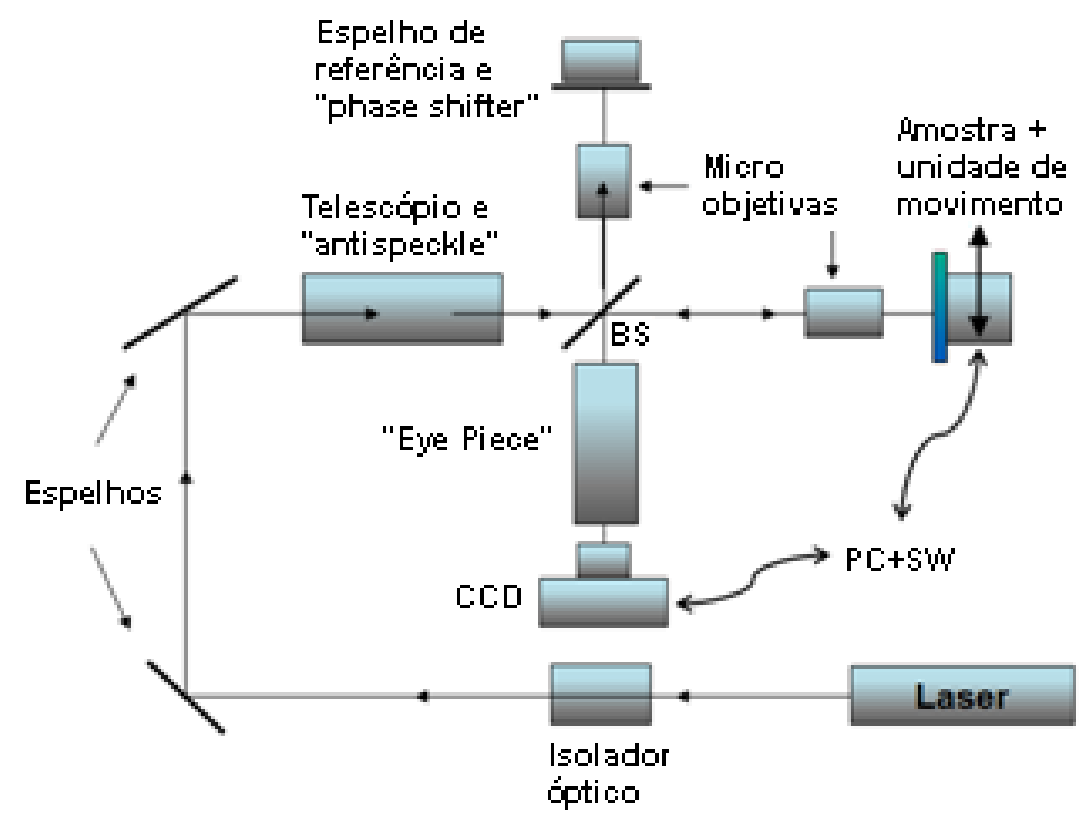

(b)

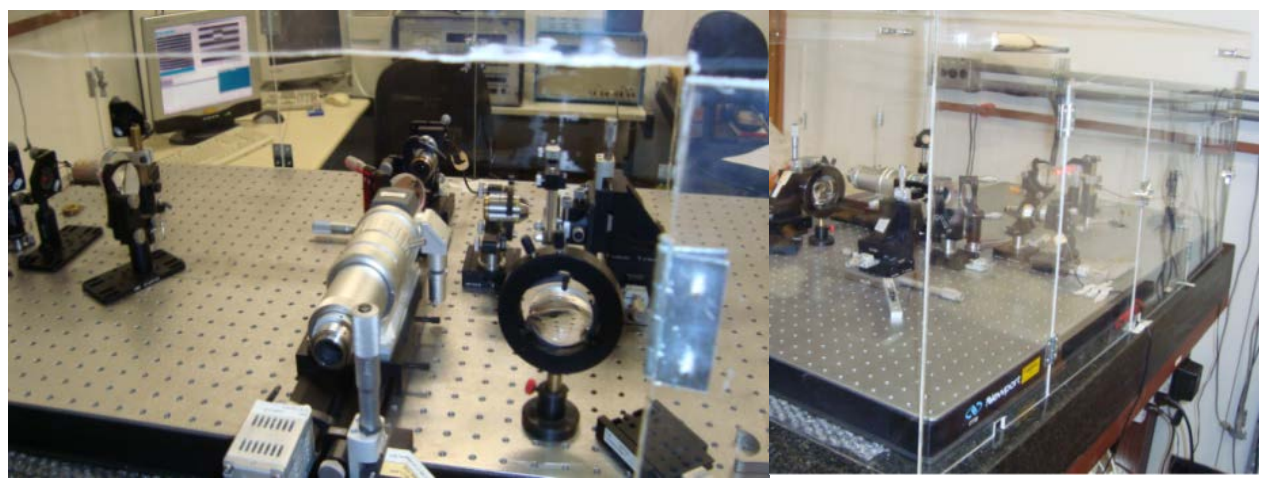

Figura 20 - (a) Diagrama esquemático e (b) Foto do sistema experimental do interferômetro Linnik.

Um laser de He-Ne de frequência estabilizada e calibrado em relação ao padrão de comprimento primário do Inmetro foi usado como fonte de referência de comprimento de onda.

Um isolador óptico foi usado no sistema para diminuir as retro reflexões do feixe laser da óptica interferométrica que perturbam o laser. Além disso, dois 
espelhos planos foram usados para fazer o laser incidir no sistema de redução de speckle, composto de duas lentes com distância focal de $10 \mathrm{~mm}$, tendo no foco delas um difusor.

Um divisor de feixe óptico (50x50) de alta qualidade $(\lambda / 20)$ foi usado para fornecer o máximo de exatidão ao interferômetro, dividindo o feixe em ambos os braços, o de referência e o de amostra. Os suportes do compartimento de amostra e o do espelho de referência têm parafusos micrométricos que ajudam no alinhamento do sistema experimental.

Foram usadas no sistema lentes objetivas semelhantes de 10x $(\lambda / 20)$ antes da amostra e do espelho de referência. Objetivas simétricas são necessárias para a operação do Linnik e a qualidade delas é importante. Também foi inserido no sistema experimental um eye piece para adaptar a imagem das franjas geradas no interferômetro para a câmera CCD, possibilitando que a imagem da franja seja observada integralmente na tela do computador.

A exatidão do sistema Linnik depende das resoluções espaciais e de pixelbit da câmera CCD usada no sistema. As franjas interferométricas são coletadas por uma CCD de alta qualidade, com 1,5 megapixels e resolução de 12 bits. Os quadros (frames) são processados via computador através da utilização de um software desenvolvido para essas medições.

O interferômetro Linnik tem a grande vantagem de medir uma amostra, como por exemplo, um padrão de altura (step height), em uma posição muito próxima do degrau, evitando fazer correções provenientes da não planicidade das superfícies da amostra que está em medição no sistema. Isto pode ser observado na figura 21, que compara a medição de um bloco degrau triplo no interferômetro Linnik e em outros interferômetros. 


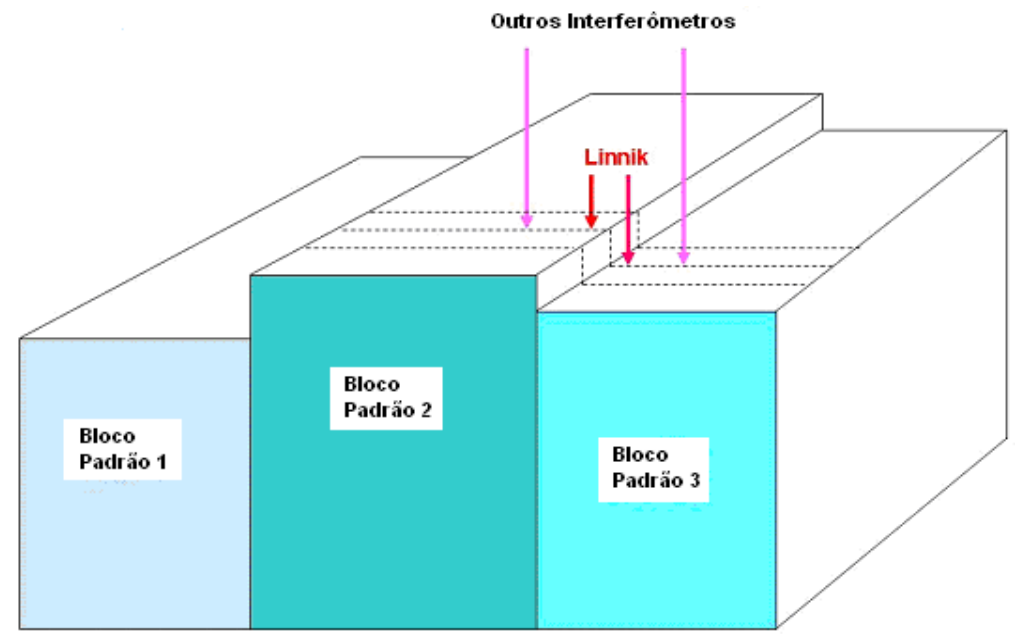

Figura 21 - Comparação de medição de bloco degrau triplo (step height) no interferômetro Linnik e em outros interferômetros.

Foi usado nas medições com o interferômetro Linnik um bloco triplo do fabricante Mitutoyo, denominado Step Master Series 516, de alturas de $10 \mu \mathrm{m}$ e 2 $\mu \mathrm{m}$, mostrado na figura 22. Esse tipo de bloco foi usado para calibração do eixo z (direção vertical) de instrumentos ópticos e é constituído de 03 (três) blocos interligados, com alturas diferentes.
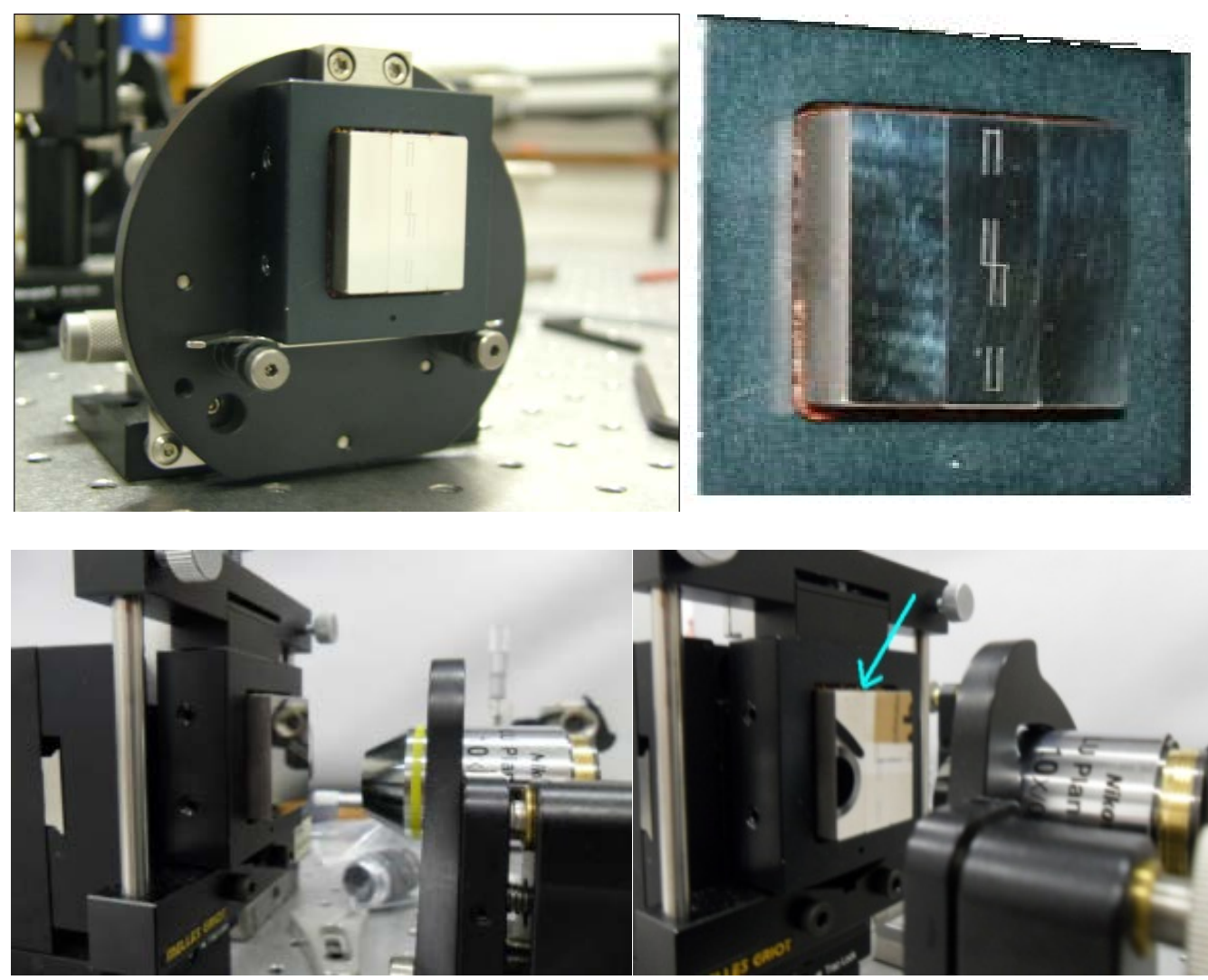

Figura 22 - Amostra de altura de $2 \mu \mathrm{m}$ e $10 \mu \mathrm{m}$, fabricante Mitutoyo. 
Também foi usado na tese um degrau de altura de $100 \mathrm{~nm}$ produzido no Inmetro pela Divisão de Metrologia de Materiais (Dimat) que pode ser observado na figura 23. A amostra de $100 \mathrm{~nm}$ foi produzida na Dimat usando a técnica de lift off por litografia de feixe de elétrons e metodologia MOCVD (metal organic chemical vapor deposition) já aplicadas na área [73, 74]. Essa amostra foi à primeira deste tipo produzida pela Dimat. A amostra tem algumas imperfeições em sua superfície, no entanto, a utilização dela é importante para verificar se o sistema de referência está otimizado para medições na escala nanométrica.

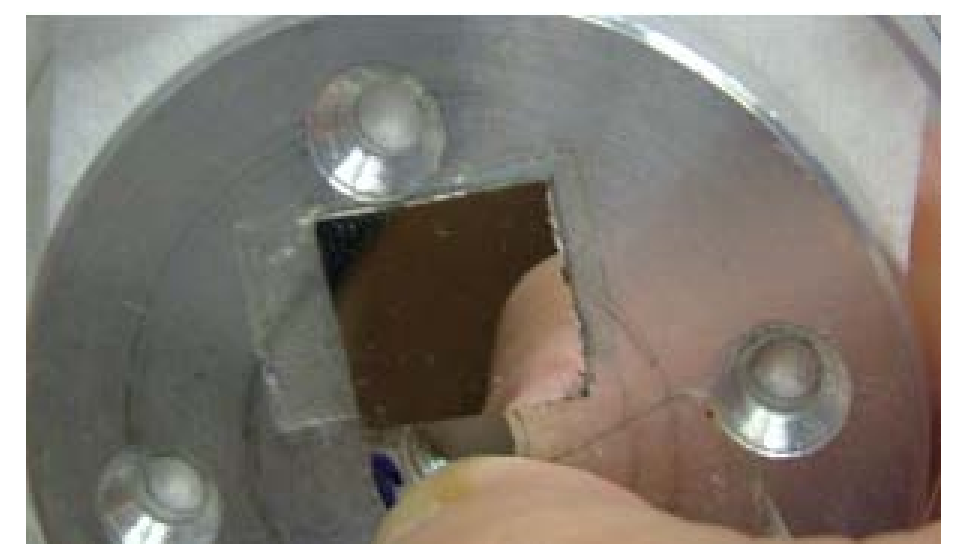

Figura 23 - Degrau de altura de $100 \mathrm{~nm}$ produzido no Inmetro pela Divisão de Metrologia de Materiais (Dimat).

O trabalho experimental da tese teve início na construção, montagem e caracterização de um interferômetro Linnik e a sua utilização como referência para prover rastreabilidade em medidas realizadas na escala sub-micrométrica de comprimento. Para realizar medições no Linnik, o sistema experimental foi alinhado e o padrão degrau foi posicionado em um suporte micrométrico em um dos braços do interferômetro. No outro braço foi colocado o espelho de referência. Para que o Linnik fosse usado como um sistema de referência, após a sua montagem e caracterização, foram avaliadas as principais componentes de incerteza que influenciavam as medições no sistema. Neste sistema interferométrico, semelhante ao interferômetro de Michelson, as franjas são observadas após a recombinação de ambos os feixes no divisor de feixe e depende da diferença de fase entre os feixes, que varia com o caminho percorrido por eles. Isto está relacionado com a otimização da distância entre as objetivas e o espelho de referência e a amostra. 
O registro da imagem da franja é feito usando um computador e é processada através da utilização de um software próprio, um processador de franja (Fringe processing SW) especialmente desenvolvido e testado para esta medição. O sistema foi alinhado de modo a ter na superfície da câmera CCD a imagem das franjas de interferência. O módulo principal do software de processamento de padrão de franja é baseado em ajuste de multi-parâmetros interativos de processamento de padrões de franjas e é baseado no ajuste do padrão de franja digitalizado ao longo do eixo vertical (ou várias linhas vizinhas). É possível fazer o ajuste da função transformada de Fourier (FFT) direto e reverso com filtro gaussiano no meio. Este filtro não perturba a fase e é usado para remover o ruído de pixel do padrão interferométrico. Adicionalmente, o ruído de pixel é removido através da média de diversas imagens para produzir o interferograma final usado para o processamento.

Para medidas de repetibilidade e reprodutibilidade do sistema experimental, a medição foi feita várias vezes no mesmo dia e em dias diferentes, além do uso de amostras diferentes no sistema experimental, respectivamente.

Na figura 24, pode-se observar a qualidade da franja e o ajuste ao longo do eixo vertical. As diferenças nos padrões são menores que $1 \%$.

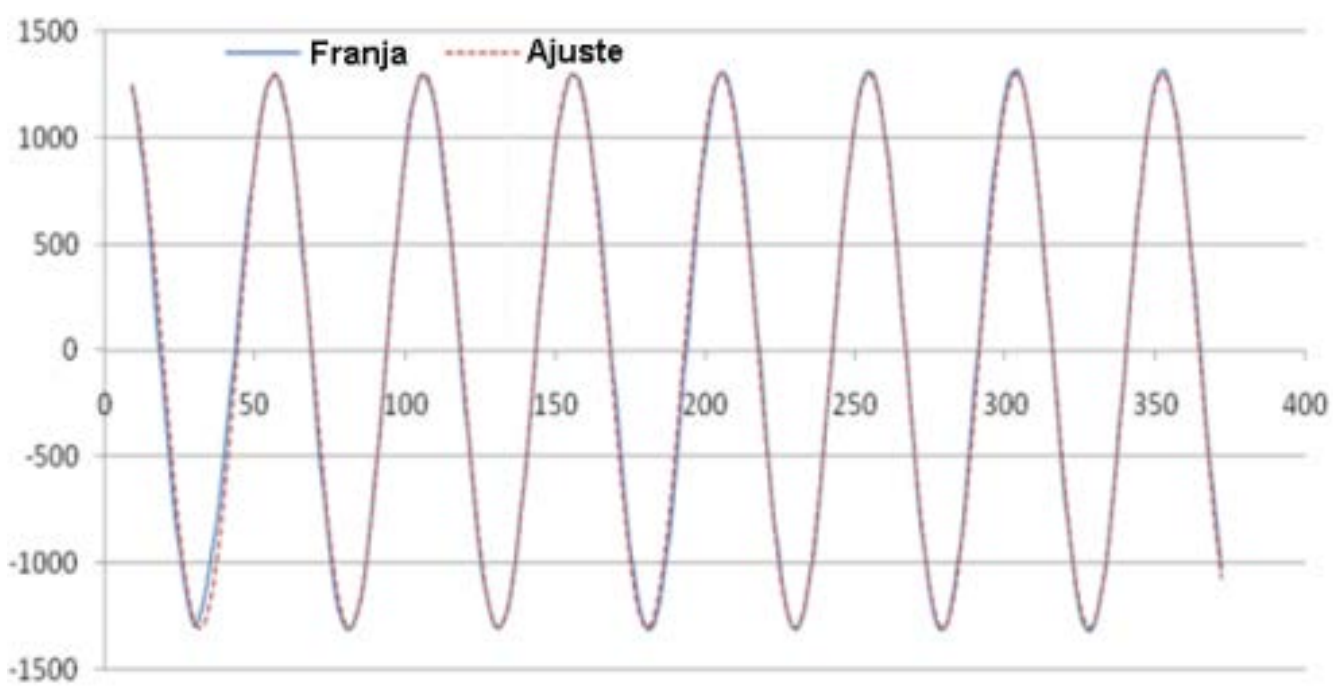

Figura 24 - Qualidade da franja (linha sólida) e ajuste (linha tracejada). 
$\mathrm{Na}$ análise dos dados medidos no sistema interferométrico Linnik, o número de pixels e resolução de intensidade (bits), como também a estabilidade e a uniformidade da câmera CCD usada é essencial para obter bons resultados.

A função de ajuste senoidal está relacionada a parâmetros, como por exemplo, a amplitude, o offset, a fase, a frequência, a modulação de fase e a modulação de amplitude.

Um critério de minimização é a diferença entre os mínimos quadrados entre os dados medidos e uma função modelo. É possível avaliar o padrão de franjas ao longo das múltiplas linhas desde que possamos calcular a topografia do artefato medido. A resolução do interferômetro é melhor que 0,1 nm (aproximadamente $\lambda / 6000$ ). A exatidão da medida é determinada pela qualidade do artefato e deve ser melhor que $1 \mathrm{~nm}$. Podemos notar que tanto o número de pixels e a resolução (bits) quanto à estabilidade/uniformidade do sensor da câmera CCD são essenciais para obter bons resultados.

As medições com o padrão comercial fabricado pela Mitutoyo de $2 \mu \mathrm{m}$ e $10 \mu \mathrm{m}$ foram feitas usando a técnica de processamento de franja interferométrica, ou seja, variando-se a posição da amostra na direção da objetiva. Para cada posição da amostra foram medidas as franjas geradas e com isto calculado o valor da correção ao valor nominal do degrau. As medidas de correção do padrão degrau feitas pelo fabricante Mitutoyo são mostrados na tabela 2.

Tabela 2 - Desvio do valor nominal e incerteza, degraus de $2 \mu \mathrm{m}$ e $10 \mu \mathrm{m}$.

\begin{tabular}{|c|c|c|}
\hline $\begin{array}{c}\text { Valor nominal } \\
\text { "step height” } \mathrm{h}_{\mathrm{o}}\end{array}$ & \multicolumn{2}{|c|}{ Resultados Fabricante } \\
\cline { 2 - 3 }$(\mu \mathrm{m})$ & $\Delta \mathrm{h}(\mu \mathrm{m})$ & $\mathrm{U}(\mu \mathrm{m})$ \\
\hline 2 & $-0,050$ & 0,050 \\
\hline 10 & $+0,050$ & 0,050 \\
\hline
\end{tabular}

Na figura 25 é mostrada a tela dos programas usados com as imagens do padrão de franjas para os degraus de altura de $2 \mu \mathrm{m}$ e $10 \mu \mathrm{m}$. 
(a)

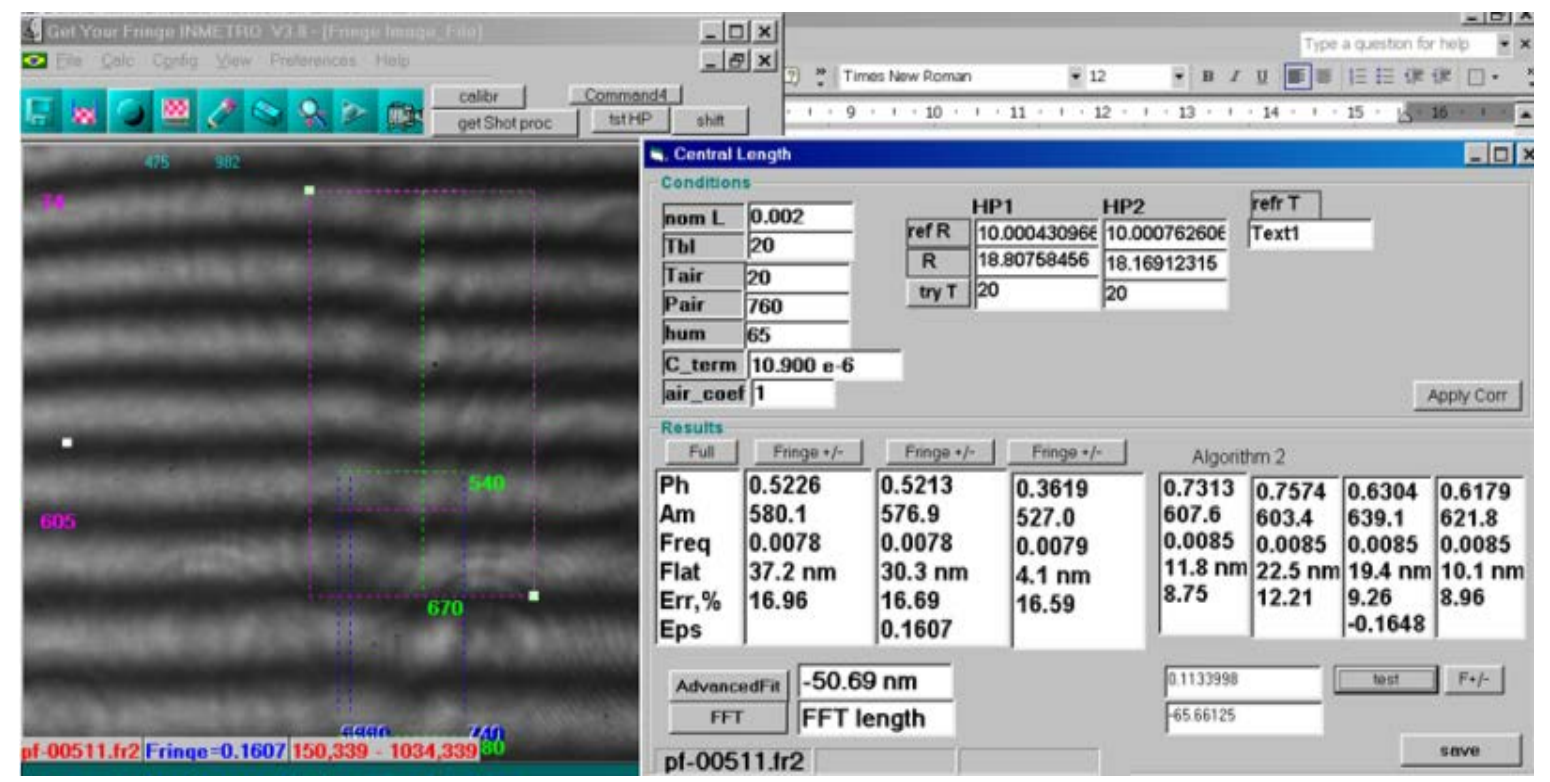

(b)

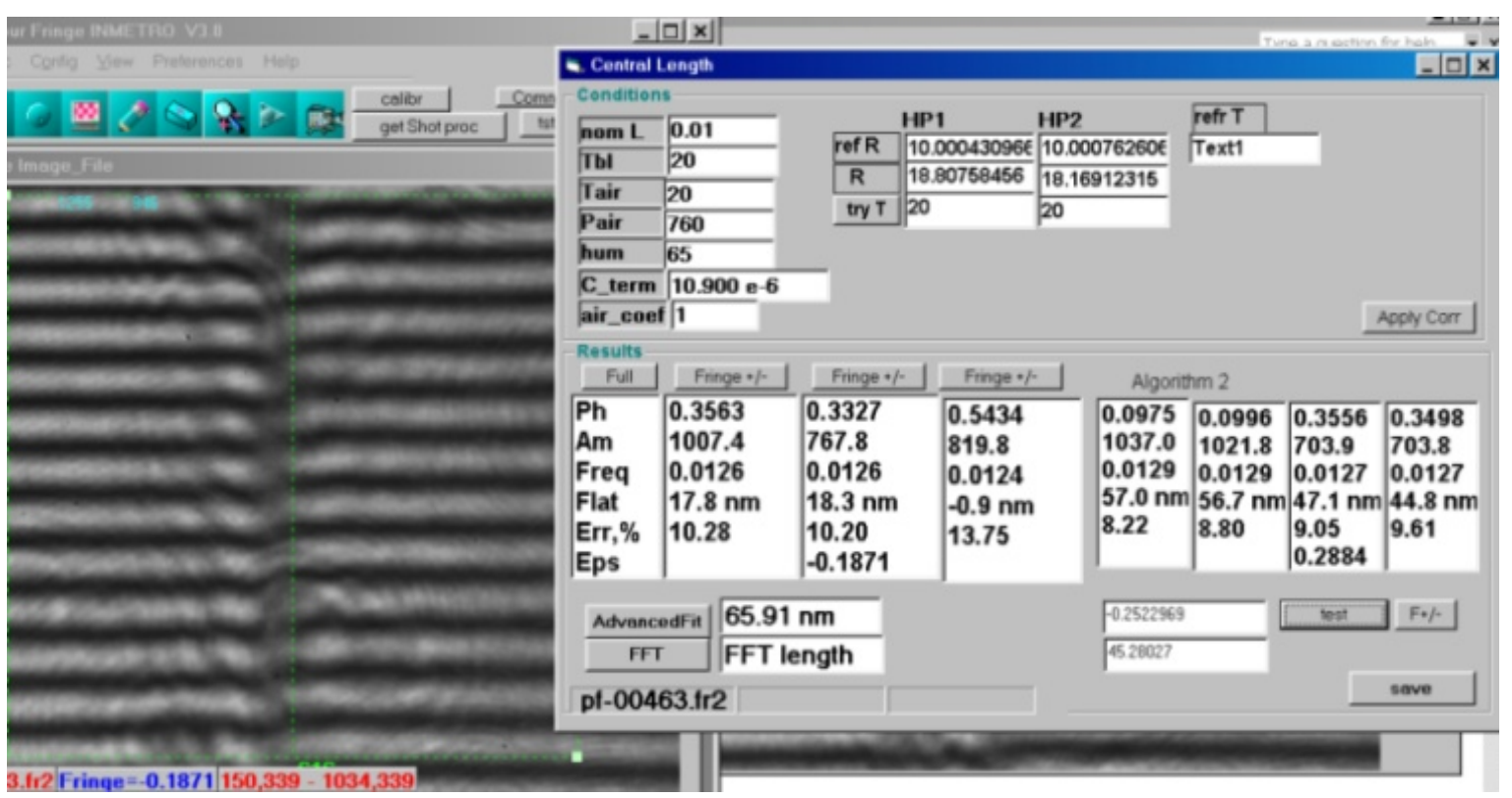

Figura 25 - Vista do software do degrau de altura de (a) $2 \mu \mathrm{m}$ e (b) $10 \mu \mathrm{m}$

Na figura 26 é mostrado o padrão de franjas medido para $10 \mu \mathrm{m}$. As linhas verticais tracejadas são guias usados para selecionar a área digitalizada do padrão de franja. 


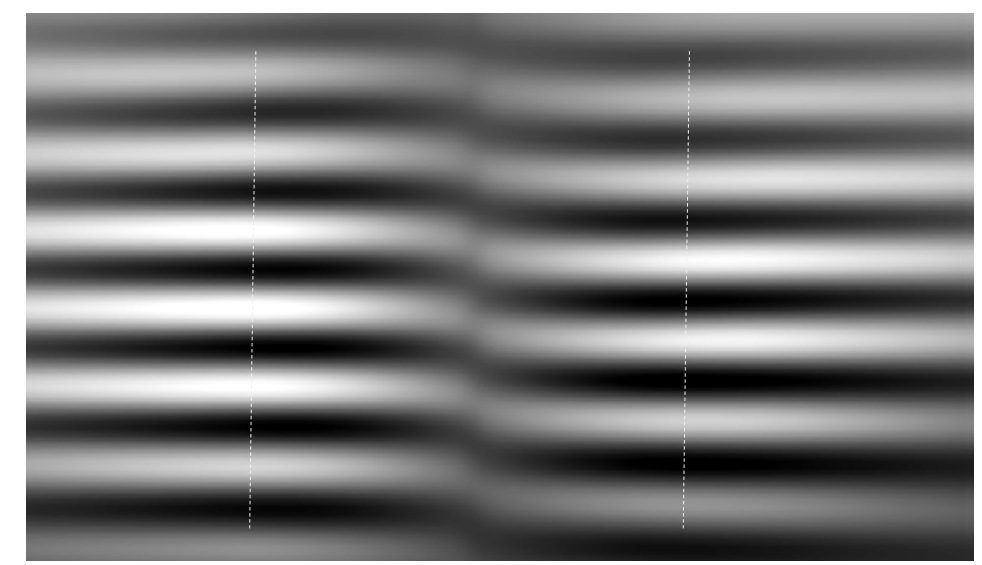

Figura 26 - Padrão de franja para um degrau de altura de $10 \mu \mathrm{m}$ obtido com o interferômetro Linnik.

Podemos observar que o padrão de franjas do degrau de altura de $10 \mu \mathrm{m}$ tem um efeito de borda (efeito barril) que pode resultar em uma medida incorreta da correção do valor do degrau. Isto pode ser minimizado através da escolha de uma área de medição reduzida e de um melhor alinhamento do sistema.

O alinhamento do sistema experimental foi melhorado, inserindo-se, por exemplo, suportes micrométricos para fixar a amostra e o espelho de referência, além de um sistema para adaptar a imagem da câmera CCD. Assim, os valores de repetitividade medidos ficaram em torno de $0,1 \mathrm{~nm}$, resultando em uma incerteza padrão combinada $\left(\mathrm{u}_{\mathrm{c}}\right)$ de 2,0 $\mathrm{nm}$ para o sistema experimental. $\mathrm{O}$ valor nominal, as correções em relação ao valor do degrau e a incerteza expandida (U) podem ser observados na tabela 3.

Tabela 3 - Desvio do valor nominal e incerteza expandida do sistema Linnik.

\begin{tabular}{|c|c|c|}
\hline $\begin{array}{c}\text { Valor Nominal } \\
\text { “Step Height” } \mathrm{h}_{\mathrm{o}}\end{array}$ & $\Delta \mathrm{h}(\mathrm{nm})$ & $\mathrm{U}(\mathrm{nm})$ \\
\cline { 2 - 3 }$(\mu \mathrm{m})$ & & $\mathrm{K}=2,04$ \\
\hline 2 & -43 & 4 \\
\hline 10 & +45 & 4 \\
\hline
\end{tabular}

O passo seguinte foi implementar mudanças no sistema experimental para que amostras com alturas menores que $2 \mu$ m pudessem ser avaliadas.

As medições no Linnik com os padrões de $2 \mu \mathrm{m}$ e, principalmente, $10 \mu \mathrm{m}$ foram importantes para prover a rastreabilidade em instrumentos ópticos com 
resolução próxima ao valor desses degraus. Os valores médios obtidos nas medições com o Linnik para esses degraus foram 1,957 $\mu \mathrm{m}$ e 10,045 $\mu \mathrm{m}$.

Com as atualizações realizadas no sistema experimental foram iniciadas medições com amostras de degrau de valor nominal de $100 \mathrm{~nm}$ e tamanho de 30 $\mu \mathrm{m}$, produzidas no Inmetro através da técnica de lift off por litografia de feixe de elétrons e metodologia MOCVD. Essas medições foram primeiramente realizadas usando-se a metodologia de processamento de franjas. Para caracterizar a amostra, foram realizadas medições em regiões distintas: antes da fenda, na fenda e depois da fenda. Isto foi feito para verificar a planicidade e eliminar possíveis erros decorrentes da medição. O valor do degrau medido é decorrente da média desses valores na fenda, diminuída da média dos valores medidos em outras regiões da amostra.

A vista do software para medidas com a amostra de $100 \mathrm{~nm}$ pode ser observada na figura 27.

Para o padrão degrau com altura de $100 \mathrm{~nm}$, produzido no Inmetro, também foi usada como metodologia de medição, além da técnica de processamento de franja interferométrica, a técnica de deslocamento de fase (phase stepping).

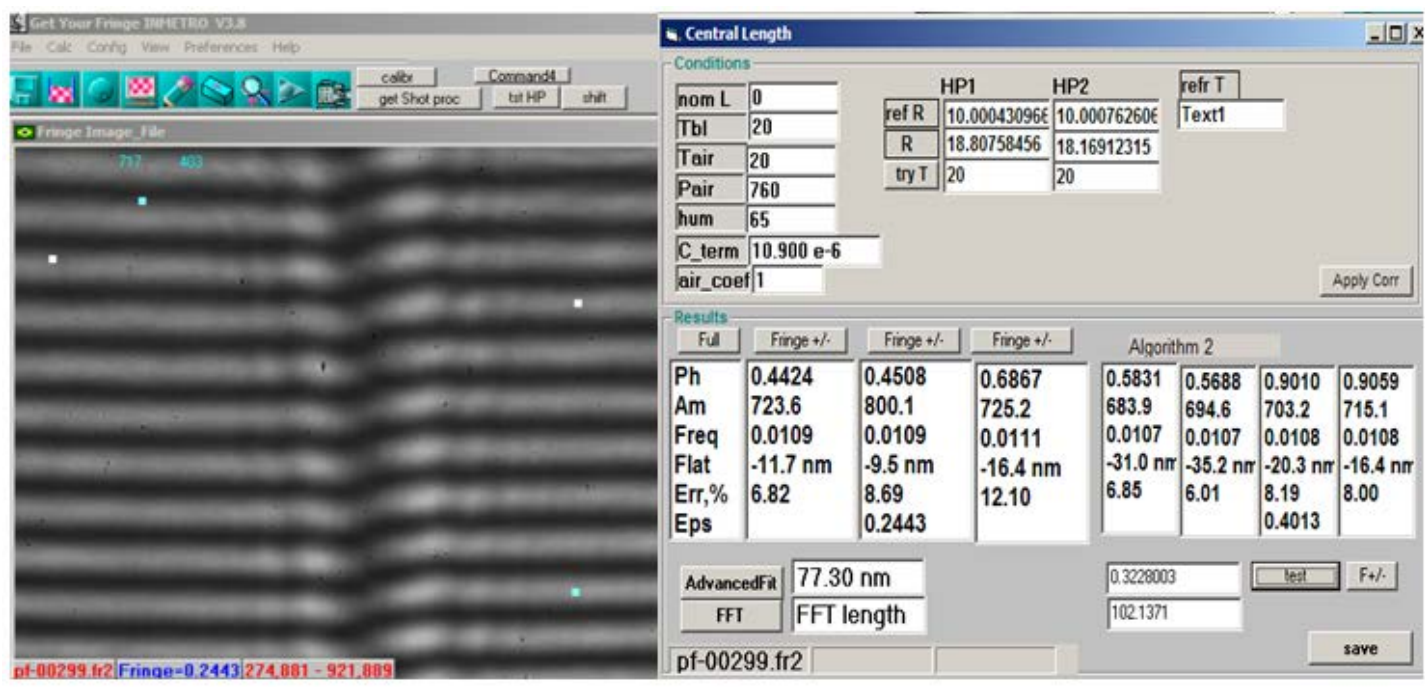

Figura 27 - Padrão de franjas observado nas medidas usando a amostra de altura de $100 \mathrm{~nm}$ 
A média das medições foi de $101 \mathrm{~nm}$ e a incerteza padrão combinada foi de $2 \mathrm{~nm}$. A incerteza aqui levou em consideração as componentes estatísticas (repetitividade e reprodutibilidade) e a incerteza de caracterização do sistema experimental.

Essas amostras foram usadas nas medições realizadas com o Linnik, no entanto para as próximas amostras que serão produzidas disponibilizamos uma lâmina para deposição que garante uma planicidade de $\lambda / 20$, importante para evitar correções nas medições relacionadas a essa grandeza.

Um dos mais sérios problemas relacionados às medições com o Linnik são os erros sistemáticos do interferômetro que estão ligados ao desalinhamento de ambos os braços, de referência e da amostra. Para que esses desalinhamentos fossem controlados, foi desenvolvido um procedimento eficiente de auto calibração com a melhoria do software usado para essas medições. Com isto medimos o padrão e, posteriormente, calibramos o padrão de franjas sobre a superfície plana do bloco padrão ou área plana do degrau de altura. Foi possível usar ambas as superfícies planas do bloco padrão para executar tal auto calibração. Assumindo-se que a superfície do bloco padrão é plana, foi possível remover o erro de desalinhamento através de correção apropriada. Para essa tarefa particular de auto calibração a unidade de deslocamento de fase é muito útil, já que existe a possibilidade de usar uma unidade de deslocamento angular (tilt-move unit) que controle não somente o movimento, mas os ângulos de movimento. É possível também fazer a análise de erros sistemáticos a esse respeito.

O sistema Linnik permite o processamento de franjas e o deslocamento de fase, o que permitirá no futuro realizar comparações em ambas as aproximações. Foram desenvolvidos no Inmetro procedimentos de software para análise detalhada da técnica de deslocamento de fase e o hardware usado mostrou-se adequado para realizar essas medições. A unidade de deslocamento de fase é baseada em uma base de deslocamento móvel com três graus de liberdade. Cada um dos três elementos PZT é independentemente programado via gerador de sinal conversor analógico-digital (DAC) de 24 bits que é amplificado com três canais HV amplificadores de baixo ruído. Desta maneira podemos programar independentemente todos os movimentos tentando compensar os efeitos não lineares do PZT. Nós movemos o espelho de referência com 100 ou mais (tipicamente 200) intervalos de distâncias iguais. Em cada ponto o interferograma 
é adquirido e salvo na memória do computador. Após fazer este procedimento, é possível processar a pilha de imagens interferométricas em cada posição versus a distância do dado movimento para reconstruir a fase para toda a superfície medida. Adicionalmente, para remover a vibração relacionada ao ruído foi feita uma média de vários interferogramas em cada posição de deslocamento de fase. Para aumentar a exatidão é possível fazer, opcionalmente, vários deslocamentos de retorno do phaser stepping em cada média de interferogramas na posição z. Cada deslocamento, scan, individual produz linhas de franjas interferométricas de aproximadamente 5-6 franjas em cada pixel (ou área em pixel) do campo de visão. Normalmente, não é usado um pixel único e sim uma área em pixel vizinha à média do ruído pixel a pixel. É possível processar interferogramas individuais da mesma maneira, o que permite comparar ambos os algoritmos nos dois métodos, padrão de franjas e deslocamento de fase. A razão sinal ruído do sistema permite chegar a uma resolução menor que $1 \mathrm{~nm}$, o que pode ser observado na figura 28, a partir da realização de múltiplos testes de repetitividade do sistema.

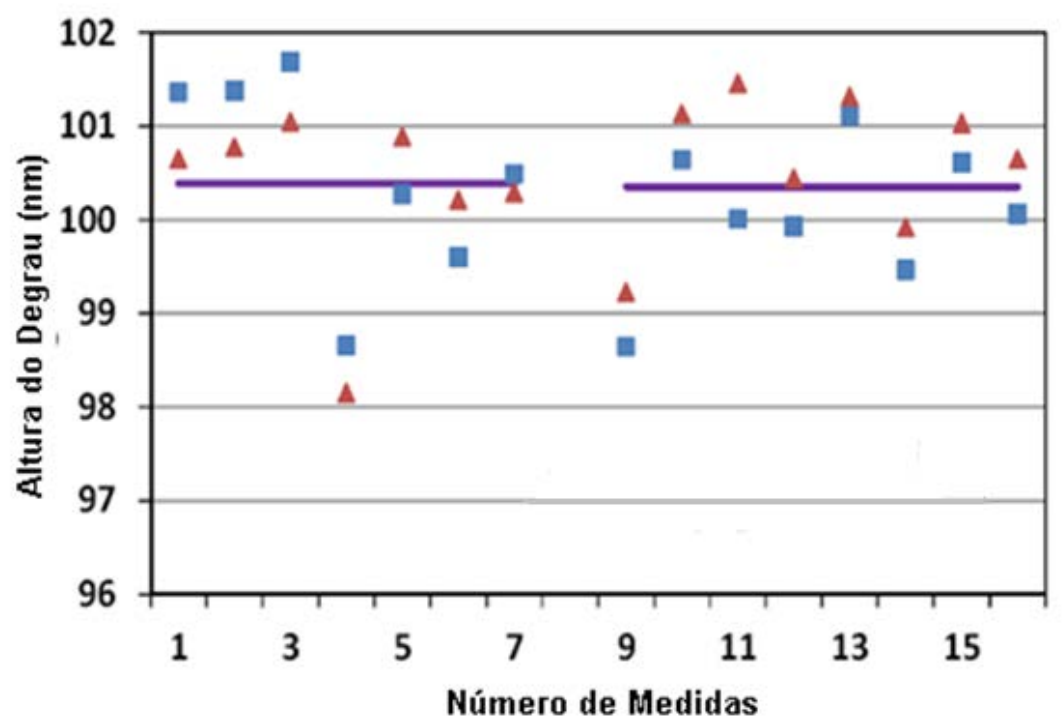

Figura 28 - Reprodutibilidade das medidas obtidas usando o degrau de altura de $100 \mathrm{~nm}$.

As medições relacionadas aos dados da figura 28 foram feitas durante um período de duas semanas. Duas séries correspondem a diferentes alinhamentos do interferômetro. As linhas correspondem à média de cada série. 
As componentes de incerteza associadas às medições realizadas para o sistema interferométrico primário Linnik e para os sistemas secundários foram avaliadas para a elaboração da planilha de incerteza do sistema. No caso do Linnik, a incerteza leva em consideração o estudo de erros sistemáticos do sistema experimental.

A estimativa de incerteza do sistema foi feita levando-se em consideração múltiplas medições. As medidas simples, sem automatização do sistema apresentaram uma relação sinal/ruído alto, o que foi evitada no sistema automatizado, pois era possível realizar uma média de múltiplas leituras nas mesmas condições.

A estabilidade do interferômetro permitiu significantes melhorias nas medições. O passo seguinte foi adicionar uma base automatizada móvel que foi útil na calibração da área plana da amostra.

A exatidão da correção é estimada sendo de aproximadamente $2 \mathrm{~nm}$. A planilha de incerteza do interferômetro Linnik pode ser observada na tabela 4.

O sistema Linnik foi otimizado e as principais componentes de incerteza avaliadas. No entanto, nada impede que após futuras avaliações de erros sistemáticos no sistema experimental ou mesmo mudanças na metodologia de medição a planilha de incerteza tenha que ser revista e resulte em uma incerteza padrão combinada ainda mais reduzida. 
Tabela 4 - Planilha de incerteza do sistema Linnik

\begin{tabular}{|c|c|}
\hline $\begin{array}{c}\text { Fontes de Incerteza de } \\
\text { Medição }\end{array}$ & $\begin{array}{c}\text { Valor da incerteza, } \mathbf{u}_{\mathbf{i}} \\
\text { (nm). }\end{array}$ \\
\hline $\begin{array}{c}\text { Alinhamento do } \\
\text { interferômetro }\end{array}$ & 0,5 \\
\hline Fração de franjas & 0,3 \\
\hline $\begin{array}{c}\text { Ruído de fase após 20 } \\
\text { médias de medidas }\end{array}$ & 0,1 \\
\hline $\begin{array}{c}\text { Repetibilidade após uma } \\
\text { média de 10 medidas }\end{array}$ & 0,8 \\
\hline $\begin{array}{c}\text { Reprodutibilidade após uma } \\
\text { média de 10 medidas }\end{array}$ & 2 \\
\hline Planicidade do artefato & $<0,01$ nm \\
\hline $\begin{array}{c}\text { Comprimento de onda do } \\
\text { laser }\end{array}$ & 2 \\
\hline $\begin{array}{c}\text { Incerteza padrão combinada, } \\
\mathbf{u}_{\mathrm{c}}\end{array}$ & Insignificante, \\
\hline
\end{tabular}

Com a metodologia de medição do sistema Linnik estabelecida, foi possível prover a rastreabilidade a outros sistemas ópticos, como Microscópios Confocais (CM), microscópio de Força Atômica (AFM) e OCT. A calibração dos equipamentos é feita levando-se em consideração a resolução dos instrumentos, a repetitividade e a reprodutibilidade das medições dos degraus de altura usado nas medições com os instrumentos assim como a incerteza do sistema de referência, o interferômetro Linnik. A correção (C) dos instrumentos é feita levando-se em consideração a diferença das medidas do degrau de altura no sistema de referência e no instrumento, sendo $\mathrm{C}=$ valor $_{\text {sistema referência }}-$ valor $_{\text {instrumento). }}$ A incerteza da correção é dada por $u_{c}=\sqrt{\sum u_{i}^{2}}$, sendo $\mathrm{u}_{\mathrm{i}}=$ incertezas da referência, reprodutibilidade, repetitividade, resolução, etc. Esta metodologia é aplicada para cada degrau de altura medido nos instrumentos, conforme pode ser observado na tabela 5 . 
Tabela 5 - Incerteza dos instrumentos ópticos

\begin{tabular}{|c|c|c|}
\hline Valor nominal & Correção & Incerteza \\
\hline $100 \mathrm{~nm}$ & $\mathrm{x}$ & $\mathrm{u}(\mathrm{x})$ \\
\hline $2 \mu \mathrm{m}$ & $\mathrm{y}$ & $\mathrm{u}(\mathrm{y})$ \\
\hline $10 \mu \mathrm{m}$ & $\mathrm{z}$ & $\mathrm{u}(\mathrm{z})$ \\
\hline
\end{tabular}

\section{2}

\section{Tomógrafos de Coerência Óptica (TD-OCT, SD-OCT e SS-OCT)}

O sistema TD-OCT montado no Inmetro é mostrado na figura 29 e é composto por um acoplador em fibra óptica de 50x50, tendo em suas pontas um diodo laser superluminescente (SLD) com baixa coerência óptica, um compartimento para colocar a amostra a ser analisada e um interferômetro de Michelson. A outra saída do acoplador é atenuada para evitar reflexões espúrias. O sinal de onda contínua é enviado para a amostra em medição através do acoplador. A luz refletida pela amostra é coletada pela fibra óptica e enviada, após passar através do acoplador, para o interferômetro de Michelson. O interferômetro contém espelhos estacionários e móveis em braços perpendiculares, e um detector no terceiro braço.

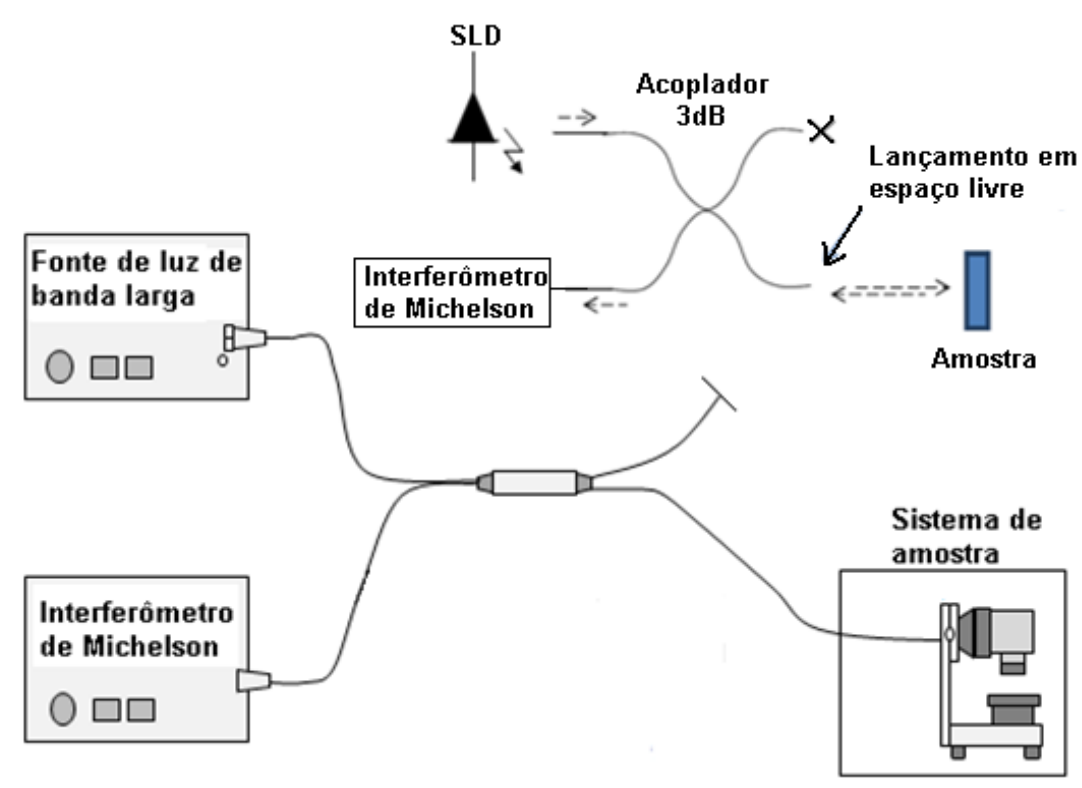

Figura 29 - Esquema do TD-OCT montado no Inmetro. 
O sinal incidente no interferômetro de Michelson, proveniente da amostra em medição é dividido nos dois braços. Um dos braços tem o caminho óptico variado por um valor maior que o comprimento de coerência da fonte e os percursos são desbalanceados nos dois sentidos.

Uma base de translação automatizada foi colocada de modo a permitir o deslocamento lateral da amostra. Um ajuste de ângulo de elevação foi colocado no suporte da amostra, assim como um posicionador para deslocamento axial.

O espectro óptico da fonte de luz usada no sistema foi avaliado com um analisador de espectro óptico e possui largura à meia altura de 92,1 nm e está centrado em 1320,71 nm, sendo operacionalizado com controle de temperatura estabilizada em $25^{\circ} \mathrm{C}$ e a corrente controlada em $450 \mathrm{~mA}$.

A resolução axial é de $8,2 \mu \mathrm{m}$. O espectro da fonte de luz pode ser observado na figura 30 .

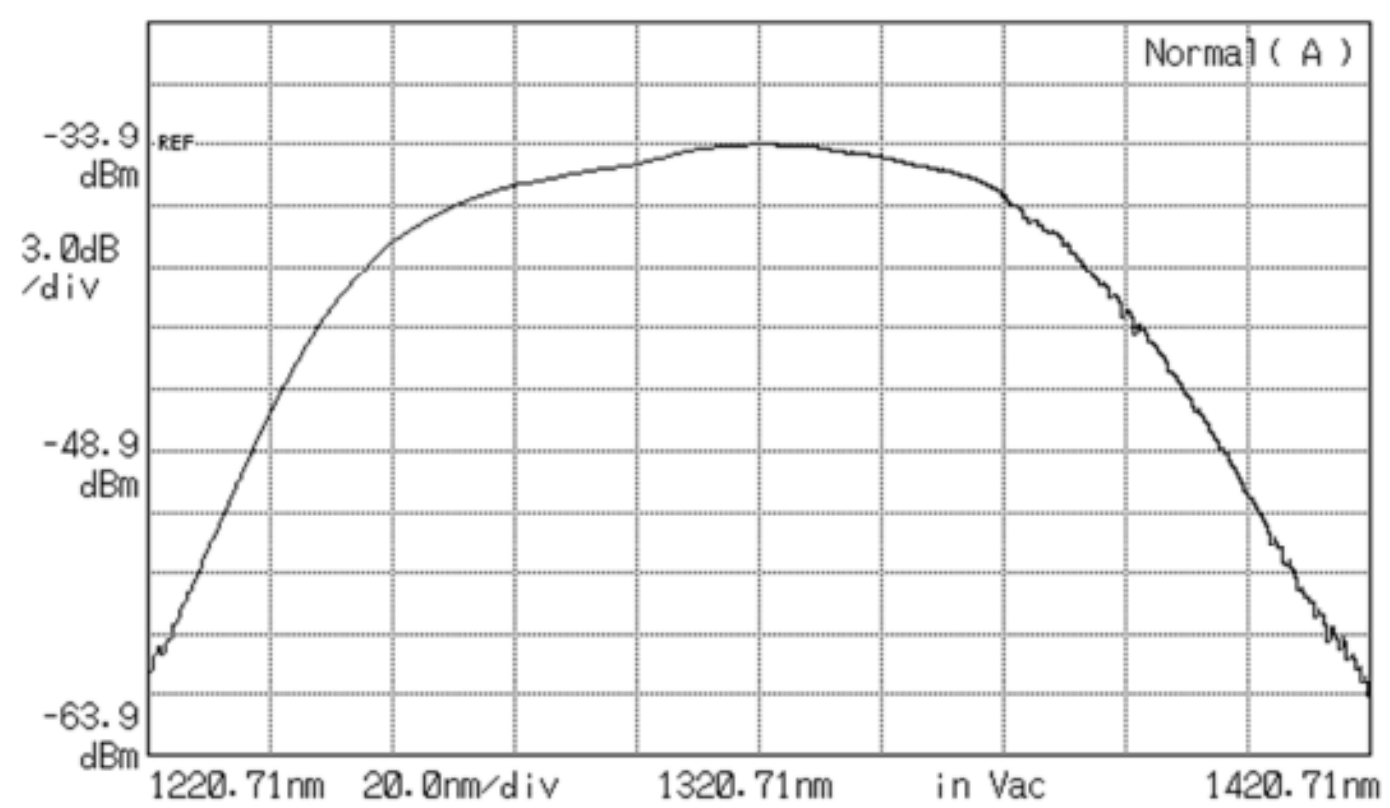

Figura 30 - Espectro óptico do diodo superluminescente (SLD).

Para aumentar a rapidez, a aquisição de dados foi automatizada através do software Labview com auxílio de uma base de translação automatizada, uma câmera (webcam) que é utilizada para monitoramento do final de cada varredura do interferômetro, uma chave operada remotamente e um mouse adaptado.

A mudança da cor do botão da tela indicava se o equipamento estava executando uma varredura (vermelho) ou aguardando comando (verde). Caso o 
equipamento estivesse em estado de espera o programa de controle acionava a chave, switch, que fecha os contatos do botão esquerdo do mouse, clicando no botão de início de varredura. Quando necessário, a base de translação era acionada para deslocar a amostra, entre varreduras.

Foi utilizada a face clivada da fibra de lançamento de forma que as medições de distância foram realizadas entre a ponta da fibra e a superfície refletora. A peça foi deslocada no sentido ortogonal ao eixo óptico de propagação e o perfil de altura foi avaliado.

Foi usado para as medições o degrau de altura de $10 \mu \mathrm{m}$ e $2 \mu$ m medido anteriormente no sistema interferométrico de referência Linnik. No sistema automatizado do TD-OCT, os padrões foram posicionados e as medições iniciadas, conforme figura 31.

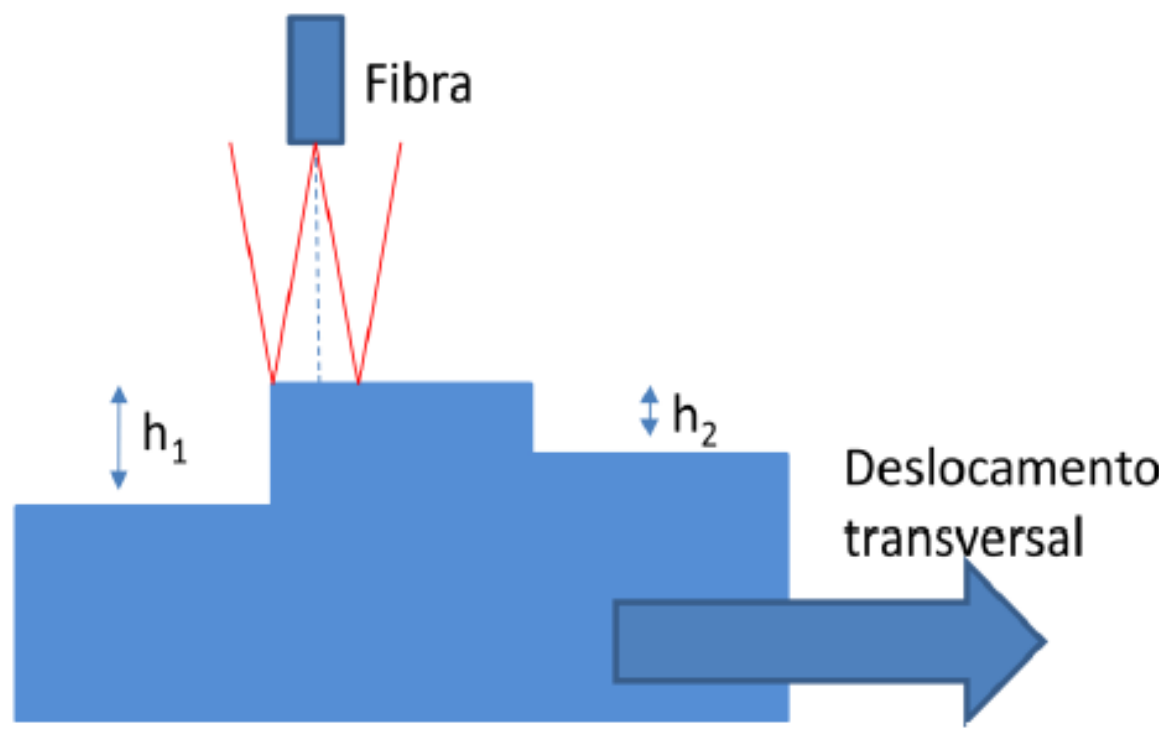

Figura 31 - Medição do padrão degrau de $2 \mu \mathrm{m}$ e $10 \mu \mathrm{m}$ do fabricante Mitutoyo.

O envelope do interferograma foi obtido em cada ciclo de varredura. A varredura axial completa e com a região de interesse ampliada é mostrada na figura 32. 


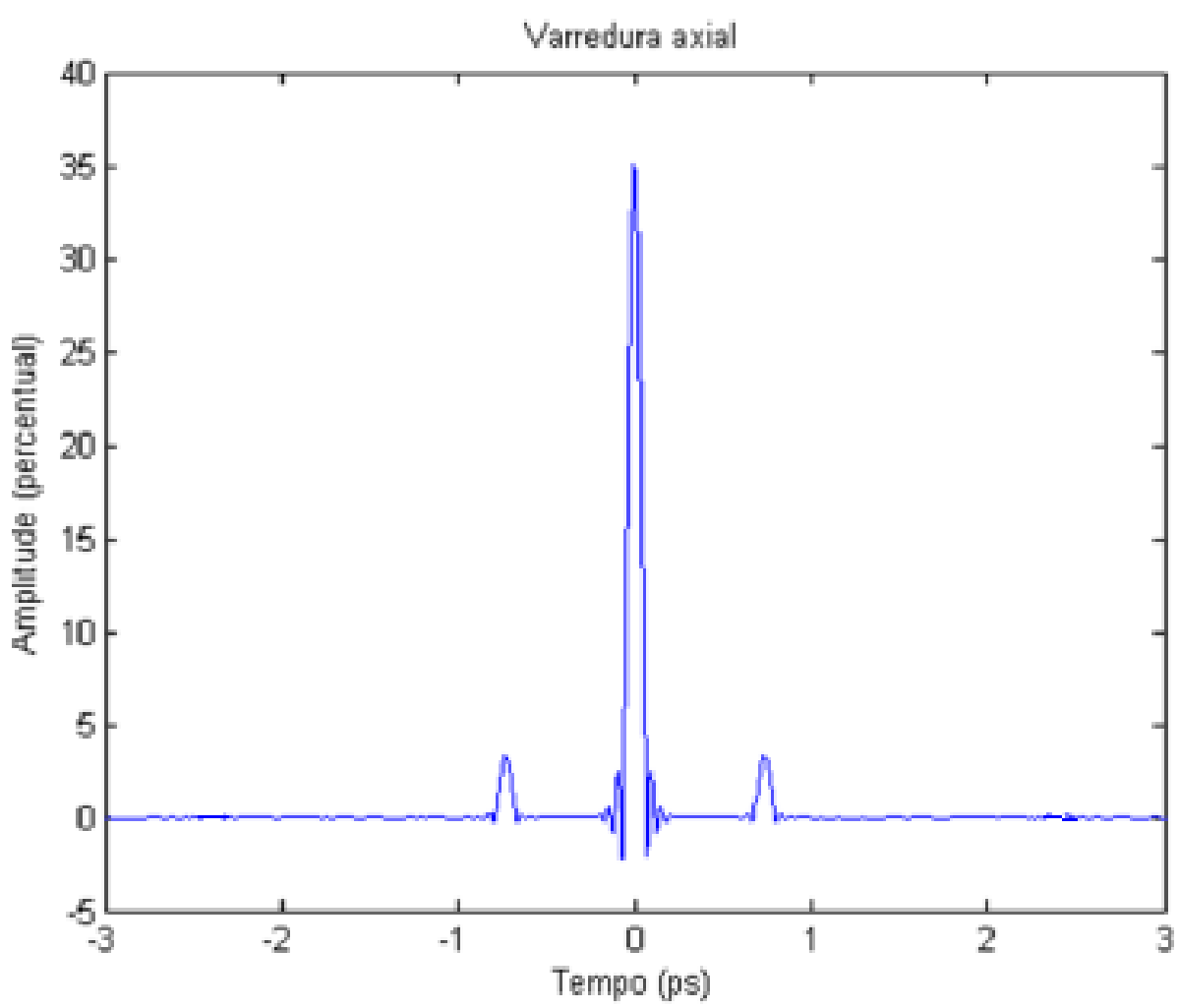

Figura 32 - Interferograma gerado nas medidas com o TD-OCT a partir de uma varredura axial completa.

A análise foi feita através da medida da distância entre o ponto máximo do pico principal e o ponto máximo do primeiro pico à direita à medida que a média progressiva das varreduras era realizada.

Cada interferograma era automaticamente salvo pelo software do interferômetro. O interferograma contém um pico de referência (reflexão de Fresnel da interface fibra-ar) e um pico lateral, com seu simétrico no sentido negativo do eixo $\mathrm{X}$, correspondendo a uma superfície refletora localizada na direção axial da fibra.

A ocorrência de três picos, ao invés de dois picos, é causada pelo uso do interferômetro de Michelson em um braço do acoplador 50/50. Algumas rotinas em Matlab foram desenvolvidas para a extração e processamento dos dados.

A imagem obtida nas medições com o TD-OCT é mostrada na figura 33, onde o pico de referência (reflexão de Fresnel na interface fibra-ar) é mostrado no centro, mais intenso.

Os dois picos das interfaces da amostra são mostrados acima e abaixo do pico principal, de forma espelhada. 


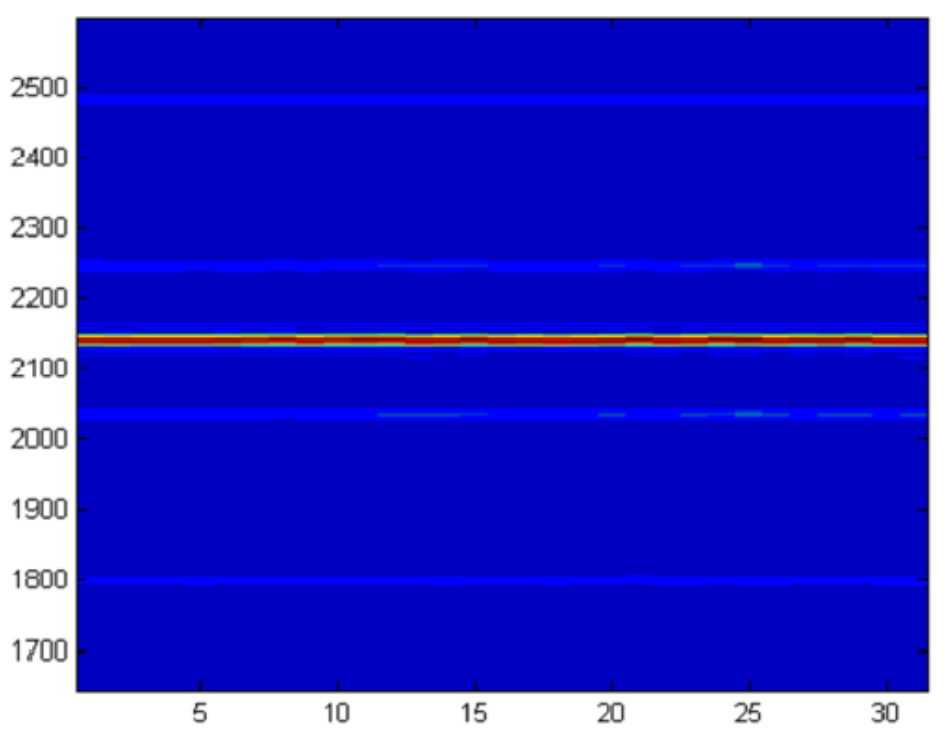

Figura 33 - Imagem gerada no TD-OCT nas medições com o degrau de altura de $10 \mu \mathrm{m}$.

A planilha de incerteza para o TD-OCT, mostrada na tabela 6, foi elaborada levando-se em consideração as incertezas relacionadas ao padrão de transferência, neste caso a incerteza tipo B do sistema interferométrico de referência Linnik e as análises estatísticas do sistema. A largura de banda espectral da fonte de luz usada no sistema foi medida e manteve-se estável durante as medições, não sendo necessário avaliar esta componente.

Tabela 6 - Planilha de incerteza do sistema TD-OCT.

\begin{tabular}{|c|c|c|}
\hline $\begin{array}{c}\text { Fontes de } \\
\text { Incerteza de } \\
\text { Medição }\end{array}$ & $\begin{array}{c}\text { Degrau de } 10 \mu \mathrm{m} \\
\text { Valor da incerteza, } u_{i} \\
(\mu \mathrm{m})\end{array}$ & $\begin{array}{c}\text { Degrau de } 2 \mu \mathrm{m} \\
\text { Valor da incerteza, } \mathbf{u}_{\mathrm{i}} \\
(\mu \mathrm{m})\end{array}$ \\
\hline $\begin{array}{c}\text { Padrão de altura } \\
\text { (calibração Linnik) }\end{array}$ & \multicolumn{2}{|c|}{0,002} \\
\hline Repetibilidade & 0,08 & 0,08 \\
\hline Reprodutibilidade & 0,09 & 0,07 \\
\hline $\begin{array}{l}\text { Incerteza padrão } \\
\text { combinada, } \mathrm{u}_{\mathrm{C}}\end{array}$ & 0,12 & 0,11 \\
\hline $\begin{array}{l}\text { Incerteza padrão } \\
\text { expandida, } \mathrm{U} \\
\mathrm{k}=2,08(10 \mu \mathrm{m}) \\
\mathrm{k}=2,1(2 \mu \mathrm{m})\end{array}$ & 0,3 & 0,2 \\
\hline
\end{tabular}


Na tabela 7 podemos observar os valores medidos para os degraus de alturas de $2 \mu \mathrm{m}$ e $10 \mu \mathrm{m}$ em relação aos valores medidos no interferômetro Linnik e as incertezas associadas a essas medições.

Tabela 7 - Medida dos degraus de altura de $2 \square \mathrm{m}$ e $10 \square \mathrm{m}$ e incer tezas associadas ao TD-OCT e Linnik.

\begin{tabular}{|c|c|c|c|c|}
\hline \multirow{2}{*}{$\begin{array}{c}\text { Valor Nominal } \\
\mathrm{h}(\mu \mathrm{m})\end{array}$} & \multicolumn{2}{|c|}{ Linnik } & \multicolumn{2}{c|}{ TD-OCT } \\
\cline { 2 - 5 } & $\mathrm{h}(\mu \mathrm{m})$ & $\mathrm{U}(\mathrm{h})(\mathrm{nm})$ & $\mathrm{h}(\mu \mathrm{m})$ & $\mathrm{U}(\mathrm{h})(\mu \mathrm{m})$ \\
\hline 2 & 1,957 & 4 & 1,9 & 0,2 \\
\hline 10 & 10,045 & 4 & 10,0 & 0,3 \\
\hline
\end{tabular}

Para comprovar que o sistema TD-OCT pode ser usado para medir outros perfis de amostras, foram analisadas diferentes topografias no sistema, usando um padrão de referência com diferentes profundidades. Este padrão consiste de uma superfície plana com 06 (seis) ranhuras que variam de $(0,264 \pm 0,008) \mu \mathrm{m}$ até $(9,457 \pm 0,020) \mu \mathrm{m}$. As medidas realizadas com o padrão de profundidade no sistema TD-OCT estão de acordo com os valores calibrados no Instituto Nacional de Metrologia da Alemanha, Physikalisch Technische Bundeanstalt (PTB), usando perfilômetros, conforme pode ser observado na tabela 8 .

Os resultados mostram a versatilidade de um sistema OCT para medir perfis variados e não somente perfis planos como os usados para medir com interferômetros. 
Tabela 8 - Medida do padrão de profundidade no TD-OCT comparado com o certificado PTB para um perfilômetro.

\begin{tabular}{|c|c|c|c|c|}
\hline $\begin{array}{c}\text { Profundidade } \\
\text { Nominal } \mathrm{d}_{0}\end{array}$ & \multicolumn{2}{|c|}{ Resultados PTB } & \multicolumn{2}{c|}{$\begin{array}{c}\text { Resultados TD-OCT } \\
\text { Inmetro }\end{array}$} \\
\cline { 2 - 5 }$(\mu \mathrm{m})$ & $\mathrm{d}(\mu \mathrm{m})$ & $\mathrm{U}(\mathrm{d})(\mu \mathrm{m})$ & $\mathrm{d}(\mu \mathrm{m})$ & $\mathrm{U}(\mathrm{d})(\mu \mathrm{m})$ \\
\hline 10 & 9,457 & 0,02 & 9,7 & 3,8 \\
\hline 6 & 6,191 & 0,15 & 6,4 & 0,2 \\
\hline 3 & 3,075 & 0,013 & 3,0 & 0,4 \\
\hline 1 & 0,979 & 0,010 & 1,0 & 0,3 \\
\hline 0,6 & 0,624 & 0,009 & 0,7 & 0,2 \\
\hline 0,2 & 0,264 & 0,008 & 0,2 & 0,2 \\
\hline
\end{tabular}

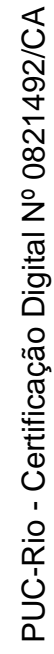

O perfil da superfície medida com o padrão de profundidade pode ser observado na figura 34 .

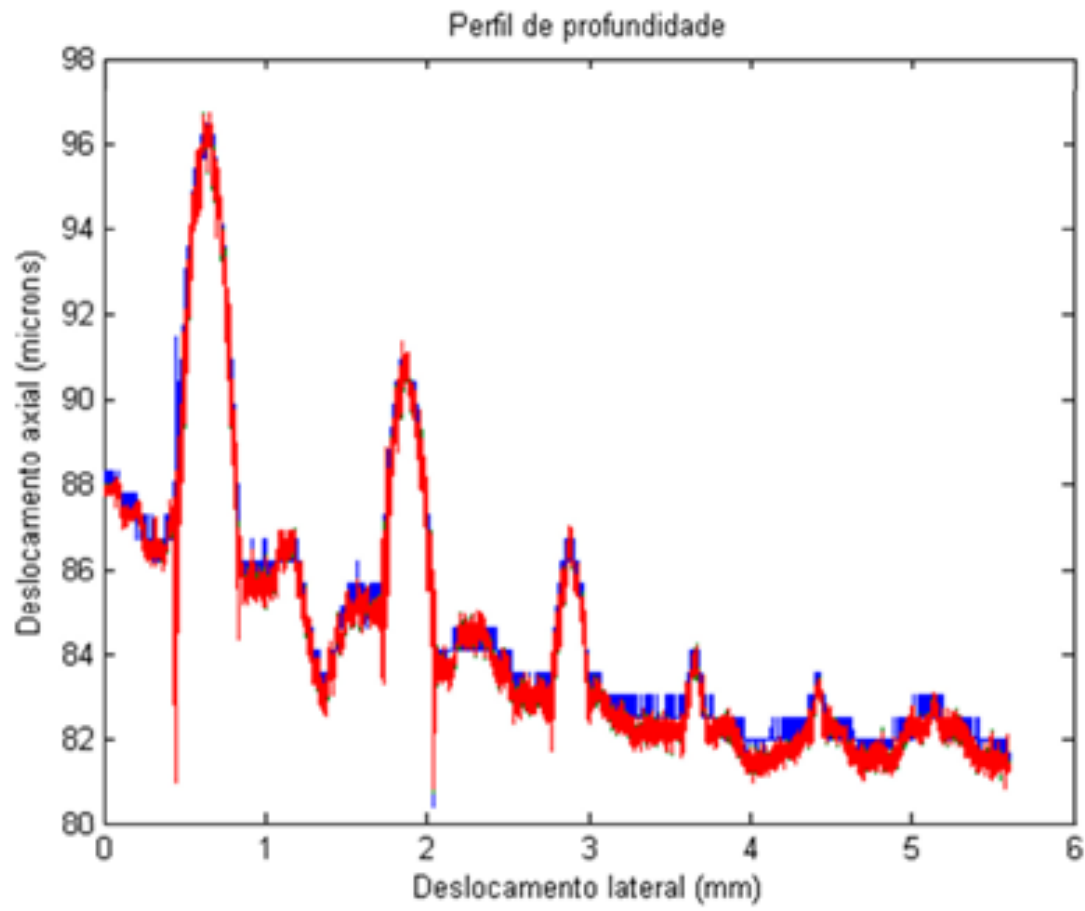

Figura 34 - Perfil obtido nas medidas com o TD-OCT para o padrão de profundidade. 
A linha de base inclinada está relacionada a uma leve inclinação angular de aproximadamente $10^{-4}$ rad entre o eixo de translação e a superfície do padrão.

Com a metodologia usada no TD-OCT foi possível calibrar dois OCT comerciais diferentes no domínio do espectro, um Spectral Radar OCT (SR-OCT) do IPEN/USP e um Swept Source OCT (SS-OCT) da PUC-Rio.

O SR-OCT e o SS-OCT tem resolução axial de 6,2 $\mu \mathrm{m}$ e $12 \mu \mathrm{m}$, respectivamente.

Nas medições realizadas nos sistemas OCT comerciais, um Swept Source OCT (SS-OCT) e um Spectral Radar OCT (SR-OCT) foram realizadas medições com ambos os degraus de altura, de $2 \mu \mathrm{m}$ e $10 \mu \mathrm{m}$. No entanto, devido a resolução axial do SS-OCT, a calibração foi feita com o degrau de altura de $10 \mu \mathrm{m}$.

Para realizar as medições em ambos os sistemas comerciais os braços com as objetivas dos OCT comerciais foram posicionados diretamente sobre o degrau de $2 \mu \mathrm{m}$ e, posteriormente, de $10 \mu \mathrm{m}$, posicionados na base $\mathrm{XY}$, conforme observado na figura 35. O sistema foi alinhado e as medições foram realizadas usando o software disponibilizado pelo sistema OCT comercial.

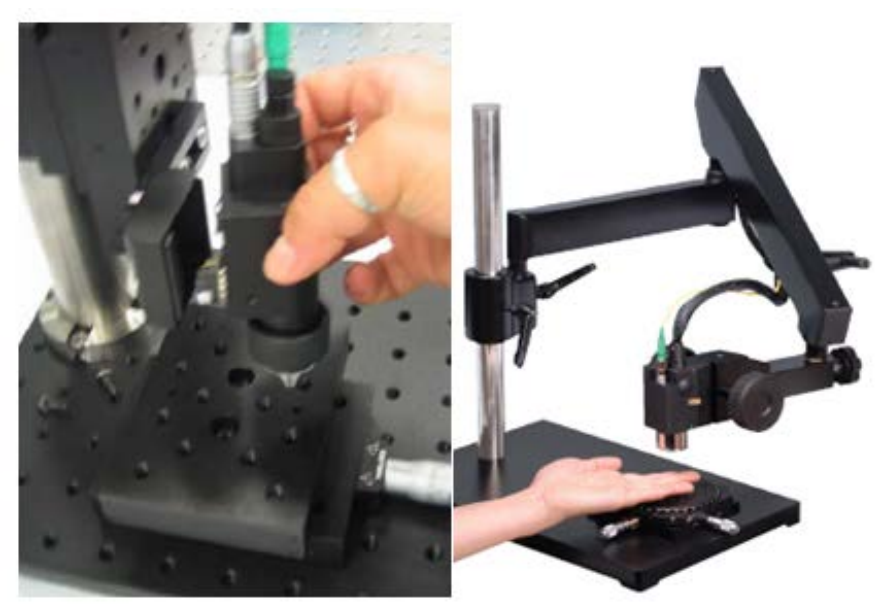

(a)

(b)

Figura 35 - Sistema de amostra dos OCT comerciais do fabricante Thorlabs, (a) SR-OCT e (b) SS-OCT.

Os dados obtidos geram imagens mostradas na figura 36, através de arquivos .img, gerados pelo software do OCT. 
Cada arquivo .img foi convertido em vários arquivos *.raw, através de programas em Labview, feitos por pesquisador do IPEN/SP, que por sua vez são possíveis de serem avaliados no software Origin, onde são geradas imagens dos espectros, observados na figura 37, que são usados para o cálculo da altura do degrau. $\quad$ Cada arquivo *.raw é aberto no Origin como uma matriz direta e os dados são avaliados através de um ajuste gaussiano.

Após isto, a altura do degrau é avaliada. A imagem gerada mostra várias linhas brilhantes deslocadas que correspondem às várias reflexões nas duas superfícies planas do degrau.

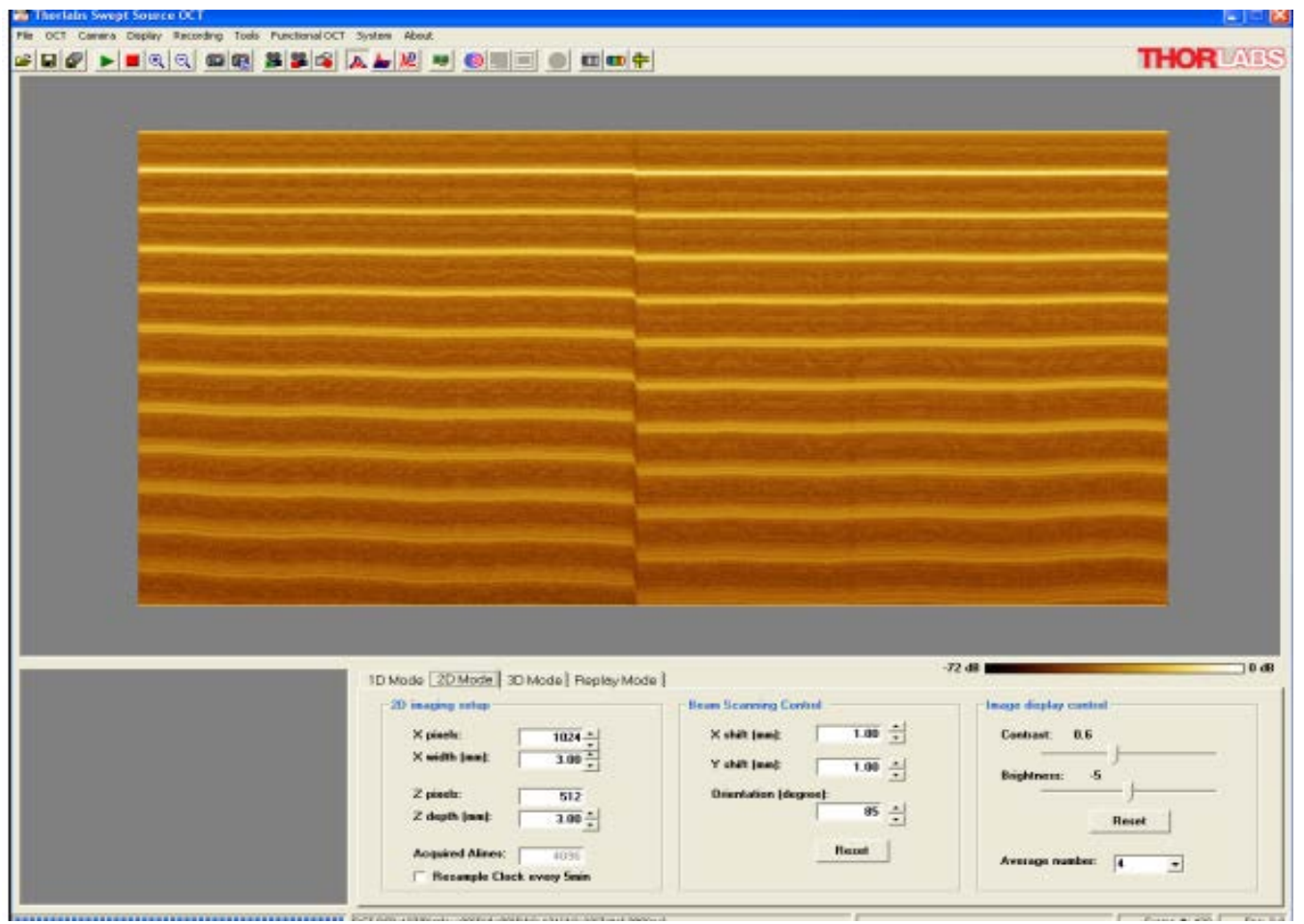

Figura 36 - Imagem gerada pelo SS-OCT para o degrau de altura de $10 \mu \mathrm{m}$. 


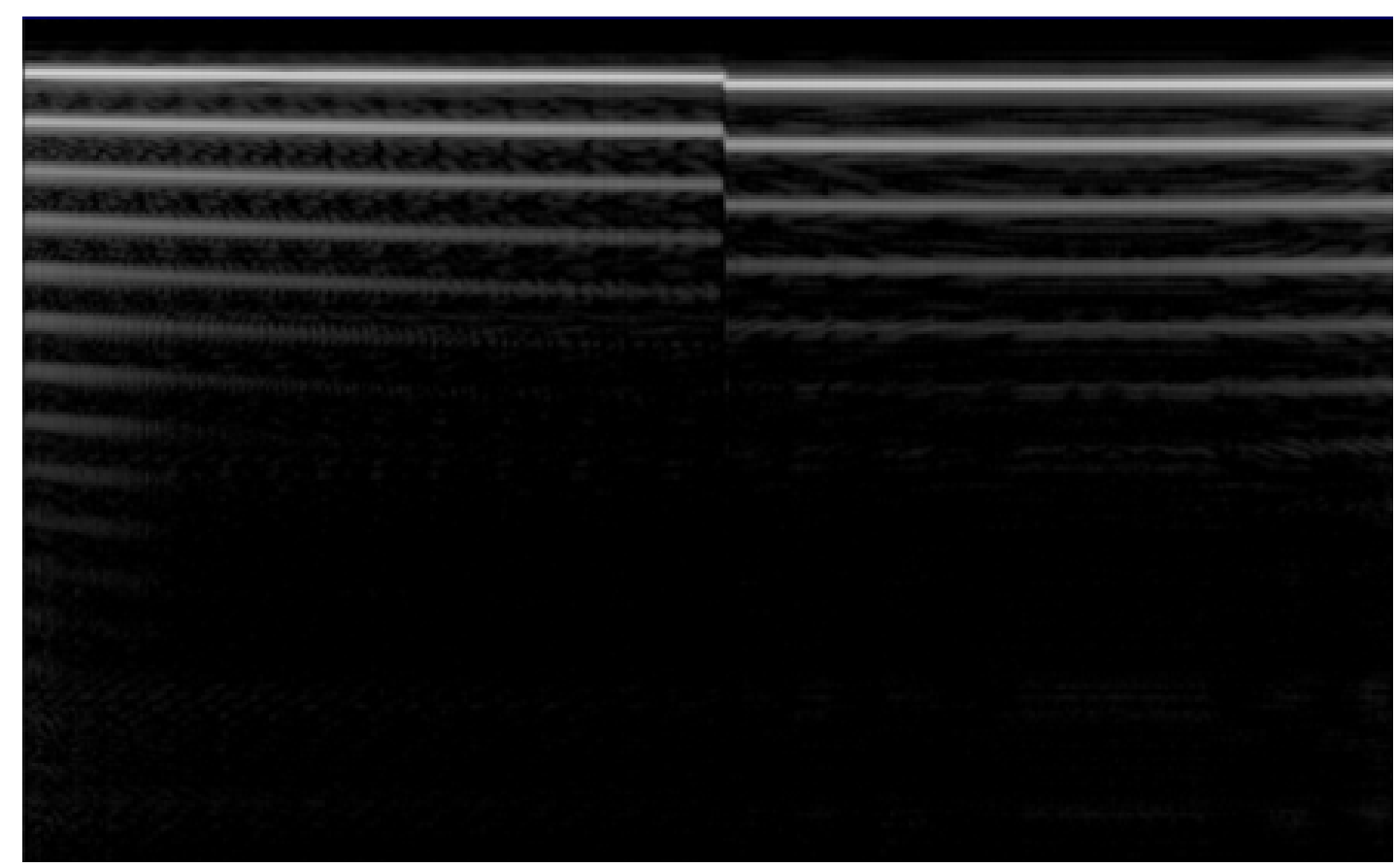

(a)

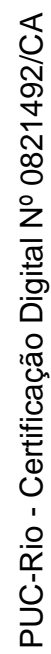

(b) 


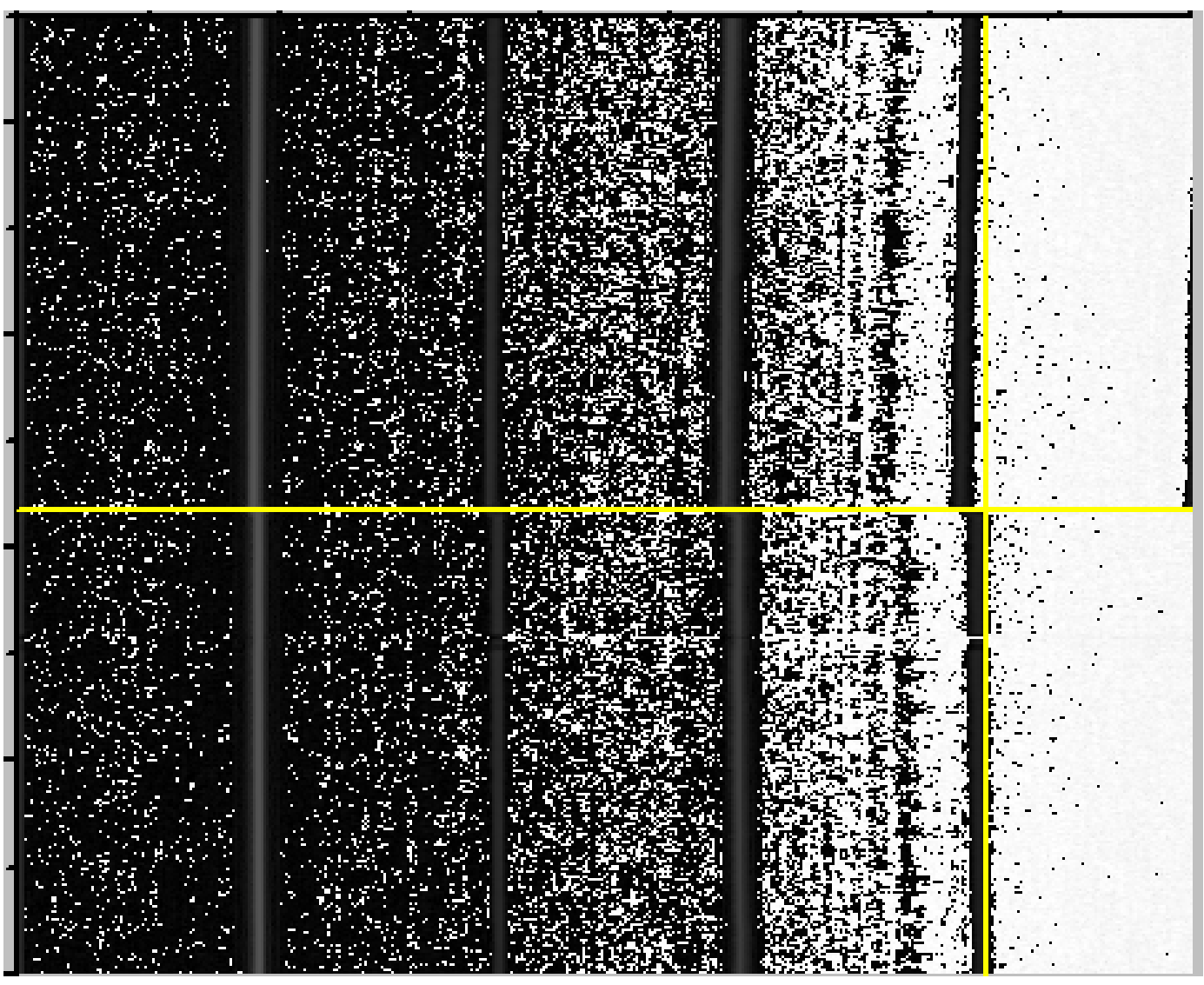

(c)

Figura 37 - Imagens geradas no Origin na análise das medidas realizadas com o SROCT (a) $10 \mu \mathrm{m}$, (b) $2 \mu \mathrm{m}$ e SS-OCT (c) $10 \mu \mathrm{m}$.

A linha mais intensa da figura 37 (a) corresponde ao primeiro pico mais intenso gerado no ajuste gaussiano, sendo a primeira reflexão da amostra para o sistema de detecção do OCT. Esta será a linha analisada para o cálculo do valor do degrau. As outras linhas que aparecem na imagem tem um espaçamento maior entre as superfícies superior e inferior medidas no degrau de altura, mas a exatidão é comprometida pelo aumento da largura da linha, por isso a opção de análise da linha mais intensa.

As medidas em pixel foram convertidas para $\mu m$ na análise de picos das gaussianas, calculando a altura, $\mathrm{h}=\left(\mathrm{pico}_{1}-\mathrm{pico}_{2}\right) \mathrm{F}_{\mathrm{c}}$, sendo $\left(\mathrm{pico}_{1}-\mathrm{pico}_{2}\right)$ a diferença entre o valor máximo e mínimo do degrau, step up - step down, e $\mathrm{F}_{\mathrm{c}}$, o fator de conversão do fabricante. $O$ fator de conversão $F_{c}$ é a razão entre a profundidade máxima da imagem (D) e o número de pixels na direção x $\left(\mathrm{N}_{\mathrm{p}}\right)$. 
Com os valores experimentais obtidos da análise dos dados das medidas com os OCT comerciais (SR-OCT e SS-OCT) foi possível avaliar a incerteza de medição dos sistemas, observadas na tabela 9.

Tabela 9 - Planilha de incerteza dos sistemas OCT comerciais.

\begin{tabular}{|c|c|c|c|}
\hline $\begin{array}{c}\text { Fontes de } \\
\text { Incerteza de } \\
\text { Medição }\end{array}$ & $\begin{array}{c}\text { SR-OCT } \\
\text { Degrau de } 10 \mu \mathrm{m} \\
\text { Valor da } \\
\text { incerteza, } u_{i}(\mu \mathrm{m})\end{array}$ & \begin{tabular}{|c|} 
SR-OCT \\
Degrau de $2 \mu \mathrm{m}$ \\
Valor da incerteza, \\
$u_{\mathbf{i}}(\mu \mathrm{m})$
\end{tabular} & $\begin{array}{c}\text { SS-OCT } \\
\text { Degrau de } 10 \mu \mathrm{m} \\
\text { Valor da incerteza, } \\
u_{i}(\mu \mathrm{m})\end{array}$ \\
\hline $\begin{array}{l}\text { Padrão de altura } \\
\text { (calibração } \\
\text { Linnik) }\end{array}$ & \multicolumn{3}{|c|}{0,002} \\
\hline Repetibilidade & 0,08 & 0,07 & 0,1 \\
\hline Reprodutibilidade & 0,1 & 0,08 & 0,1 \\
\hline $\begin{array}{c}\text { Comprimento de } \\
\text { onda e largura de } \\
\text { banda }\end{array}$ & 0,005 & 0,005 & 0,015 \\
\hline $\begin{array}{c}\text { Incerteza padrão } \\
\text { combinada }\left(\mathrm{u}_{\mathrm{C}}\right)\end{array}$ & 0,16 & 0,13 & 0,3 \\
\hline $\begin{array}{l}\text { Incerteza padrão } \\
\text { expandida (U) } \\
\text { a) SR-OCT } \\
\mathrm{k}=2,03(10 \mu \mathrm{m}) \\
\mathrm{k}=2,02(2 \mu \mathrm{m}) \\
\text { b) SS-OCT } \\
\mathrm{k}=2,02\end{array}$ & 0,3 & 0,3 & 0,6 \\
\hline
\end{tabular}

Os valores experimentais do degrau de altura de $2 \mu \mathrm{m}$ e de $10 \mu \mathrm{m}$ medidos no SR-OCT e no SD-OCT são mostrados na tabela 10. 
Tabela 10 - Medida do degrau de altura no sistema interferométrico Linnik e nos OCT comerciais, SS-OCT e SR-OCT.

\begin{tabular}{|c|c|c|c|c|c|c|}
\hline $\begin{array}{c}\text { Valor Nominal } \\
\text { padrão degrau } \\
(\mu \mathrm{m})\end{array}$ & \multicolumn{2}{|c|}{ Linnik } & \multicolumn{2}{c|}{ SR-OCT } & \multicolumn{2}{c|}{ SS-OCT } \\
\cline { 2 - 7 } & $\begin{array}{c}\text { Valor } \\
\text { medido } \\
(\mu \mathrm{m})\end{array}$ & $\begin{array}{c}\mathrm{U} \\
(\mu \mathrm{m})\end{array}$ & $\begin{array}{c}\text { Valor } \\
\text { medido } \\
(\mu \mathrm{m})\end{array}$ & $\begin{array}{c}\mathrm{U} \\
(\mu \mathrm{m})\end{array}$ & $\begin{array}{c}\text { Valor } \\
\text { medido } \\
(\mu \mathrm{m})\end{array}$ & $\begin{array}{c}\mathrm{U} \\
(\mu \mathrm{m})\end{array}$ \\
\hline 2 & 1,957 & 0,004 & 2,0 & 0,3 & - & - \\
\hline 10 & 10,045 & 0,004 & 10,0 & 0,3 & 10,4 & 0,6 \\
\hline
\end{tabular}

Com os sistemas rastreados na escala de comprimento é possível ter confiabilidade na medição de outros tipos de artefatos, como por exemplo, amostras biológicas. Neste caso, como existe a penetração na mesma, pode-se avaliar também a estatística referente à mudança da objetiva no sistema, o que pode ser importante na análise de incerteza referente a essas medições. Outro parâmetro importante de avaliação de incerteza é a componente relacionada ao compartimento de amostra que consiste de uma base XY. Neste caso, a calibração foi realizada, mas a componente não foi levada em consideração, pois a medida realizada foi feita diretamente sobre o degrau. Isto será importante para uma amostra biológica onde pode ser importante fazer uma avaliação em toda a sua superfície.

Além da avaliação dos OCT, outras medições foram realizadas, como a rastreabilidade da escala de comprimento de um microscópio confocal do DCTA/IEAv e do AFM do Inmetro, mostrados nas próximas seções.

\section{3}

\section{Microscópio Confocal}

O microscópio confocal (CM) usado foi um Olympus OLS 3100 com resolução axial(z) de $10 \mathrm{~nm}$. O sistema é composto de um laser de diodo de comprimento de onda de $408 \mathrm{~nm}$ que varre a superfície da amostra. A intensidade do feixe refletido pela amostra define o mapa de contorno para cada posição da varredura vertical e com isto é possível fazer imagens 3D da amostra usada, no caso os degraus de altura de $2 \mu \mathrm{m}, 10 \mu \mathrm{m}$ e $100 \mathrm{~nm}$. Primeiramente, para realizar as medições, a amostra é visualizada (foco) no microscópio óptico. 
Posteriormente, é usado o microscópio confocal. O perfil é nivelado o mais próximo possível de linhas retas na vertical e na horizontal (eixo y e eixo x). Depois de nivelado o perfil, as medições são iniciadas. Se o perfil não está adequado, muda-se a escala do instrumento para melhorar o perfil e realizar a medida na amostra. Na figura 38 é mostrada a imagem obtida nas medições com o microscópio confocal usando o degrau de $2 \mu \mathrm{m}$. Uma imagem similar foi obtida para as medições com o degrau de altura de $10 \mu \mathrm{m}$.

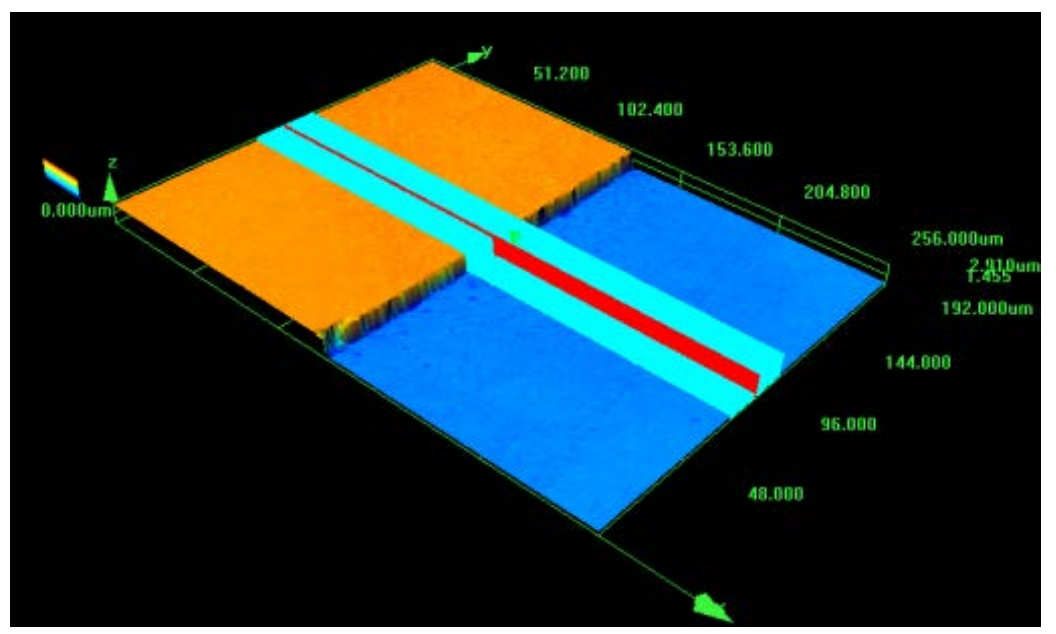

Figura 38 - Imagem das medições com o microscópio confocal para o degrau de altura de $2 \mu \mathrm{m}$.

Para a análise da incerteza do sistema experimental foram realizadas medições em 20 diferentes locais da amostra para o qual foi obtido um valor de altura médio de $2,1 \mu \mathrm{m}$ e $10,5 \mu \mathrm{m}$ para os degraus de valor nominal de $2 \mu \mathrm{m}$ e 10 $\mu \mathrm{m}$, respectivamente. Também foram realizadas medições com o degrau de 100 $\mathrm{nm}$ resultando em um valor médio de $110 \mathrm{~nm}$. A planilha de incerteza do CM é mostrada na tabela 11 . 
Tabela 11 - Planilha de incerteza do microscópio confocal.

\begin{tabular}{|c|c|c|c|}
\hline $\begin{array}{c}\text { Fontes de } \\
\text { Incerteza de } \\
\text { Medição }\end{array}$ & $\begin{array}{c}\text { Degrau de } 2 \mu \mathrm{m} \\
\text { Valor da incerteza, } u_{i} \\
(\mu \mathrm{m})\end{array}$ & $\begin{array}{c}\text { Degrau de } 10 \mu \mathrm{m} \\
\text { Valor da incerteza, } u_{i} \\
(\mu \mathrm{m})\end{array}$ & $\begin{array}{c}\text { Degrau de } 100 \mathrm{~nm} \\
\text { Valor da incerteza, } u_{i} \\
(\mathrm{~nm})\end{array}$ \\
\hline $\begin{array}{l}\text { Padrão de altura } \\
\text { (calibração Linnik) }\end{array}$ & \multicolumn{2}{|c|}{0,002} & 2,0 \\
\hline Repetibilidade & 0,079 & 0,08 & 6,4 \\
\hline Reprodutibilidade & 0,08 & 0,1 & 8,2 \\
\hline Resolução (z) & 0,003 & 0,003 & 8,3 \\
\hline $\begin{array}{l}\text { Incerteza padrão } \\
\text { combinada, } \mathrm{u}_{\mathrm{C}}\end{array}$ & 0,11 & 0,13 & 11 \\
\hline $\begin{array}{l}\text { Incerteza padrão } \\
\text { expandida (U), } \\
\mathrm{k}=2,02(2 \mu \mathrm{m}) \\
\mathrm{k}=2,02(10 \mu \mathrm{m}) \\
\mathrm{k}=2,0(100 \mathrm{~nm})\end{array}$ & 0,2 & 0,3 & 22 \\
\hline
\end{tabular}

\section{4}

\section{Microscópio de Força Atômica}

O Microscópio de Força Atômica (AFM) usado foi um modelo comercial Witec Alpha 300, com resolução axial (Z) de $1 \mathrm{~nm}$. As medições foram realizadas usando os degraus de altura de $2 \mu \mathrm{m}$ e $100 \mathrm{~nm}$.

No sistema AFM não foi possível realizar medidas com o padrão degrau de $10 \mu \mathrm{m}$, por causa do limite de resolução do instrumento. As medições com os degraus de altura de $2 \mu \mathrm{m}$ e de $100 \mathrm{~nm}$, produzido na Dimat/Inmetro, foram realizadas em diferentes posições com o padrão movendo-se ao longo da direção do passo em um modo de contato. Na figura 39 pode ser observada a imagem do degrau de $2 \mu \mathrm{m}$ a partir das medidas realizadas no AFM do Inmetro.

O valor médio medido para os degraus de altura usados nas medições foi de 2,06 $\mu \mathrm{m}$ e $102,6 \mathrm{~nm}$. 
A amostra é colocada no suporte de amostra e é varrida sob a agulha usando uma base de varredura piezoelétrica. A topografia é mostrada como uma imagem.

O instrumento fornece informação perpendicular e paralela à superfície, com resolução axial (z) na faixa de 1nm.

Na figura 39 pode ser observada a imagem do degrau feita no AFM para $100 \mathrm{~nm}$.
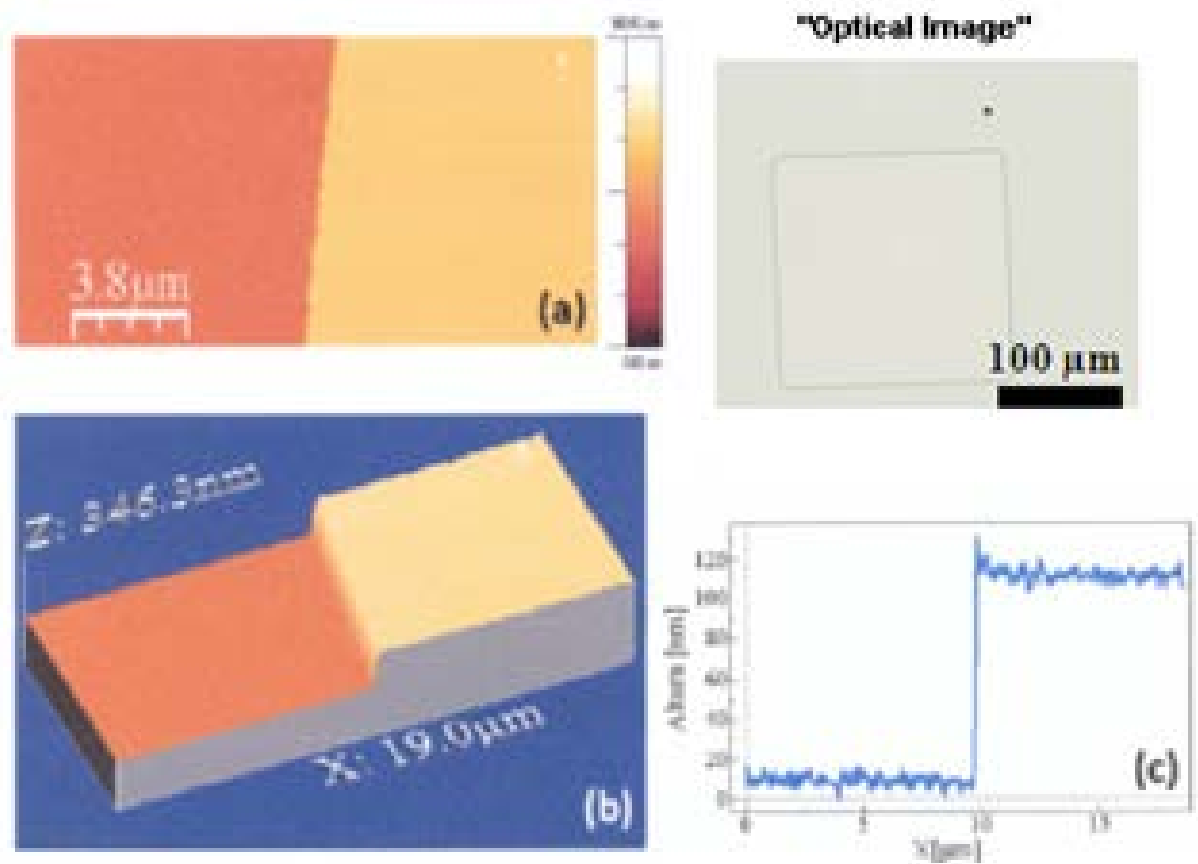

Figura 39 - Imagem no AFM com o degrau de $100 \mathrm{~nm}$, (a) 2D, (b) 3D e (c) perfil de altura.

A planilha de incerteza gerada nas medidas realizadas com o AFM pode ser observada na tabela 12 . 
Tabela 12 - Planilha de incerteza do microscópio de força atômica.

\begin{tabular}{|c|c|c|}
\hline $\begin{array}{c}\text { Fontes de } \\
\text { Incerteza de } \\
\text { Medição }\end{array}$ & $\begin{array}{c}\text { Degrau de } 2 \mu \mathrm{m} \\
\text { Valor da incerteza, } u_{i} \\
(\mu \mathrm{m})\end{array}$ & $\begin{array}{l}\text { Degrau de } 100 \mathrm{~nm} \\
\text { Valor da incerteza, } \mathbf{u}_{\mathrm{i}} \\
(\mathrm{nm})\end{array}$ \\
\hline $\begin{array}{l}\text { Padrão de altura } \\
\text { (calibração Linnik) }\end{array}$ & 0,002 & 2 \\
\hline Repetibilidade & 0,03 & 0,8 \\
\hline Reprodutibilidade & 0,02 & 0,9 \\
\hline Resolução (z) & 0,0003 & 0,6 \\
\hline $\begin{array}{l}\text { Incerteza padrão } \\
\text { combinada,u } \mathrm{u}_{\mathrm{C}}\end{array}$ & 0,04 & 2,3 \\
\hline $\begin{array}{l}\text { Incerteza padrão } \\
\text { expandida (U), } \\
\mathrm{k}=2,0(2 \mu \mathrm{m}) \\
\mathrm{k}=2,0(100 \mathrm{~nm})\end{array}$ & 0,08 & 5 \\
\hline
\end{tabular}

\section{5}

\section{Rastreabilidade}

A partir do desenvolvimento do sistema interferométrico de referência, o interferômetro Linnik, instrumentos ópticos foram rastreados na escala de comprimento cujos resultados são mostrados na tabela 13. Nesta tabela são mostrados os resultados correspondentes às medições com os degraus de altura de $100 \mathrm{~nm}, 2 \mu \mathrm{m}$ e $10 \mu \mathrm{m}$. Além disso, é mostrado o valor da correção dos instrumentos rastreados em relação à medida realizada no sistema de referência, o interferômetro Linnik.

Essas correções, assim como suas incertezas associadas para cada instrumento e para cada degrau de altura usado ( $2 \mu \mathrm{m}, 10 \mu \mathrm{m}$ e $100 \mathrm{~nm})$ nas medições podem ser observadas nos gráficos da figura 40 . 
Tabela 13 - Medida dos degraus de altura realizadas no Linnik e nos instrumentos ópticos para (a) $100 \mathrm{~nm}$, (b) $2 \mu \mathrm{m}$ e (c) $10 \mu \mathrm{m}$.

(a)

\begin{tabular}{|c|c|c|c|c|}
\hline $\begin{array}{c}\text { Instrumento } \\
\text { (degrau de } \\
\text { altura de 100 } \\
\text { nm) }\end{array}$ & $\begin{array}{c}\text { Média das } \\
\text { medições (nm) }\end{array}$ & $\begin{array}{c}\text { Correção } \\
\mathbf{( n m )}\end{array}$ & $\begin{array}{c}\text { Incerteza Padrão } \\
\text { Combinada } \\
\mathbf{u}_{\mathbf{c}}(\mathbf{n m})\end{array}$ & $\begin{array}{c}\text { Incerteza } \\
\text { Padrão } \\
\text { Expandida } \\
\mathbf{U}(\mathbf{n m})\end{array}$ \\
\hline Linnik & 101,4 & 2 & $4(\mathrm{k}=2)$ \\
\hline CM & 110,0 & $-8,6$ & 11 & $22(\mathrm{k}=2)$ \\
\hline AFM & 102,6 & $-1,2$ & 2,3 & $5(\mathrm{k}=2)$ \\
\hline
\end{tabular}

(b)

\begin{tabular}{|c|c|c|c|c|}
\hline $\begin{array}{c}\text { Instrumento } \\
(\text { degrau de } \\
\text { altura de } 2 \boldsymbol{\mu m})\end{array}$ & $\begin{array}{c}\text { Média das } \\
\text { medições } \\
(\boldsymbol{\mu m})\end{array}$ & $\begin{array}{c}\text { Correção } \\
(\boldsymbol{\mu m})\end{array}$ & $\begin{array}{c}\text { Incerteza Padrão } \\
\text { Combinada } \\
\mathbf{u}_{\mathbf{c}}(\boldsymbol{\mu m})\end{array}$ & $\begin{array}{c}\text { Incerteza } \\
\text { Padrão } \\
\text { Expandida } \\
\mathbf{U}(\boldsymbol{\mu m})\end{array}$ \\
\hline Linnik & 1,957 & 0,002 & $0,004(\mathrm{k}=2)$ \\
\hline SR-OCT & 2,0 & $-0,04$ & 0,13 & $0,3(\mathrm{k}=2,02)$ \\
\hline TD-OCT & 1,9 & 0,06 & 0,11 & $0,2(\mathrm{k}=2,1)$ \\
\hline CM & 2,1 & $-0,14$ & 0,11 & $0,2(\mathrm{k}=2,02)$ \\
\hline AFM & 2,06 & $-0,10$ & 0,04 & $0,07(\mathrm{k}=2)$ \\
\hline
\end{tabular}

(c)

\begin{tabular}{|c|c|c|c|c|}
\hline $\begin{array}{c}\text { Instrumento } \\
(\text { degrau de } \\
\text { altura de } \mathbf{1 0} \boldsymbol{\mu \mathrm { m } )}\end{array}$ & $\begin{array}{c}\text { Média das } \\
\text { medições } \\
(\boldsymbol{\mu \mathrm { m } )}\end{array}$ & $\begin{array}{c}\text { Correção } \\
(\boldsymbol{\mu \mathrm { m } )}\end{array}$ & $\begin{array}{c}\text { Incerteza Padrão } \\
\text { Combinada } \\
\mathbf{u}_{\mathbf{c}}(\boldsymbol{\mu m})\end{array}$ & $\begin{array}{c}\text { Incerteza } \\
\text { Padrão } \\
\text { Expandida } \\
\mathbf{U}(\boldsymbol{\mu m})\end{array}$ \\
\hline Linnik & 10,045 & 0,002 & $0,004(\mathrm{k}=2)$ \\
\hline SR-OCT & 10,0 & 0,05 & 0,16 & $0,3(\mathrm{k}=2,03)$ \\
\hline TD-OCT & 10,0 & 0,05 & 0,12 & $0,3(\mathrm{k}=2,08)$ \\
\hline SS-OCT & 10,4 & $-0,36$ & 0,3 & $0,6(\mathrm{k}=2,02)$ \\
\hline CM & 10,47 & $-0,43$ & 0,13 & $0,3(\mathrm{k}=2)$ \\
\hline
\end{tabular}




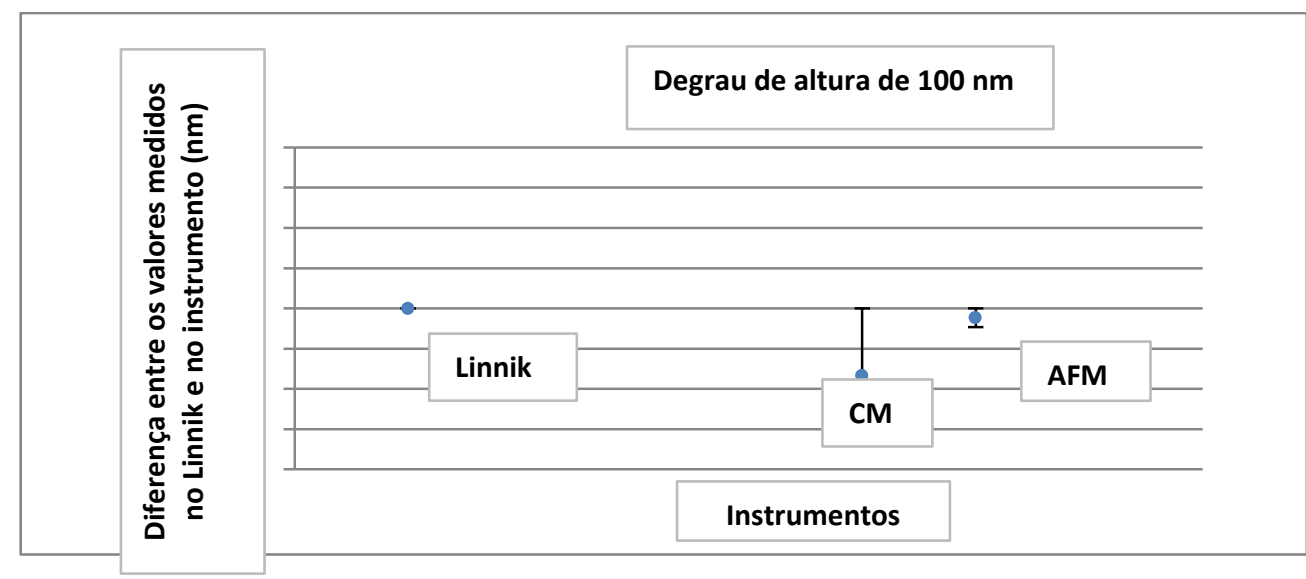

(a)

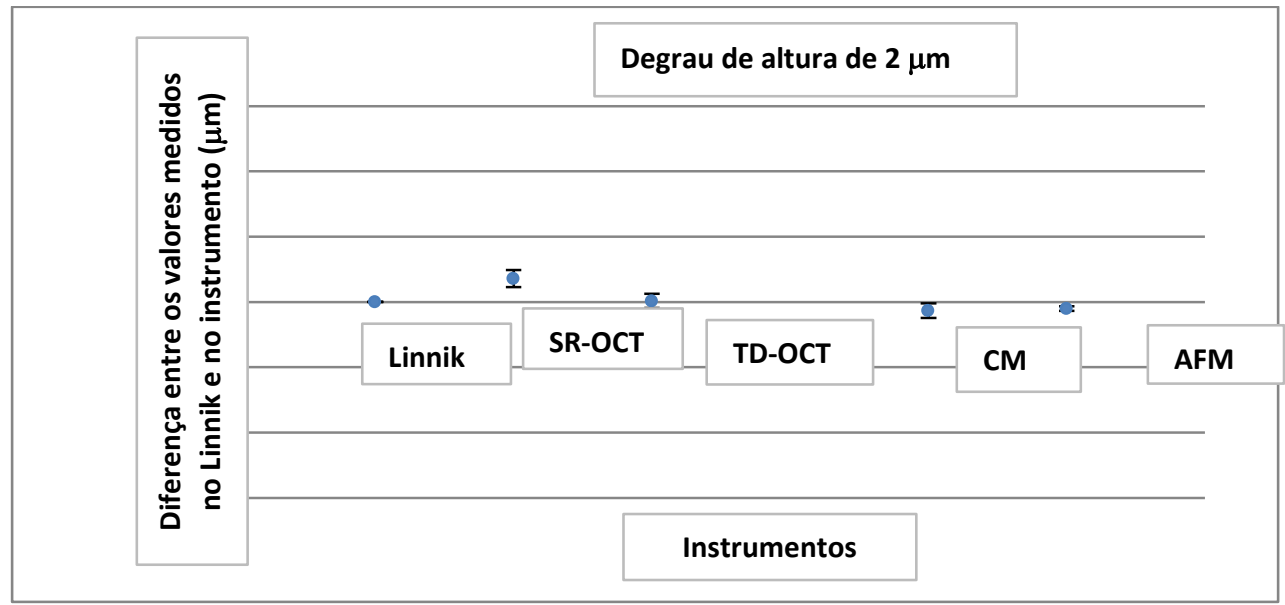

(b)

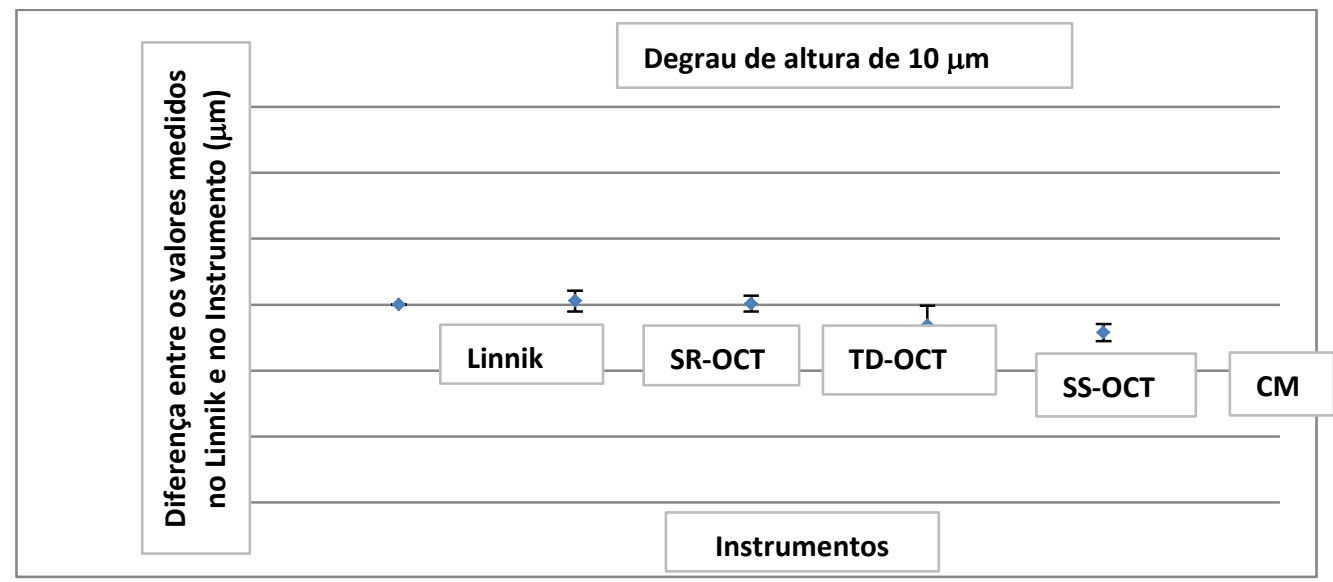

(c)

Figura 40 - Comparação das medições no sistema Linnik, microscópio confocal (CM), Microscópio de força atômica (AFM) e sistemas OCT para os degraus de altura de (a) $100 \mathrm{~nm} \mu \mathrm{m}$, (b) $2 \mu \mathrm{m}$ e (c) $10 \mu \mathrm{m}$. 
Não foi possível realizar medições com os 03 degraus de altura ( $2 \mu \mathrm{m}, 10$ $\mu \mathrm{m}$ e $100 \mathrm{~nm}$ ) em todos os instrumentos.

O degrau de $100 \mathrm{~nm}$, figura 41 (a), foi medido no AFM e no microscópio confocal, já que a resolução dos OCT não possibilitou as medições com degrau dessa magnitude. Na figura 41 (b) não estão os resultados da medição do degrau de $2 \mu \mathrm{m}$ com o SS-OCT. O degrau foi medido no instrumento, mas na análise das várias medições realizadas o valor do degrau obtido não estava coerente com o valor nominal do degrau, o que pode ser devido à vibração do sistema OCT durante as medições. Isto também interferiu nas medições com o degrau de 10 $\mu \mathrm{m}$, mas alguns conjuntos de dados tinham valores mais estáveis e foi possível fazer a análise. As medições com o AFM e com o CM mostram que os sistemas apresentam correções maiores que nos outros instrumentos. Na Figura 41 (c) é mostrado o resultado com o degrau de $10 \mu \mathrm{m}$. Neste caso, por causa da resolução do instrumento e da sua superfície levemente curva esse degrau não foi medido no AFM. As medições do CM para os degraus de $2 \mu \mathrm{m}$ e $10 \mu \mathrm{m}$ mostraram comportamento semelhante.

Em todos os instrumentos, a correção é de magnitude igual à diferença em relação ao valor medido no sistema de referência (Linnik), ou seja, em todas as medições realizadas com esses instrumentos, essa correção tem que ser aplicada para que sejam confiáveis e tenham a sua rastreabilidade garantida. No CM foi possível realizar medições nos 03 degraus de altura. Isto possibilitou, apesar da grande diferença de passo entre eles, fazer um ajuste nas medições realizadas no instrumento que pode ser observado na figura 41.

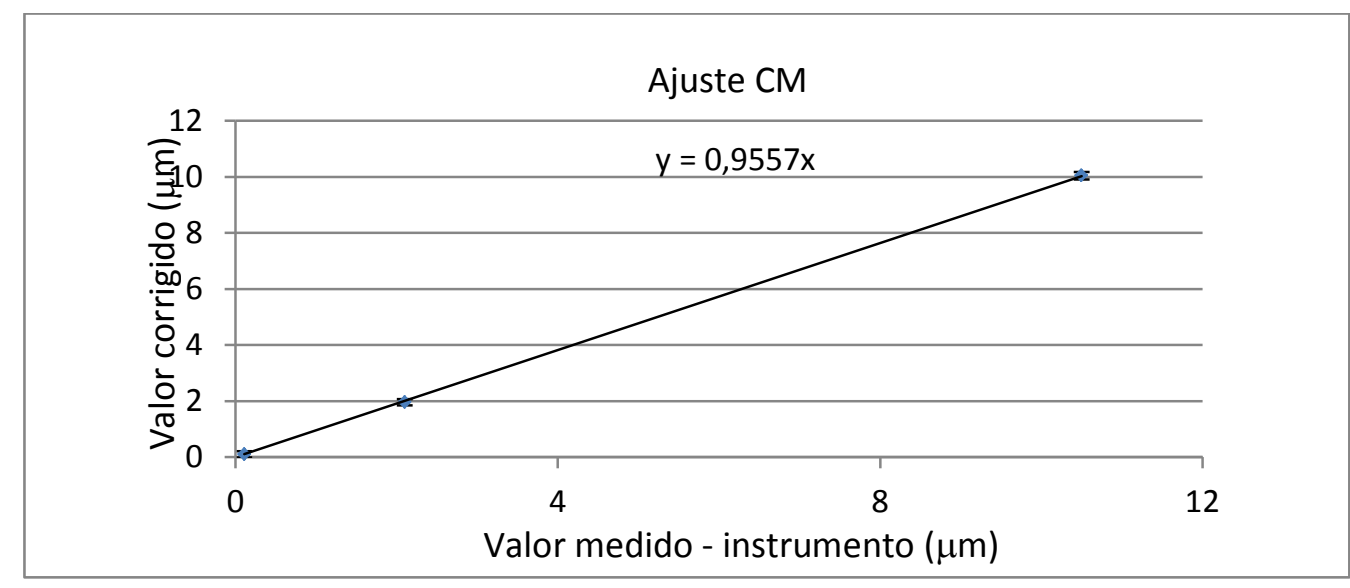

Figura 41 - Ajuste CM com os degraus de 100 nm, $2 \mu \mathrm{m}$ e $10 \mu \mathrm{m}$. 
A rastreabilidade de todos os instrumentos medidos foi efetivada e os resultados foram apresentados ao longo do trabalho. No entanto, seria importante ter degraus de altura em faixas diferenciadas para melhor estimar o desempenho desses instrumentos ao longo das suas faixas de trabalho. 


\section{8}

\section{Conclusão e perspectivas futuras}

O interferômetro Linnik foi desenvolvido, caracterizado, otimizado e usado para realizar medidas de comprimento de amostras na escala micrométrica e sub-micrométrica. Além disso, a rastreabilidade em relação à grandeza de comprimento para os OCT, AFM e microscópio confocal foi realizada para alguns institutos no país.

Melhorias no sistema experimental do Linnik foram realizadas, como por exemplo, para diminuir a influência de temperatura nas medições de comprimento, todo o set up experimental foi protegido em relação às variações das condições ambientais do laboratório (caixa de acrílico com aberturas laterais). Isto foi fundamental para obter resultados com maior exatidão e menor dispersão o que poderá ser importante no desempenho do laboratório em futura comparação internacional na área.

Um desdobramento do trabalho foi o início da produção de amostras de degrau de altura no Inmetro que podem ser calibradas no sistema de referência Linnik e serem usadas como referência para institutos, empresas e universidades para prover confiabilidade às medições realizadas com esses instrumentos.

Uma atividade futura será realizar um estudo mais detalhado de modo a identificar novas grandezas de influência e assim aprimorar o modelamento da incerteza de medição do sistema de referência e dos instrumentos ópticos que, atualmente, foi estabelecida apenas com a avaliação estatística do sistema. Para ajudar nesse modelamento é apropriado fazer medições com degraus com alturas diferentes para fazer uma avaliação mais completa do sistema.

Atualmente, estamos realizando medições nos degraus de altura de valores nominais de $19 \mathrm{~nm}$ e $180 \mathrm{~nm}$ do fabricante VLSI Standards Incorporated, que foram medidos em um perfilômetro mecânico de alta resolução no INM americano (NIST), cujos resultados foram 19,3 nm $\pm 1 \mathrm{~nm}$ e 178,8 nm $\pm 2 \mathrm{~nm}$. Os primeiros resultados das medições no sistema Linnik para esses padrões foram 19,2 nm $\pm 2 \mathrm{~nm}$ e 179,0 nm $\pm 2 \mathrm{~nm}$. A incerteza do Linnik também está sendo melhorada e achamos que num futuro próximo será reduzida para menos de $1 \mathrm{~nm}$. 
Também foram realizadas medições com esses degraus no AFM do Inmetro, mas a estatística relacionada a essas medições ainda está sendo avaliada. Com os valores medidos será possível, da mesma forma que o CM, fazer um ajuste de medições no AFM referenciadas ao sistema de referência Linnik.

Foram apresentados dois trabalhos em congressos internacionais na área (SPIE 2011 e IMEKO 2012). O trabalho apresentado no SPIE 2011 foi disponibilizado na revista eletrônica OCT News. Foi aceito um trabalho para apresentação em congresso nacional, Metrologia 2013, que foi selecionado para a edição especial do Journal of Physics: Conference Series (JPCS). Um artigo referente à tese foi aceito para ser publicado na revista ACTA IMEKO. 


\section{Referências bibliográficas}

[1] KLEIN, H.A. The Science of Measurement, a historical survey, Dover Publications Inc, New York, 1988. 736 p.

[2] DE MATTOS, L. J. D. Medida, normalização e qualidade: aspectos da história da Metrologia no Brasil, coedição do Inmetro e Editora e da Fundação Getúlio Vargas, Rio de Janeiro, 1998. 292 p.

[3] BUREAU INTERNATIONAL DES POIDS ET MEASURES (BIPM). The Metre Convention. Disponível em: http://www.bipm.org/en/convention/. Acesso em: 01 ago. 2013.

[4] BIPM - LE SYSTÈME INTERNATIONAL D’UNITÉS, SI. Organisation intergouvernementale de la Convention du Mètre, 8 édition, 2006. Disponível em: http://www.bipm.org/en/si/_brochure_8.pdf.

[5] INMETRO. Sistema Internacional de Unidades, SI. 8a Edição (revisada) Rio de Janeiro, 2007. 114 p., ISBN 85-87-87090-85-2, Tradução da publicação do BIPM, 8a edição, 2006.

[6] LEWIS, A.J. Absolute length measurement using multiple-wavelength phase-stepping interferometry. 1993. $323 \mathrm{f}$. PhD thesis. University of London, Department of Physics and Applied Optics, 1993. Disponível em: http://jartweb.net/thesis/TITLE.pdf.

[7] BAILEY, A.E. Units and standards of measurement. J. Phys. E: Sci. Instrum. v.15, p. 849-856, 1982.

[8] CONFERENCE GENERALE DES POIDS ET MESURES, THE COMITÈ INTERNATIONAL DES POIDS ET MESURES AND THE COMITE CONSULTATIF POUR LA DEFINITION DU MÈTRE. Documents Concerning the New Definition of Metre, Metrologia, v. 19, p. 163-177, 1984.

[9] QUINN, T.J. Practical realization of the definition of the metre, Metrologia, v. 36, p. 211-244, 1999.

[10] QUINN, T.J. Practical realization of the definition of the metre, including recommended radiations of other optical frequency standards (2001), Metrologia, v.40, p. 103-133, 2003.

[11] FELDER, R. Practical realization of the definition of the metre, including recommended radiations of other optical frequency standards (2003), Metrologia, v.42, p. 323-325, 2005. 
[12] CORDIALE, P.; GALZERANO, G.; SCHNATZ, H. International comparison of two iodine-stabilized frequency-doubled Nd:YAG lasers at $\lambda 532$ nm, Metrologia, v. 37, p. 177-182, 2000.

[13] YE, J.; SCHNATZ, H.; HOLLBERG, L.W. Optical Frequency Combs: From Frequency Metrology to Optical Phase Control, IEEE Journal of Selected Quantum Topics in Quantum Electronics, v.9, p. 1041-1058, 2003.

[14] HOLLBERG, L. et al. The measurement of optical frequencies, Metrologia, v.42, p. S105-S124, 2005.

[15] RAYMUNDO, E.V. Construção de um padrão de referência metrológica de freqüência laser em torno de 532 nm. 2009. 97 f. Dissertação de mestrado, Programa de Pós Graduação em Metrologia da PUC-Rio, Rio de Janeiro, 2009.

[16] RAYMUNDO, E.V. et al. Construção de um padrão de referência metrológica de freqüência laser em torno de $532 \mathrm{~nm}$. In: V CONGRESSO BRASILEIRO DE METROLOGIA, 2009, Anais eletrônicos. Salvador, 2009.

[17] ZOLOTAREVSKIV Y.M.; LEVIN G.G. Interference measurements in Nanotechnologies, Measurement Techniques, v.55, p. 770-772, 2012.

[18] TITOV, A.; MALINOVSKY, I.; MASSONE, C.A. Nanometrology Regime in Length Measurements of Material Artefacts with Nominal Lengths up to 100 nm. In: XVII IMEKO World Congress, 2003, Proceedings. Croatia, 2003.

[19] APOSTOL, D.; DAMIAN, V.; LOGOFATU, P. C. Nanometrology of Microsystems: Interferometry, Romanian Reports in Physics, v. 60, p. 815-828, 2008.

[20] LYSENKO, V.G. et al. Nanometrology and Features of Metrological Assurance of Measurements of the Roughness and Relief Parameters of Nanostructured Surfaces, Measurement Techniques, v. 53, p. 815-828, 2011.

[21] SALAS-TELLEZ, J.A. et al. A traceability scheme for materials metrology, Metrologia, v. 47, p. S18-S22, 2010.

[22] MIRANDA, S.F. Estudo sobre Interferometria, Revista Inmetro, Rio de janeiro, 1982.

[23] O’SHEA, D.C. Elements of Modern Optical Design. A Wileyinterscience publication, John Wiley \& Sons, 1985.

[24] HARIHARAN, P. Optical Interferometry. 2nd edition. Nova York: Elsevier, 2003.

[25] STEEL, W.H. Interferometry. 2nd edition. Cambridge: Cambridge University Press, 1983.

[26] DARNEDDE, H. High-Precision Calibration of Long Gauge Blocks Using the Vacuum Wavelength Comparator, Metrologia, v.29, p. 349-359, 1992. 
[27] FACAO, M. Interferômetro de Michelson: princípios e aplicações, Departamento de Física, Universidade de Aveiro, 1999. Disponível em: http://sweet.ua.pt/mfacao/pedag.pdf.

[28] NACHMAN, P. Mach zehnder interferometer as an instructional tool. American Journal of Physics, v.63, p. 39-43, 1995.

[29] PERKAL'SKIS, B.S.; LATIN, V.L. A mach-zender interferometer for instructional use. Soviet Physics Journal, v.10, p. 58-63, 1967.

[30] RAO, V.V.; MOHAN, N.K. Optical image processing using phase reversal Twyman -Green interferometer. In: SPIE Visual Information Processing 2002, Proceedings. EUA, 2002.

[31] LINNIK, V.P. Ein Apparat Fur Mikroskopisch-Interferometrische Untersuchungen Reflektierender Objecte (Mikrointerferometer), Acad. Sci. URSS, v. 1, p. 18-23, 1993.

[32] HARRIS, W.; MROWKA, S.; SPEER, R.J. Linnik interferometer: its use at shortwavelengths, Applied Optics, v. 21, p. 1155-1155, 1982.

[33] SINCLAIR, M.B.; DE BOER, M.P.; CORWIN, A.D. Long-workingdistance incoherent-light interference microscope, Applied Optics, v. 44, p. 77147721, 2005.

[34] ZEYLIKOVICH, I. Short coherence length produced by a spatial incoherent source applied for the Linnik-type interferometer, Applied Optics, v.47, p. 2171-2177, 2008.

[35] BIEGEN, J.F. Calibration requirements for Mirau and LINNIK Interferometers, Applied Optics, v.28, p. 1972-1974, 2008.

[36] HUANG, D. et al. Optical Coherence Tomography. Web of Science, v. 254, p. 1178-1181, 1991.

[37] HUANG, D. Optical Coherence Tomography. 1993. 117 f. PhD Thesis, Harvard-MIT Division of Health Sciences and Technology, MIT, Boston, 1993.

[38] CHENNU, A. Optical Coherence Tomography, a Literature Survey, MSc in Photonics, 2007-2008, 64 f. Heriot Watt University, 2007-2008.

[39] FUJIMOTO, J.G. Optical coherence tomography for ultrahigh resolution in vivo imaging. Nature Biotechnology, v.21, p. 1361-1367, 2003.

[40] HEE, M.R. Optical Coherence Tomography of the Eye. 1997. 230 f. $\mathrm{PhD}$ Thesis. Department of Electrical engeneering and Computer Science, Massachussetts Institute of Technology. Cambridge, MA - USA, 1997.

[41] BREZINSKY, M. Optical Coherence Tomography, Principles and Applications. London: Elsevier, 2006. 
[42] FREDERICK, W.K. Diagnostic ultrasound: principles, instrumentation and exercises. 2nd edition, Philadelphia: Grune and Stratton, 1984.

[43] FUJIMOTO, J.G. et al. Optical coherence tomography: high resolution imaging using echoes of light. Optics and Photonics News, v.11, p. 24-31, 2000.

[44] HEE, M.R. Handbook of Optical Coherence Tomography: Optical Coherence Tomography, Cap 2, Theory. New York: Marcel Dekker, 2002.

[45] FUJIMOTO, J.G.; DREXLER, W. Optical Coherence Tomography, Technology and Applications: Introduction to Optical Coherence Tomography. Springer, 2008.

[46] DREXLER, W. et al. In vivo ultrahigh resolution optical coherence tomography, Optics Letters, v.24, p. 1221-1223, 1999.

[47] GLADKOVA, N.D. et al. In vivo optical coherence tomography imaging of human skin: norm and pathology. Skin Research and Technology, v.6, p. 616, 2000.

[48] KYOTOKU, B.B.C. Desenvolvimento de um sistema de imageamento usando a tomografia de coerência óptica no domínio temporal e de Fourier. 2006. 83 f. Tese de mestrado, Departamento de Física, UFPE, 2006.

[49] ZANARDI, F.Z. Caracterização de Tecidos Biológicos através de Tomografia de Coerência Óptica. 2007. 118 f. Tese de Doutorado, IPEN/USP, 2007.

[50] CARVALHO, M.T. Técnicas de Interferometria Óptica Aplicadas à Medicina, Odontologia e Comunicações Ópticas. 2006. 165 f. Tese de Doutorado, Departamento de Física, UFPE, 2006.

[51] BOUMA, B.E.; TEARNEY, G.J. Handbook of Optical Coherence Tomography, New York: Marcel Dekker, 2002.

[52] THORLABS, Spectral Radar OCT Systems. Disponível em: http://www.thorlabs.com/. Acesso em: 15 jun. 2011.

[53] THORLABS, Swept Source OCT Systems. Disponível em: http://www.thorlabs.com/. Acesso em: 05 set. 2012.

[54] MINSKY, M. Memoir on inventing the confocal scanning microscopy. Scanning, v.10, p. 128-138, 1988.

[55] WEBB, H.R. Confocal optical microscopy. Rep. Prog. Phys. v. 59, p. 427-471, 1996.

[56] BRAKENHOFF, G.J.; BLOM, P.; BARENDS, P. Confocal Scanning Light Microscopy with High Aperture Immersion Lenses. Journal of Microscopy, v.117, p. 219-232, 1979. 
[57] ROSA, C.C. Biópsia Óptica OCT, Artigo geral, Gazeta de Física. Disponível em: http://www.gazetadefisica.spf.pt/magazine/98/pdf. Acesso em: 01 ago. 2013.

[58] AMOS, W.B.; WHITE, J.G. How the Confocal Laser Scanning Microscope entered Biological Research, Biology of the Cell, v. 95, p. 335-342, 2003.

[59] OLIVEIRA, A.R.F. Desenvolvimento de um microscópio confocal de varredura laser para caracterização topográfica de superfície. 2012. $90 \mathrm{f}$. Dissertação de Mestrado, Universidade Federal de Uberlândia, 2012.

[60] CARL ZEISS, Confocal Laser Scanning Microscopy Principles. Disponível em: http://zeisscampus.magnet.fsu.edu/referencelibrary/pdf/zeissconfocalprinciples. Acesso em: 30 abr. 2013.

[61] NISTAL, A.M. Microscopía Láser Confocal. Universidad de Oviedo. Disponível em: http://www.unioviedo.es/BOS/Novedades/Libro/0prefac.pdf. Acesso em: 21 ago. 2013.

[62] HERRMANN, P.S.P. et al. Microscopia de Varredura por Força: uma Ferramenta Poderosa no Estudo de Polímeros, Polímeros: Ciência e Tecnologia, v. 7, p. 51-61, 1997.

[63] ALMEIDA, C.M.S. Análise por XPS e AFM da superfície de blendas de PVC/PHB. 2005. 70 f. Dissertação de Mestrado, PUC-Rio, 2005.

[64] MOREAU, A.L.D. Microscopia de Força Atômica em Materiais Biológicos: Biossensores e Nanoferramentas, 2011. 90 f. Tese de Doutorado, UNICAMP, 2011.

[65] MAZZEO A.D. et al. Atomic force microscope for accurate dimensional metrology. Precision Engineering, v.33, p. 135-149, 2009.

[66] BUREAU INTERNATIONAL DES POIDS ET MEASURES (BIPM). International Vocabulary of Metrology - Basic and general concepts and associated terms (VIM), JCGM, BIPM, $3^{\text {a }}$ edição, 2008. Disponível em: http://www.bipm.org/utils/common/documents/jcgm/JCGM_200_2012.pdf.

[67] INMETRO. Vocabulário Internacional de Metrologia - conceitos fundamentais e gerais e termos associados (VIM), Tradução da publicação do BIPM, $3^{\text {a }}$ edição, 2009.

[68] INMETRO. ISO GUM, Avaliação de dados de medição - Guia para a expressão de incerteza de medição, BIPM, JCGM 100:2008, Grupo de trabalho Inmetro para tradução do GUM, 2008.

[69] COUCEIRO, I.B. et al. Development of traceability methodology for optical coherence tomography (OCT) using step height standard as calibration reference. In: SPIE Conference, 2011. Electronic Proceedings, Munique, 2011. 
[70] MALINOVSKY, I. et al. Primary Imaging Interference Microscope for Nanometrology. In: XXI MEKO World Congress, Metrology for Green Growth. Electronic Proceedings. Korea, 2012.

[71] MALINOVSKY, I. et al. Primary traceable nanometrology in step height measurements at Brazil and national inter-laboratorial comparisons, submetido a revista Measurement Scientific and technology (MST), dezembro de 2012.

[72] MALINOVSKY, I. et al. Primary imaging interference microscope for nanometrology, aceito pela revista ACTA IMEKO, março de 2013.

[73] HANDBOOK OF VLSI MICROLITHOGRAPHY: PRINCIPLES, TECHNOLOGY AND APPLICATIONS, 2a Edição. Noyes Publications, 2001. Disponível em: http://lib.semi.ac.cn:8080/tsh/dzzy/ebooks/full/fn138.pdf.

[74] BERGER, S.D. et al. Projection electron-beam lithography: A new approach. Journal of Vacuum Science and Technology. v.B9, p. 2996-2999, 1991. 